\title{
THE ROLE OF DESTINATION IMAGE IN INFLUENCING ENVIRONMENTALLY SUSTAINABLE PURCHASING BEHAVIOUR OF TOURISTS
}

\author{
By
}

Diána Kham

\begin{abstract}
A thesis submitted to the Victoria University of Wellington as partial fulfillment of requirements for the degree of Master of Tourism Management.
\end{abstract}

Victoria University of Wellington 


\begin{abstract}
A large proportion of typical holiday activities are directly dependent on the natural resources at the destination and as these natural areas represent the main resource for many tourism destinations (Dolnicar \& Leisch, 2007), destinations are under pressure to protect it. Current efforts to promote pro-environmental behaviors by tourists found largely ineffective. This is partly because the travel context of tourists is often ignored when studying environmentally sustainable behaviors despite the significant impact it can have on tourists' behavior. Current literature looking at destination image offers limited insight into how (or if) destination image influences environmentally sustainable behavior of tourists outside of product-specific contexts such as eco-tour experiences or green accommodations. To fill this research gap, this thesis examines the role of destination image in influencing tourists' environmentally sustainable (tourism-related) purchasing behavior in New Zealand.
\end{abstract}

This thesis adopted a qualitative approach. The data collection consisted of 25 semi-structured indepth interviews with international tourists in New Zealand. Data were then analyzed using the framework analysis technique. The analysis focused on three things: (1) how New Zealand is perceived by tourists, (2) tourists' intentions of behaving environmentally sustainable, and (3) identifying aspects of the destination image that evoke or trigger pro-environmental intentions by tourists.

The findings revealed that destination image does play a role in influencing environmentally sustainable purchasing behavior by not only evoking pro-environmental intentions but also providing an encouraging and enabling environment. The characteristics and qualities of New Zealand that were found particularly influential in evoking a sense of responsibility and/or connection towards nature were the fragile environment appeal, dependence on nature, aesthetically pleasing, and unique landscape. Other factors contributing to this were also identified providing a more comprehensive understanding of how the relationship is moderated. These factors were personal factors, habit and routine, contextual factors, personal capabilities, and attitudinal factors. 
The outcome of this research carries important implications particularly for destination managers and destination marketers wanting to promote environmentally sustainable (tourism-related) purchasing behavior. The complexity of environmentally sustainable behavior and the subjective nature of destination image however require further research, especially in identifying the applicability of this study to other (types of) destinations.

Keywords: destination image, environmentally sustainable purchasing behavior, New Zealand 


\section{Acknowledgments}

What a journey.

First and foremost, a huge thank you to my supervisor Dr Ina Reichenberger. You are the absolute best, I feel very lucky to have had you. Thank you for bringing your German attitude to your supervision, which helped me a lot keeping focused and ensured I am always on track. Your advice and support were very valuable to me and I have learned so much from you. You are amazing, Vielen Dank!

I thank AProf Christian Schott, AProf Mondher Sahli, AProf Ian Yeoman, and Prof Karen Smith for their continuous support, encouragement, various experiences, and memories they have blessed me with over the years. You have all taught me so much, I will always be grateful. A special thank you to Garry Tansley for his support, and the endless opportunities to get involved at the university. Lastly, Luisa and Megan, thank you for your enthusiastic administrative support.

I would like to also congratulate my master colleagues especially: Wing Cheung (Joe), Gayan Edirisinghe, Mercury Yang, Cindy Yan, Ollie Zhou, Paula Ash, and Taran Jørgensen. Thank you for sharing this journey with me. Now what?

Most importantly, thank you to my family for supporting and believing in me, but also keeping up with me in darker times. Without your support, this just would not have been possible.

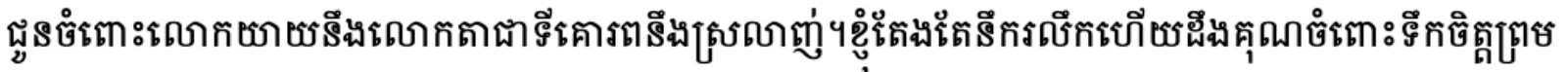

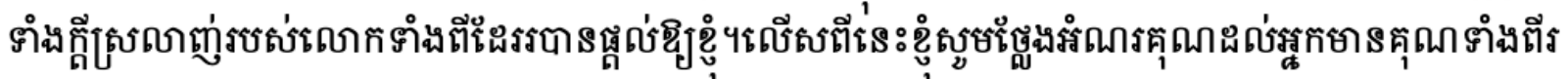

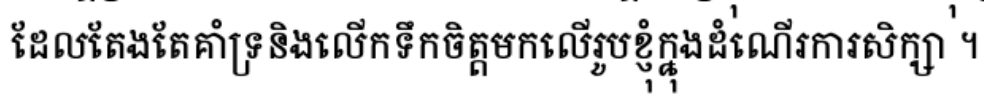

Anya, Zsanett és Ádám, köszönöm a támogatást, az ideiglenes figyelemelterelést, illetve hogy kibírtatok és segítettetek mindez idő, alatt. 


\section{Table of Contents}

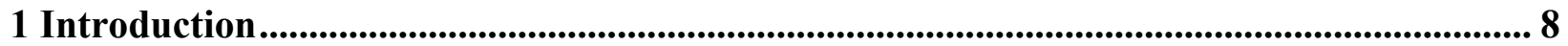

1.1 Research Gap................................................................................................................ 9

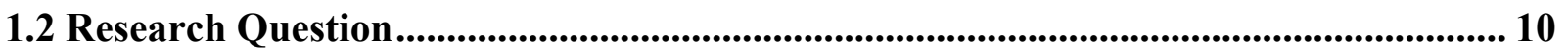

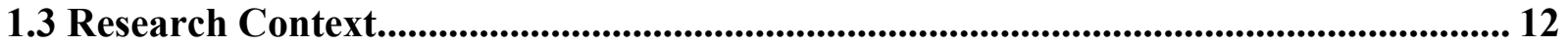

1.4 Thesis Structure..................................................................................................... 14

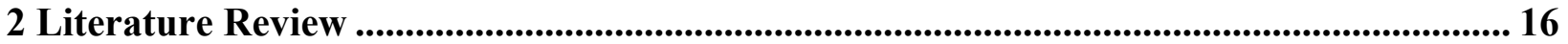

2.1 Environmentally Sustainable Behavior...................................................................... 16

2.1.1 Defining Environmentally Sustainable Behavior .............................................. 17

2.1.2 Understanding Environmentally Sustainable Purchasing Behavior .......................... 18

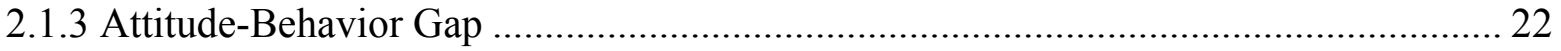

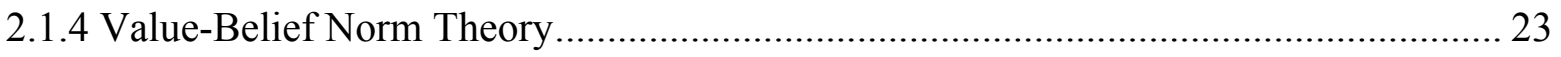

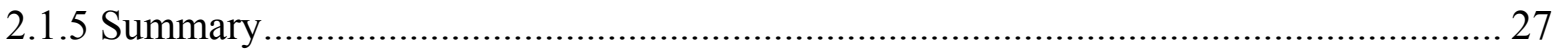

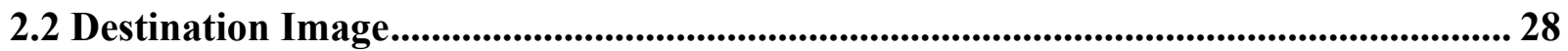

2.2.1 Defining Destination Image ............................................................................ 28

2.2.2 Components of Destination Image ..................................................................... 29

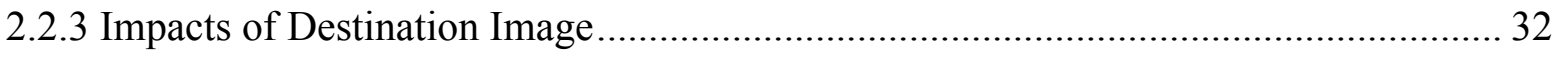

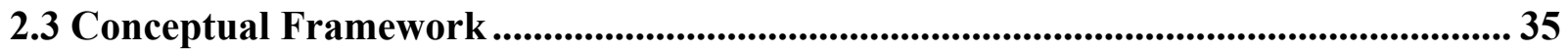

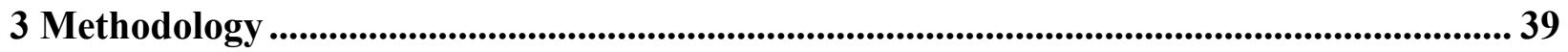

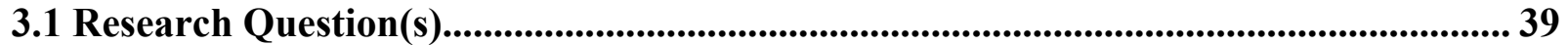

3.2 Research Paradigm ............................................................................................................. 41

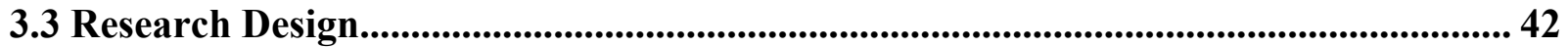

3.3.1 Qualitative Research................................................................................. 42

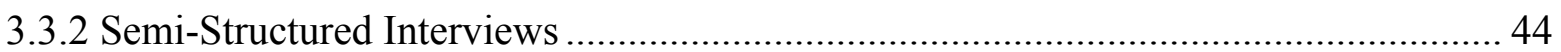

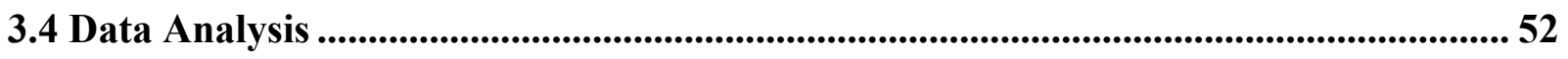

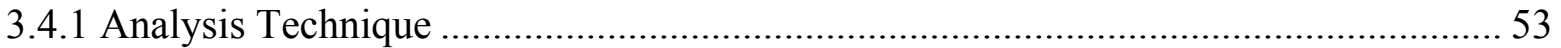

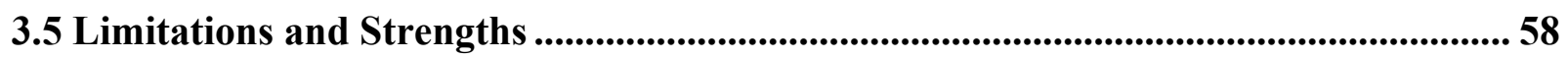

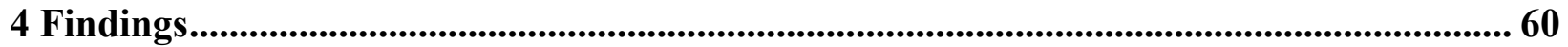

4.1 Sample Characteristics ..................................................................................60

4.2 Perceived Destination Image .............................................................................. 62

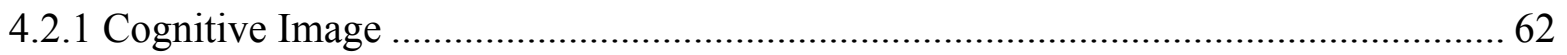

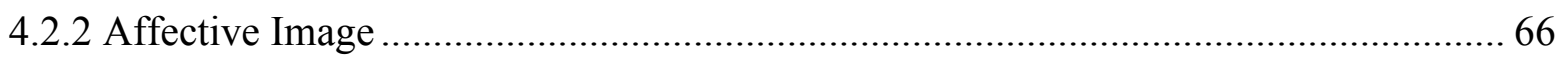

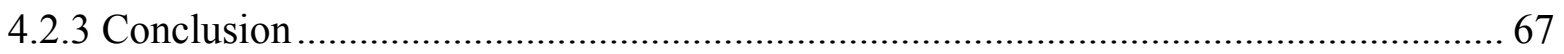

4.3 Environmentally Sustainable Purchasing Behavior ............................................... 68

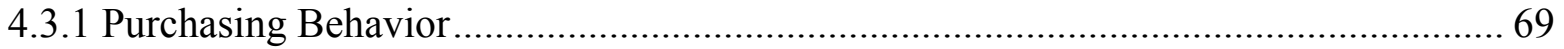

4.3.2 Causal Factors.............................................................................................. 74

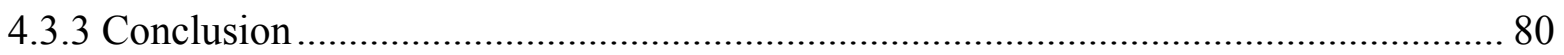

4.4 Value Orientation ...................................................................................................... 80 
4.4.1 Beliefs and Values Attached to the Environment............................................. 81

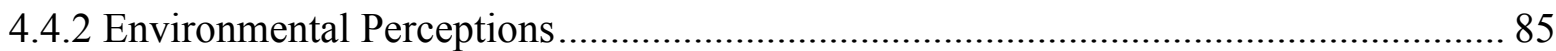

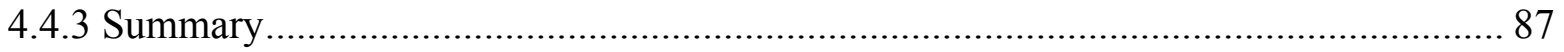

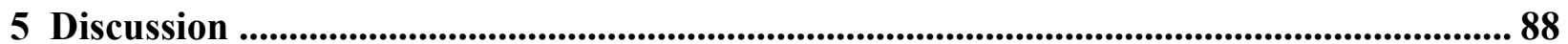

5.1 Perceived Destination Image ..................................................................................... 88

5.1.1 Conceptualization of Destination Image ........................................................... 88

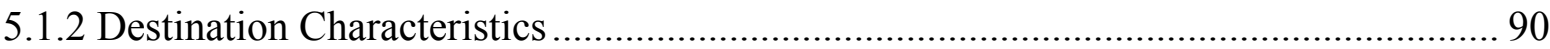

5.2 Environmentally Sustainable Purchasing Behavior ...................................................... 92

5.2.1 Conceptualization of Environmental Sustainable Behavior ................................... 92

5.2.2 Understanding Environmentally Sustainable Purchasing Behavior .......................... 94

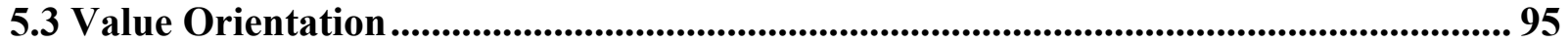

5.3.1 Nature of Respondents' Value Orientation ......................................................... 95

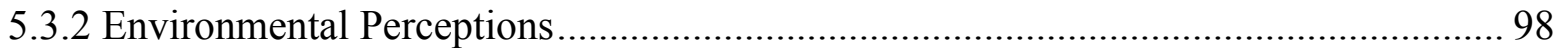

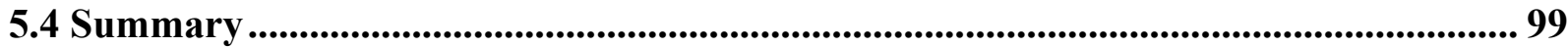

5.5 A Revised Conceptual Framework ......................................................................... 101

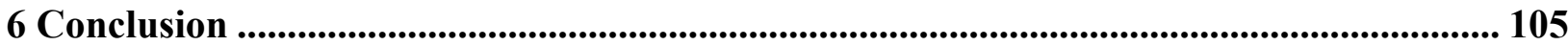

6.1 Concluding the research question(s) ........................................................................... 105

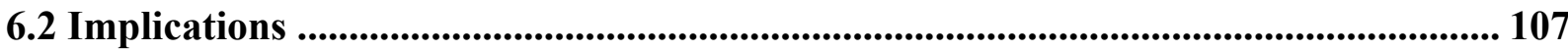

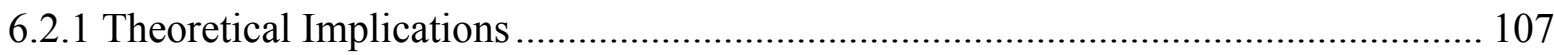

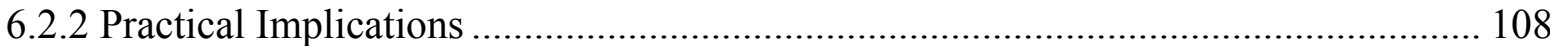

6.3 Limitations and Future Research ................................................................................... 109

Appendices................................................................................................................................ 110

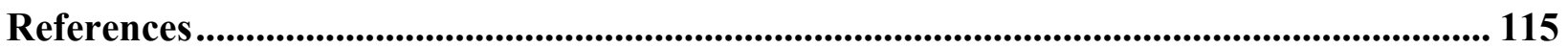




\section{List of Tables}

Table 3. 1: Design of interview questions based on the literature ........................................... 46

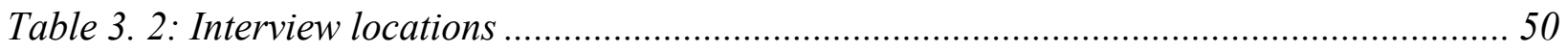

Table 3. 3: Example of Stage 3 and 4 .......................................................................................... 55

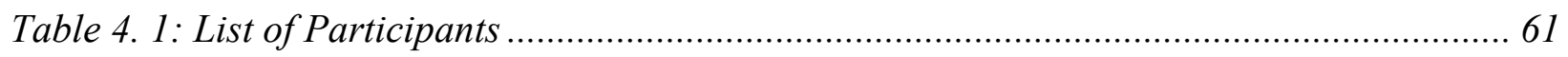

Table 4. 2: Causal factors mentioned by respondents ............................................................ 75

\section{List of Figures}

Figure 1. 1: 100\% Pure New Zealand advertisements in 1999-2019..................................... 13

Figure 1. 2: Tiaki promise guiding principles .............................................................. 14

Figure 2. 1: Tourists holiday choices and associated environmental impacts.......................... 19

Figure 2. 2: Types of environmentally sustainable tourist behavior (and percentage of studies

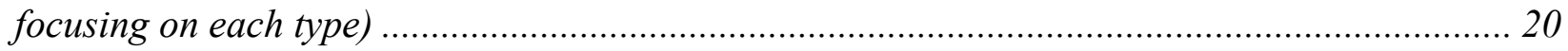

Figure 2. 3: A schematic representation of variables in the VBN theory of environmentalism ... 24

Figure 2. 4: Types of environmentally significant behaviors and casual variables influencing

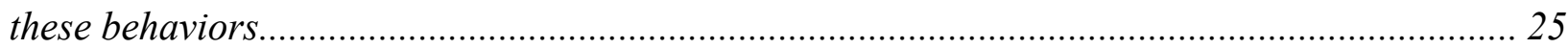

Figure 2. 5: Interactive System of Image Components ....................................................... 30

Figure 2. 6: The components of destination image ................................................................. 31

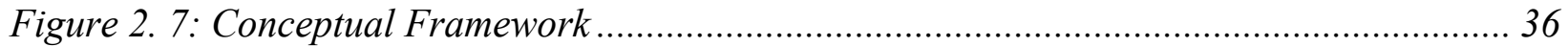

Figure 3. 1: Stages of framework analysis ..................................................................... 52

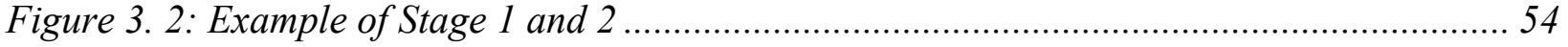

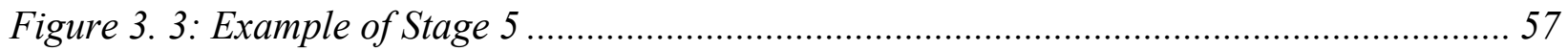

Figure 5. 1: Revised conceptual framework .............................................................. 102 


\section{Introduction}

There is a growing awareness of the negative impacts of tourism on the environment, and as tourism continues to be one of the biggest economic sectors in the world, this is expected to intensify, bringing more environmental degradation to destinations (Nepal, Irsyad \& Nepal, 2019). The effects of global environmental changes are also worsening this (Gössling \& Hall, 2006), making destinations more vulnerable and less appealing to tourists (Gössling et al., 2012). As the natural environment represents the main resource for many tourism destinations (Dolnicar \& Leisch, 2007), destinations are under pressure to protect it (Salvatierra \& Walters, 2017).

Many tourism businesses have started to produce environmentally sustainable tourism products to mitigate the negative environmental consequences resulting from the consumption of tourism products with not much success as the consumption of such products remain low (Abdullah, Samdin, Teng, \& Heng, 2019; Line \& Hanks, 2016; Stanford, 2008; Tölkes, 2018a). Although tourists have also developed positive attitudes towards purchasing tourism products that are environmentally sustainable (Tölkes, 2018a; Budeanu, 2007; Line \& Hanks, 2016), as these have the capability to enable them to enjoy their travel with minimal negative impacts on the environment, only a few tourists purchase accordingly (Budeanu, 2007). This low support from tourists is one of the main barriers to progress towards sustainable tourism. Understanding why this gap occurs between tourists intentions and behavior (also known as attitude-behavior gap) has been at the focus of many research looking environmentally sustainable behavior (Juvan \& Dolnicar, 2014; Tölkes, 2018b), but when studying this gap, contextual elements are often neglected (Chiu, Lee \& Chen, 2014; Dolnicar, 2010; Line \& Hanks, 2016; Untaru, Epuran \& Ispas, 2014). Research looking at consumer beliefs about green hotels by Line and Hanks (2016) found that the perceptions of a hotel's destination can have a strong influence on attitudes and behaviors toward green hotels. In the same research, it was found that tourism to urban destinations is more likely to evoke negative attitudinal evaluations of green hotels than tourism to nature-based destinations (Line \& Hanks, 2016). This thesis, therefore, aims to build on this, by focusing specifically on examining the role of destination image in influencing environmentally sustainable purchasing behavior by tourists in a more general setting; not limited to product-specific contexts. By understanding this, it will not only reduce the current research gap, but will also help destination 
managers and marketers create more effective measures to promote environmentally sustainable behavior for tourists.

This introductory chapter will first outline the research gap and the importance of examining the role of destination image in regards to environmentally sustainable behavior. The research questions guiding this thesis will also be identified and the research context will also be introduced. Lastly, the outline of the structure of this thesis will be given.

\subsection{Research Gap}

Although the literature provides a solid base to understand the nature of tourists' environmentally sustainable behavior, the attitude-behavior gap still poses one of the biggest challenges in better understanding it. Tourists overall have a positive attitude towards pro-environmental behavior, but only a few engage in it. Extant studies have attempted to understand the attitude-behavior gap by looking at tourists' travel choices, the effect of sustainability communication (Tölkes, 2018a; Tölkes, 2018b), tourists' environmental awareness, environmental concern (Abdullah, Samdin, Teng, \& Heng, 2019), and perceptions of green products (Line \& Hanks, 2016; Juvan \& Dolnicar, 2013; Juvan \& Dolnicar, 2014; Tan, Johnstone \& Yang, 2016) with little success understanding this gap. While other articles that examined the nature of the relationship between tourists' beliefs, attitudes, and real behavior found that the relationship is in fact fragile (Chiu, Lee \& Chen, 2014; Wearing, Cynn Ponting \& Mcdonald, 2002. This is partly because tourism takes place in an environment that is outside tourists usual environment and this new environment (the destination) can significantly affect consumers' attitudes towards environmentally sustainable behavior (Untaru, Epuran \& Ispas, 2014; Abdullah, Samdin, Teng \& Heng, 2019; Chiu, Lee \& Chen, 2014; Dolnicar, 2010; Line \& Hanks, 2016).

The contextual environment in which tourism takes place is often neglected despite its strong impact; it can have on behavior (Tasci, Gartner, \& Cavusgi, 2007; Huete Alcocer \& López Ruiz, 2019). Extant literature on destination image and environmentally sustainable behavior has predominantly been focusing on ecotourism experiences (Wearing, Cynn Ponting \& Mcdonald, 
2002; Chiu, Lee \& Chen, 2014) and green accommodations (Bell, 2008; Line \& Hanks, 2016), while only a few studies have looked at destination image influence on environmentally sustainable tourist behavior outside of ecotourism experiences or green accommodations (Dolnicar \& Leisch, 2008; Imran, Alam \& Beaumont, 2014; Mohaidin, Wei \& Ali Murshid, 2017). Therefore these have prohibited a comprehensive understanding of how (or if) destination image influences tourists' environmentally sustainable purchasing behavior outside of these product-specific contexts. Thus, this thesis aims to reduce this gap by understanding the nature of the relationship between destination image and environmentally sustainable purchasing behavior.

Throughout this thesis, the term environmentally sustainable purchasing behavior will refer to any consumption attitude or behavior that intends to contribute to ecological sustainability in a holiday context (Mehmetoglu, 2009). Environmentally sustainable behavior will also interchangeably used with pro-environmental behavior.

\subsection{Research Question}

To reduce the research gap, a deeper understanding is needed of the nature of the relationship between destination image and tourists' environmentally sustainable purchasing behavior. Although the literature review in Chapter 2 will examine this in more detail, a more in-depth understanding is needed on tourists' perception of destination image and the factors feeding into it. Tourists' environmentally sustainable purchasing intentions are also needed to be examined particularly, how and why it occurs. The aspects of destination image that influence tourists' proenvironmental intentions also needed to be explored. Extant literature highlighted that certain destination characteristic are more influential on behavior, but these also need to be investigated in a more general setting. Drawing upon this, the following research question and sub questions will be addressed in this thesis:

What is the role of destination image in influencing environmentally sustainable purchasing behavior of tourists? 
This question is broken down into the following sub-questions:

1. What is tourists' perceived destination image?

2. Do tourists have the intention and/or actual behavior to purchase their tourism products and services environmentally sustainably? If so, how and why?

3. What aspects of perceived destination image influence tourists' environmentally sustainable purchasing behavior and why?

To answer the research question, it is essential to first understand how the destination is perceived by tourists. As a destination image highly subjective (Bramwell \& Rawding, 1996; Line \& Hanks, 2016; Huete Alcocer \& López Ruiz, 2019), tourists are likely to have different perceptions of it. By understanding the unique perceptions of the destination image it will help understand what characteristics and attributes that are perceived and recognized.

The second sub-question aims to examine the nature of tourists' environmentally sustainable purchasing behaviors including how and why it occurs. This identifies whether tourists have the intention to behave environmentally sustainably and the factors that may feed into that.

The last sub-question explores the aspect of the perceived destination image that influences tourists' environmentally sustainable purchasing behavior. This question aims to identify what characteristics and attributes of the perceived destination image foster pro-environmental intentions or behavior and why.

Providing answers for each of these will benefit the academia, destination tourism managers, and marketers who can use this knowledge to promote environmentally sustainable behavior through destination image. Regarding academia, this research aims to reduce the gap between environmentally sustainable behavior and destination image by adopting a more generic approach to environmentally sustainable purchasing behavior that is not limited to particular products only. Additionally, there is already indication in the literature on the potential importance of the contextual environment on tourists' pro-environmental behavior, but this has not been empirically confirmed outside of eco-tourism and green accommodations.. 


\subsection{Research Context}

The chosen research context for this study is New Zealand due to its unique characteristics that provide a very interesting context to examine how and what aspects of the destination may evoke or trigger pro-environmental intentions. New Zealand as a tourist destination offers a diverse range of activities and attractions both in nature and urban areas that make the country appeal to a broad range of tourists (Morgan, Pritchard \& Piggott, 2002). Tourist experiences available in New Zealand are mainly made up of outdoor activities (e.g. hiking, kayaking, or diving), and adventure tourism such as bungy jumping, skydiving, jet boating or skiing. There are also cultural experiences (such as the Māori Kapa Haka (traditional Māori performing arts)) as well as film experiences available (such as Hobbiton Movie Set). However, the biggest attraction for tourists remains the natural environment (Morrow \& Mowatt, 2015; Tourism New Zealand, 2019; Morgan, Pritchard \& Piggott, 2002). The natural landscape is fundamentally what draws tourists to the country (Yeoman \& Mcmahon-Beattie, 2014; Tourism New Zealand, 2019; Morgan, Pritchard \& Piggott, 2002).

The perception of New Zealand as a natural wonderland started when it promoted itself as 'clean \& green' destination in the 1970s and since 1999, it has been promoted as $100 \%$ Pure New Zealand, which continues to be vigorously advertised internationally (Bell, 2008). The 100\% Pure brand draws on many features of the country, including the natural landscapes (see figure 1.1), the people, and the Lord of the Rings movie trilogy positioning New Zealand as Middle-Earth (Tourism New Zealand, 2019; Bell, 2008). The success of this campaign was due to the focus on

New Zealand's environment that links the destination image to a 'clean and green' image with landscape at the core (Bell, 2008). These are believed to play a significant role in forming New Zealand's image and reputation, suggesting a pristine, pollution-free environment (Bell, 2008). The fact that it is also located relatively far from other countries, it conjures up the image of a relatively undiscovered and untouched land (Morgan, Pritchard \& Piggott, 2002). 
Figure 1. 1: 100\% Pure New Zealand advertisements in 1999-2019
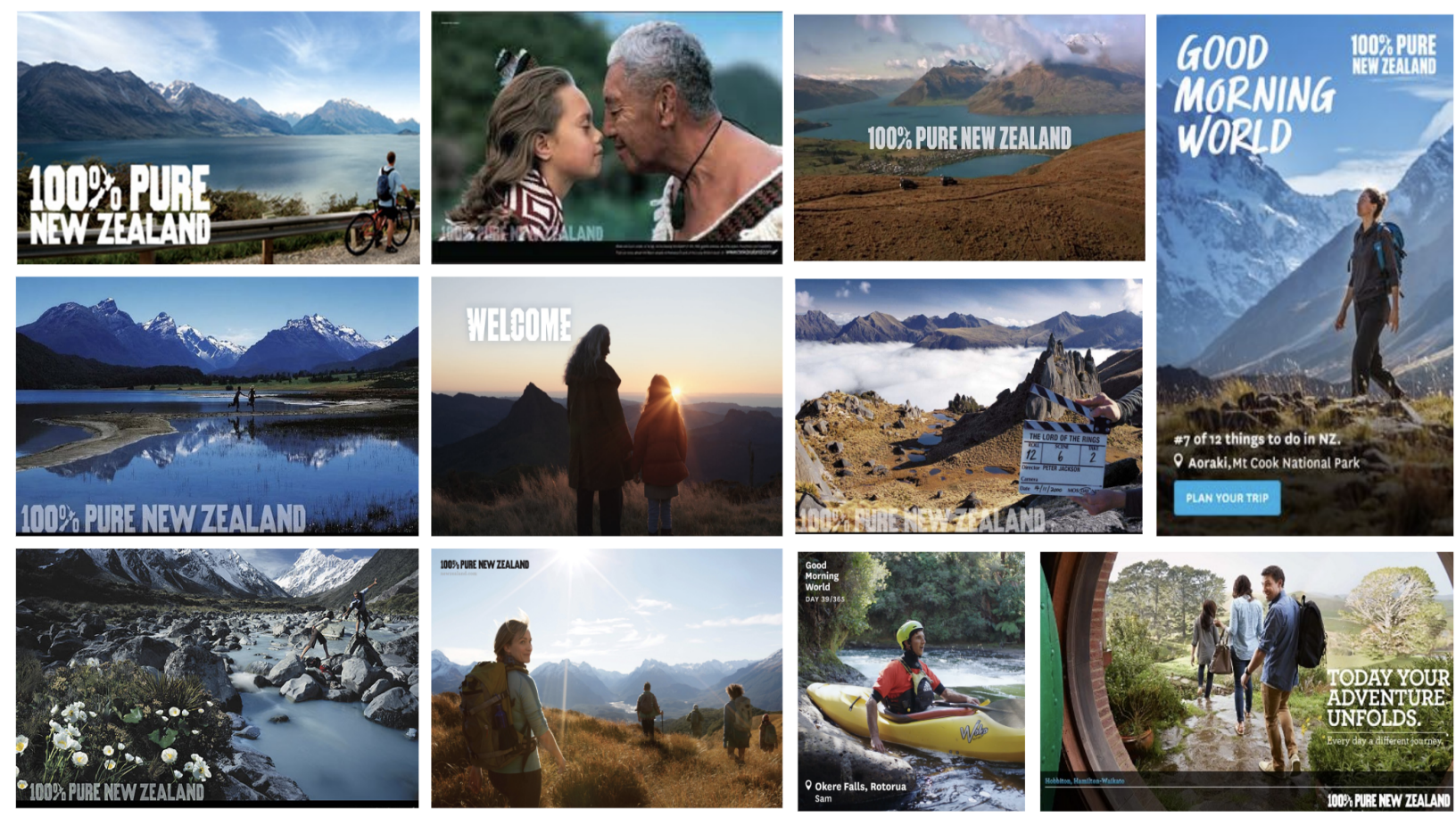

In addition to New Zealand's strong brand image of being clean and green, the country is also involved in various environmental efforts specific to the tourism industry that aimed to protect the environment, which include a range of sustainability 'certifications and commitments' to look out for tourists traveling in New Zealand e.g. Qualmark, Enviro-Mark or CarboNZero (Kenworthy, 2018). The Department of Conservation (manages 30\% of New Zealand's land) also created pocket guides to educate visitors on how to have a minimal impact on the environment by adopting 'the kiwi way' (DOC, 2018). Additionally, Leave No Trace is an American Non-Profit organization with which New Zealand has teamed up to educate and challenge the New Zealand public and visitors on how and why to minimize their environmental impacts while enjoying natural and cultural heritage areas (LNT, 2020). The Tiaki Promise initiative, which was developed by multiple New Zealand organizations to encourage international and domestic travelers to act as guardians of Aotearoa. (Tourism New Zealand, 2018). The Tiaki promise offers a set of guiding principles for visitors to follow, showing them how to contribute to preserving and protecting New Zealand (see figure 1.2). Although this is not a complete list, it demonstrates the various efforts undertaken by New Zealand to promote pro-environmental behavior. 
Figure 1. 2: Tiaki promise guiding principles
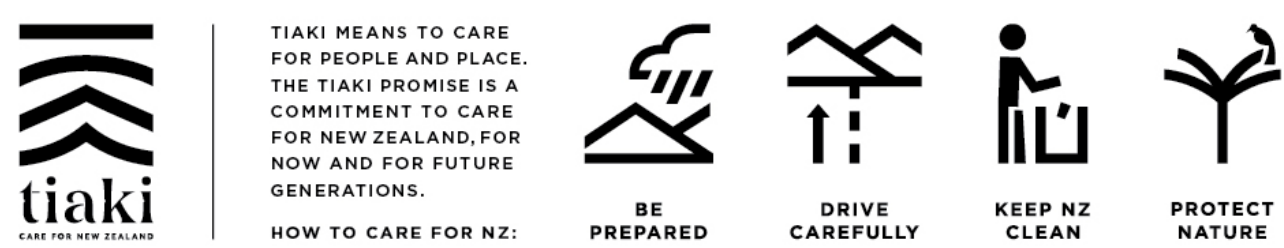

As New Zealand offers a diverse range of tourism product offerings, this not only enables the research to examine environmental perceptions of the destination but also more generic aspects. As highlighted earlier, extant literature on destination image had a strong focus on particular contexts or specific types of destinations only e.g. urban environment, ecotourism destinations, or focus on products only. By New Zealand having such diverse product offerings, it will enable this research to examine the destination image in a more general setting, while also exploring the environmental perceptions of the destination. As New Zealand offers a variety of experiences that are nature-based, it will enable tourists to be more apparent to the conditions of the environment and pro-environmental behaviors carried out by locals.

\subsection{Thesis Structure}

This thesis consists of six chapters. The current chapter has identified the research gap in academic literature. The main research question and its sub-questions that highlight what needs to be known to better understand the role of destination image in influencing environmentally sustainable behavior. The chapter concludes by introducing the research context, New Zealand.

Chapter 2 provides a comprehensive literature review that explores environmentally sustainable purchasing behavior and destination image. It begins with defining and exploring both concepts such as the types of environmental sustainable behaviors, barriers in understanding it, and examining theories that were previously used to study it. The concept of destination image is also 
explored its components, and its impact on tourists behavior. Theories previously used to examine destination images are also covered. The literature is then integrated into a conceptual framework, on which the methodological approaches are based.

Chapter 3 outlines the methodological approaches of this thesis. The interpretive paradigm that directed the qualitative approach and analysis is described. This is followed by the methodological procedures used to collect data that consisted of personal semi-structured in-depth interviews with international tourists within the Wider Wellington region. To analyze the data, framework analysis was used which is also explained. The chapter concludes by discussing the limitations and strengths of this research.

Chapter 4 presents the results of the data analysis. It provides an overview of the sample population and presents relevant findings for each of the sub-questions underpinning this thesis.

Chapter 5 presents the discussion of findings using concepts and theory from the literature. The original research question is also revisited and answered. The chapter is concluded with a revised conceptual framework that illustrates the contributions of the findings to academic literature.

Chapter 6 concludes this thesis through addressing the implications of the findings. The subquestions and original research questions are revisited, to recognize the contributions of this research to both academia and destination managers and marketers. Limitations and strengths are also discussed followed by recommendations for future research. 


\section{Literature Review}

The previous chapter has identified the importance of exploring the role of destination image in influencing environmentally sustainable purchasing behavior and has outlined the information that is required to answer the research question. The following chapter provides a review of literature on environmentally sustainable (purchasing) behavior and destination image to deepen the understanding of the nature of relationship. The literature review concludes with the conceptual framework which combines what is currently understood, limitations, and gap(s) of existing literature, which will guide the research methodology later on.

The first part of the literature review begins with defining environmentally sustainable (purchasing) behavior in tourism. Relevant theories that help to understand environmentally sustainable behavior are also examined to understand the complexities and limitations that are present in extant literature.

The second part of the literature review focuses on destination image by first defining it. Individual components of destination image are also explored and their impact on behavior is also examined. Theories offering insight into the impact of destination on behavior are also discussed to understand behavior and the nature of relationship between destination image and proenvironmental behavior.

The last section of the literature review presents the conceptual framework, which outlines the current understanding of constructs and the link between each other. Overlaps and gaps of the existing literature are also illustrated, which will guide the research methodology.

\subsection{Environmentally Sustainable Behavior}

The following section defines what environmentally sustainable (purchasing) behavior means in tourism and discusses the merits and shortcomings of previous definitions. Following this, this section also draws upon what is currently understood regarding environmentally sustainable 
behavior including limitations and gaps in existing literature. Lastly, relevant theories looking at environmentally sustainable tourist behavior will be examined to better understand it.

\subsubsection{Defining Environmentally Sustainable Behavior}

The term originates from sustainable tourism which encompasses the practice of tourism in a way that "takes full account of its current and future economic, social and environmental impacts, addressing the needs of visitors, the industry, the environment and host communities" (UNWTO, 2005 , p. 11-12). As seen in the above definition, sustainable tourism reflects three main principles of sustainable development, namely, social and cultural sustainability, economic sustainability, and lastly, environmental sustainability (UNWTO, 2005; Mehmetoglu, 2009).

Environmentally sustainable behavior entails a broad range of actions and interchangeably used with environmentally responsible behavior, pro-environmental or environmentally friendly behavior (Kiatkawsin \& Han, 2016). Juvan and Dolnicar (2016) define environmentally sustainable tourist behavior as a "tourist behavior, which does not negatively impact the natural environment (or may even benefit the environment) both globally and at the destination" (p. 31). The limitation of this definition, however, is that it suggests that behavior can only be considered environmentally sustainable if it does not impact the environment negatively. However, given the nature of tourism, that is inevitable. Everything that tourists do has an impact on the environment but the extent to which these are negative are different. For example, traveling itself to the destination already involves the use of transport and other resources that have negative impact on the environment (Dolnicar, Crouch, \& Long, 2008), therefore considering behavior environmentally sustainable only if it does not have any negative impact is too narrow. Similar to earlier definition, Lee, Jan, and Yang (2013) define environmentally responsible behavior as "any action that alleviates the adverse environmental impact of an individual or group" (p. 466), which also overlooks the fact that behavior can also impact the environment positively rather than just eliminating the negative impact. 
These definitions are relatively constraining which does not reflect the nature of environmentally sustainable behavior which is very broad yet complex thus, requires definition that also accommodates that. Taking these into account, Mehmetoglu (2009) defines sustainable behavior in tourism as "any consumption attitude or behavior that intends to contribute to ecological, social, cultural and/or economic sustainability in a holiday context" (p. 8). Although the definition has an overall sustainability focus, it was found most fitting to describe environmentally sustainable behavior for various reasons. First, the definition proposes a contribution to ecological sustainability in one way or another and does not demand all negative impacts of a holiday to be eliminated as part of environmentally sustainable behavior. Second, it does not demand behavior to be non-negative or both attitude and behavior to be present when tourists purchase their tourism products as not all environmentally sustainable behavior is intentional or conscious (Tölkes, 2018b). Third, it also acknowledges the consumption nature of tourism products as tourism from the consumer's point of view is about selecting and choosing tourism products and services that make up the travel experience. For the rest of this thesis, Mehmetoglu's definition will be used when referring to environmentally sustainable behavior without the economic, and socio-cultural focus of the definition as this thesis focuses on environmentally sustainable behavior only. After the adjustments, environmentally sustainable behavior is defined as any consumption attitude or behavior that intends to contribute to ecological sustainability in a holiday context.

\subsubsection{Understanding Environmentally Sustainable Purchasing Behavior}

In simple terms, tourism destinations can be considered "a package of tourism facilities and services which like any other consumer product or service, is composed of a number of multidimensional attributes that together determine its attractiveness to a particular individual in a given choice situation" (Echtner \& Ritchie, 1993, p. 26). Therefore, purchasing behavior in tourism is made up of a combination of individual product choices that take place throughout the holiday process (Budeanu, 2007). When looking at environmentally sustainable purchasing behavior, it is important to note the complexity that tourists may encounter when selecting different products or services. As figure 2.1 shows, a single product choice can have various negative environmental impacts and the consideration of each can make environmentally sustainable 
purchasing behavior a complex and challenging process (Budeanu, 2007; Jurowski \& Black, 2015).

Figure 2. 1: Tourists holiday choices and associated environmental impacts

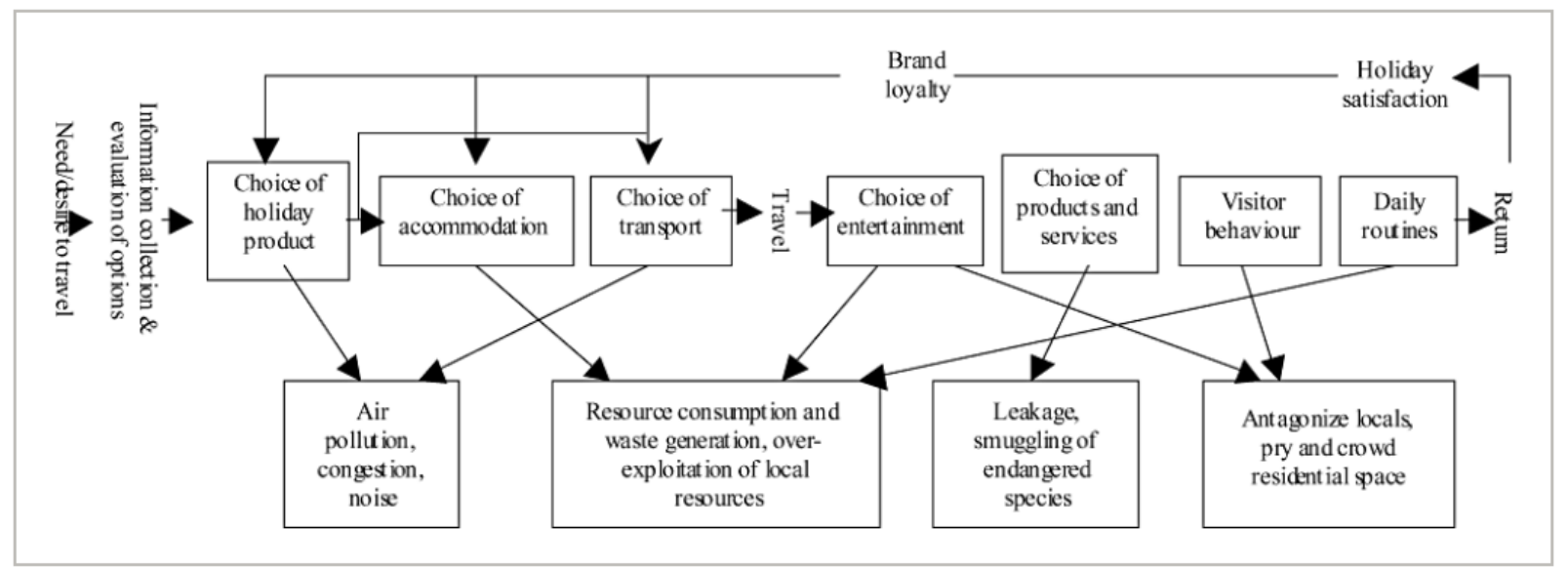

Source: Budeanu (2007, p. 501).

\subsubsection{The four types of Environmentally Sustainable Behavior}

Juvan and Dolnicar (2016) differentiate between four different types of environmentally sustainable behaviors that are present in extant literature (see figure 2.2). Tourists can either display environmentally sustainable behavior or not (vertical axis on figure 2.2) and people can either have pro-environmental intent or not (horizontal axis on figure 2.2) (Juvan \& Dolnicar, 2016). Tourists who show good intentions but do not behave accordingly cannot be qualified as environmentally sustainable tourists (quadrant 1 in figure 2.2). The same goes for proenvironmental beliefs and values as on their own are insufficient to ensure environmentally sustainable behavior (Juvan \& Dolnicar, 2016). While accidental or unintended environmentally sustainable behavior cannot be fully qualified as pro-environmental behavior either. Tourists may not intend to purchase environmentally sustainable tourism products but do so accidentally. Research by Tölkes (2018b), found that research participants were largely unaware of having booked a certified sustainable tourism product. This means that tourists may purchase environmentally sustainable tourism products without perceiving the availability, the value or the 
distinctiveness of environmentally sustainable products (Juvan \& Dolnicar, 2016; Tölkes, 2018b). Lastly, quadrant 3 represents the combination of intent and behavior, which means that tourists who behave environmental sustainability with the intent to contribute to ecological sustainability. Tourists in this quadrant make conscious decisions and want to behave in an environmentally sustainable way (Juvan \& Dolnicar, 2016). Although each type of environmentally sustainable behavior is made up of a different combination of intent and behavioral outcome, they all qualify as environmentally sustainable behavior according to Mehmetoglu's definition. Accordingly, environmentally sustainable behavior can consist of either a consumption attitude or behavior that intends to contribute to ecological sustainability; therefore all types of environmentally sustainable behavior identified by Juvan and Dolnicar (2016) are relevant for this research.

Figure 2. 2: Types of environmentally sustainable tourist behavior (and percentage of studies focusing on each type)

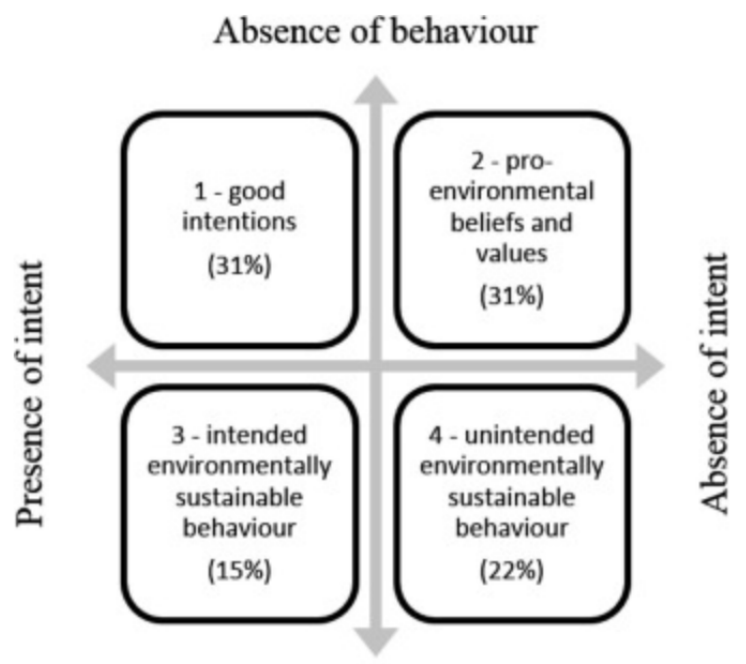

Presence of behaviour

Source: Juvan and Dolnicar (2016, p. 35)

Although the four types of environmentally sustainable behavior are relatively simple to distinguish in between, but understanding the nature of environmentally sustainable behavior can be a lot more complicated. This is because tourists' choices are moderated by multiple factors such as their concern towards the environment, social, cognitive, situational, and cultural factors (Jurowski \& Black, 2015). Tourists' purchases (such as the choice of accommodation or transport) are influenced by the context in which it takes place (Woodside \& Dubelaar, 2002; Line \& Hanks, 
2016). Therefore, the choice of destination can have implications for the types of purchases (Dolnicar, 2010; Wang, Zhang, Cao, Hu \& Yu, 2018; Stanford, 2008). Additionally, tourists may purchase environmentally sustainable tourism products, but it does not necessarily mean willingness to protect the environment (Budeanu, 2007). Tourists may engage in environmentally sustainable behavior due to emotional affinity towards nature, present and past experiences with nature (Juvan, Crouch \& Long, 2010; Giacon, 2014; Stern, 2000) or for self-interests (Wearing, Cynn, Ponting \& McDonald, 2002; Stern, 2000) and not necessarily for the conservation of the environment itself. In fact, tourists may choose alternative transport options to save costs and not necessarily do so to protect the environment (Juvan \& Dolnicar, 2016). While those tourists who only have pro-environmental attitudes present without adherent behavior may have intrinsic reasons for not behaving sustainably such as habits and convenience (Stern, 2000), which are worsened when they are on holiday. This is because behaving environmentally sustainably on a holiday often conflicts with tourist's short-term personal gains or hedonic desires (Budeanu, 2007). Additionally, a common concern by tourists who regularly practice sustainable behaviors at home is not having the right infrastructure when on a holiday to enable them to behave environmentally sustainable, which may explain why tourists exhibit different behaviors when home and when on a holiday (Dolnicar, 2010; Juvan \& Dolnicar, 2014; Untaru, Epuran \& Ispas, 2014). Another practical difficulty for tourists wanting to obtain environmentally sustainable tourism products is limited availability or availability is poorly communicated (Wearing, Cynn, Ponting, \& McDonald, 2002; Jurowski \& Black, 2015; Tölkes, 2018a; 2018b). While businesses have tried sustainability communications to promote sustainable purchases, these were found largely ineffective. This is because by the time tourists see it, they are in the destination already and by then most booking and purchasing have been made, and even then, they do not always perceive the significance of it or do not see it as relevant to them or simply find it confusing (Wearing, Cynn, Ponting \& McDonald, 2002; Line \& Hanks, 2016; Jurowski \& Black, 2015). However, the biggest challenge in understanding environmentally sustainable behavior remains to be the attitude-behavior gap, which is discussed in the following section. 


\subsubsection{Attitude-Behavior Gap}

The attitude-behavior gap currently poses a great challenge in understanding and predicting environmentally sustainable behavior as it is still not fully understood in the literature as to why it exists (Terlau \& Hirsch, 2015; Juvan \& Dolnicar, 2014; Stanford, 2008: Line \& Hanks, 2016; Wearing, Cynn, Ponting \& McDonald, 2002; Budeanu, 2007). The term attitude-behavior gap refers to a disconnect between individuals' attitudes and behaviors. For instance: tourists in general hold positive attitudes toward the environment and do not wish to behave in a way that negatively impacts the environment (Juvan \& Dolnicar, 2014). However, despite tourists' declared positive attitudes towards environmentally sustainable tourism, only a few behave accordingly (Budeanu, 2007). Attitudes are considered to be "an enduring set of beliefs about an object that prompts individuals to behave in particular ways toward the object, reflects value orientation and determines how facts are interpreted" (Jurowski \& Black, 2015, p. 180). Attitudes flow naturally and automatically from individual beliefs regarding the associated object and is considered to be the most important predictor of environmentally sustainable behavior (Untaru, Epuran, Ispas, 2014). Thus tourists, who demonstrate pro-environmental attitudes are also expected to translate that into their purchasing behavior (Line \& Hanks, 2016; Untaru, Epuran, Ispas, 2014; Giacon, 2014). However, as previously mentioned, pro-environmental attitudes are no guarantee for environmentally sustainable purchasing behavior.

To provide an explanation for the attitude-behavior gap, many of the previous studies on environmentally sustainable behavior draw upon the cognitive dissonance theory (Tölkes, 2018a; Tölkes, 2018b; Juvan \& Dolnicar, 2014). The theory suggests that people experience psychological discomfort when there is an inconsistency between "cognitions about themselves, about their behavior, and their surroundings" (Festinger, 1957, p. 9). It occurs when people have a desire to achieve a certain outcome (e.g. environmentally sustainable behavior) but the dissonance gives them psychological discomfort (Juvan \& Dolnicar, 2014). People respond to this dissonance by adjusting their beliefs or behaviors to transfer the states of dissonance to states of consonance to eliminate the inconsistencies. In a study with members of environmental organizations, respondents often provided explanations as to why they did not behave environmentally sustainably despite knowing the harmfulness of their real behavior on the environment (Juvan \& 
Dolnicar, 2014). Therefore instead of changing behavior, tourists change their attitude to be consistent with their behavior to avoid the state of dissonance (Hares, Dickson \& Wilkes, 2010; Juvan \& Dolnicar, 2014). Research analyzing environmentally sustainable behavior has previously reported observing cognitive dissonance happening and suggested it for the reason it may be happening (Tölkes, 2018a).

As pointed out earlier, environmentally sustainable behavior is a very complex area to study due to the various types that exist, and the considerations that need to be made by tourists (Budeanu, 2007; Juvan \& Dolnicar, 2016). Up to date, the attitude-behavior gap poses one of the biggest challenges in understanding environmentally sustainable behavior. Even though cognitive dissonance theory offers a deeper insight into environmentally sustainable behavior, (Tölkes, 2018a;Tölkes, 2018b; Juvan \& Dolnicar, 2014) it still does not provide a full picture.

\subsubsection{Value-Belief Norm Theory}

The Value-Belief-Norm (VBN) theory by Stern (2000) offers a wider insight into environmental sustainable purchasing behavior than cognitive dissonance theory as it considers antecedents of pro-environmental behavior and other factors that could potentially influence it.

The VBN theory provides a casual and hierarchical relationship between different variables that influence environmentally sustainable behavior (see figure 2.3). The theory "postulates a relationship between a person's values and beliefs about the environment, one's responsibility for the environment conditions and personal norms relating to the environment, which in turn cause pro-environmental behavior" (Juvan \& Dolnicar, 2016, p. 78). Each variable in the chain directly affects the next and may also directly affect variables farther down the chain (Stern, 2000). 
Figure 2. 3: A schematic representation of variables in the VBN theory of environmentalism

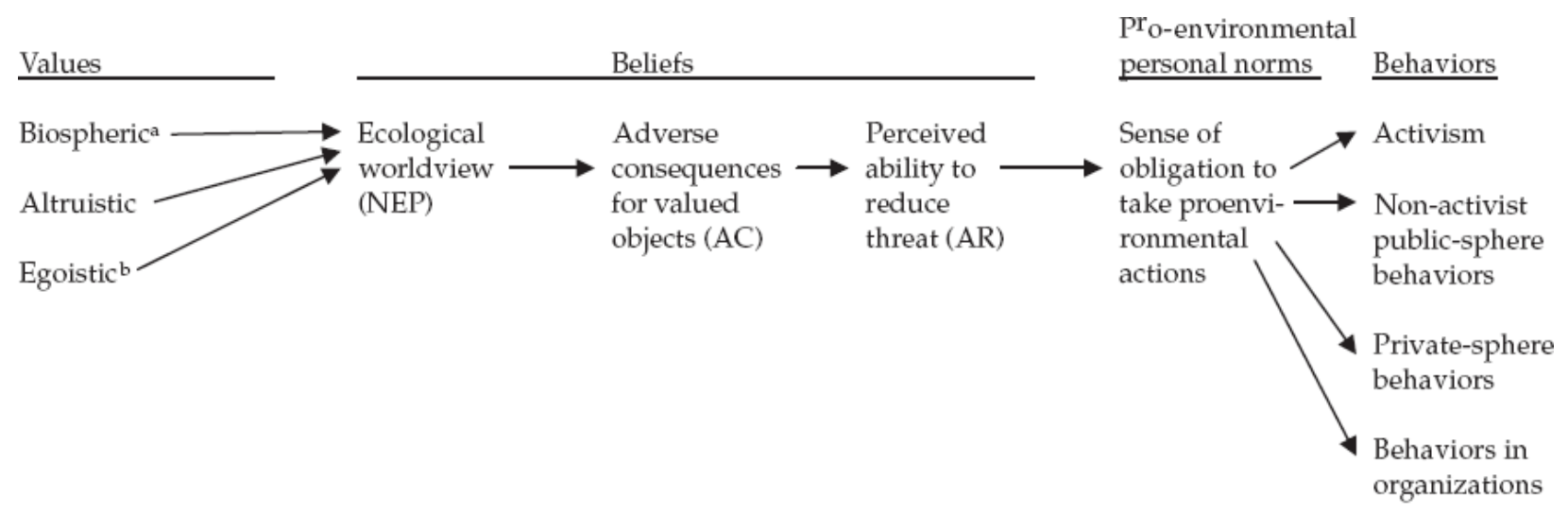

\footnotetext{
${ }^{\text {a }}$ Arrows represent postulated direct effects. Direct effects may also be observed on variables more than one level downstream from a causal variable.

${ }^{\mathrm{b}}$ Empirically, measures of egoistic values have been negatively correlated with indicators of environmentalism.
}

Source: Stern (2000, p. 412)

The formulation of VBN distinguishes between three value types (altruistic, biospheric, and egoistic) that influence the beliefs linked to environmental behavior (Stern, 2000; Tölkes, 2018b; De Groot \& Steg, 2009). Accordingly, people demonstrating biospheric values orientation, show concern for the environment, while people with altruistic value orientation show concern for the well-being of others. In contrast, people with egoistic value orientation attempt to increase their personal benefits through their behaviors (Stern, 2000; De Groot \& Steg, 2009; Tölkes, 2018b). Regardless of which value orientation people may possess, it directly affects people's (environmental) worldview (see figure 2.3) and beliefs about the human-environment relationship. The theory suggests that two specific beliefs affect pro-environmental behavior that are (1) the awareness of consequences of behavior on the things people value (AC) and (2) the ascription of responsibility, indicating that people believe they are responsible for protecting that which they value so highly (AR) (Lopez-Mosquera \& Sanchez, 2012; Juvan \& Dolnicar, 2016; Tölkes, 2018b; Stern, 2000). In other words, pro-environmental behavior is activated by beliefs that environmental conditions threaten things that individual values (AC) and the individual can act to reduce the threat (AR).

The final stage of VBN theory is behavior. Stern (2000) differentiates between four types of environmentally significant behavioral outcomes which include activism, non-activist public- 
sphere behaviors, behaviors in organisations, and private-sphere behaviors (such as purchasing behavior). In the context of tourism, tourists' purchasing behavior can be classified as 'privatesphere environmentalism' to the different behavioral outcomes distinguished (Tölkes, 2018b). Each behaviors are then determined by a different combination of causal factors that are categorized into: attitudinal (perceived costs and benefits of action, product attributes), personal capabilities (e.g. financial resources, skills), contextual factors (e.g. social norms, advertising), and habit and routine (see figure 2.4). These causal variables account for certain capabilities and constraints that affect the efficacy of a tourist undertaking environmentally sustainable behavior (Tölkes, 2018b; Stern, 2000).

Figure 2. 4: Types of environmentally significant behaviors and casual variables influencing these behaviors

\begin{tabular}{ll}
\hline Causal variables & Environmentally significant behaviors \\
\hline $\begin{array}{l}\text { Attitudinal } \\
\text { General environmentalist predisposition }\end{array}$ & $\begin{array}{l}\text { Environmental activism } \\
\text { Behavior-specific norms and beliefs }\end{array}$ \\
$\begin{array}{l}\text { Nonenvironmental attitudes } \\
\text { (e.g., about product attributes) }\end{array}$ & $\begin{array}{l}\text { Environmental citizenship } \\
\text { (e.g., petitioning, joining groups) }\end{array}$ \\
Perceived costs and benefits of action & Policy support \\
Personal capabilities & \\
Literacy & Private-sphere environmentalism \\
Social status & Consumer purchase behaviors \\
Financial resources & Maintenance of household equipment \\
Behavior-specific knowledge and skills & Changes in equipment use, lifestyle (curtailment) \\
& Waste disposal behaviors \\
Contextual factors & "Green consumerism" \\
Material costs and rewards & Other \\
Laws and regulations & Behaviors affecting organizational decisions \\
Available technology & \\
Social norms and expectations & \\
Supportive policies & \\
Advertising & \\
Habit and routine & \\
\hline
\end{tabular}

a The VBN theory incorporates various attitudinal variables believed to create this predisposition. ${ }^{b}$ These norms and beliefs figure prominently in applications of norm-activation theory and the theory of planned behavior to specific proenvironmental behaviors.

Source: Stern (2000, p. 421) 
VBN theory was found most fitting for understanding environmentally sustainable behavior in the context of this research as it does not suggest the consideration of all potential factors that may influence behavior (Tölkes, 2018b), but acknowledges the causal factors that may be present. Moreover, it does not presume that behavior is rational as opposed to the Theory of Planned Behavior does ( a framework commonly used to explain decision-making in sustainable tourism) as in fact environmentally sustainable behavior can be accidental and not necessarily be representative of a person's attitudes (e.g. attitude-behavior gap) (Budeanu, 2007; Tölkes, 2018b; Line \& Hanks, 2016; Stanford, 2008).

Despite the effectiveness of VBN theory to explain environmentally sustainable behavior, the application of it has been relatively scarce and recent. Tölkes (2018b) for example used it to study the information processing of sustainability information in tourism as contextual factors for which the theory was found well-suited. While others have used it to understand the attitude-behavior gap in environmentally sustainable tourism particularly looking at environmental activists who are known to have pro-environmental attitudes and willingness to engage in behavior that helps the environment (Juvan \& Dolnciar, 2014). Same as with Tölkes' work, VBN was found to be effective in understanding environmentally sustainable behavior in a tourism context, and also contributed to understanding the attitude-behavior gap by identifying some of its complexities. The causal factors identified by Stern (2000) also acknowledge potential barriers or constraints to environmentally sustainable behavior therefore acknowledges that even if pro-environmental values, attitudes, and beliefs are present, behavior is still influenced by the combination of causal variables that are present.

Though, one shortcoming of VBN is that it does not account for the fact that tourists act environmentally sustainably accidentally or unintentionally without recognizing the product attributes as particularly sustainable or added value therefore, it falls outside of the framework, which in fact happens often (Budeanu, 2007; Tölkes, 2018b; Line \& Hanks, 2016; Stanford, 2008). Despite this, the framework was found promising to identify environmental attitudes, beliefs, and values which motivate tourists environmental purchasing behavior hence will be used to underpin this thesis and to better understand tourist environmentally sustainable purchasing behavior (Juvan \& Dolnicar, 2014; 2016; Tölkes, 2018b). For the remaining part of the thesis, 
VBN will be referred to as value orientation, to simply refer to what the VBN theory encompasses, that value orientations of individuals determine their environmentally sustainable purchasing behavior and can presumably influenced by the destination image, which will be explored in later sections under the term value orientation.

\subsubsection{Summary}

In conclusion, environmentally sustainable behavior is complex and multifaceted. The combination of tourists purchases that make-up tourists purchasing behavior, can only be considered environmentally sustainable, if tourists display an intent and/or adherent behavior to contribute to the ecological sustainability both globally and at the destination. As the previous section discussed, understanding such behavior is difficult due to the various types of environmentally behavior that exists and the presence of attitude-behavior gap, which remains a challenge in understanding environmentally sustainable behavior. However, cognitive dissonance theory has been found to better understand the attitude-behavior gap, while the VBN found more promising in understanding and predicting environmentally sustainable purchasing behavior. The VBN theory also considers various causal variables that play a role in influencing tourist behavior including contextual factors that many studies on environmentally sustainable behavior have previously neglected. By understanding these, it will help to identify and recognize relevant behaviors and/or intentions towards environmentally sustainable purchasing behavior by tourists, which will be helpful when constructing the conceptual framework and the interview questions. Having environmentally sustainable purchasing beahvior explored, the following section will now explore the extant literature on destination image. 


\subsection{Destination Image}

The previous section examined existing literature on environmentally sustainable purchasing behavior and the following section will now focus on destination image which is the other topic area explored in this thesis. This section will first define what the destination image is, and explore its different components. Second, the literature concerning destination image impact on tourists behavior are also examined. While discussing these, merits and limitations of extant literature are also highlighted. Relevant theories to understand destination image are also considered to gain a deeper understanding of destination image and its impact on environmentally sustainable behavior.

\subsubsection{Defining Destination Image}

In simple terms, destination image is a mental representation of the destination in the individual's mind (Kock, Josiassen \& Assaf, 2016). The extant literature has used various conceptualization over the years, many vague, incomplete or lacking. Destination image is a multifaceted term and none of the existing definition is without limitations. Given the subjective nature of image, people perceive it uniquely (Bramwell \& Rawding, 1996; Line \& Hanks, 2016; Castro, Martín Armario \& Martín Ruiz, 2007; Huete Alcocer \& López Ruiz, 2019). Current approaches to define a destination image are either attribute-based or holistic (Ryan \& Cave, 2005; Echtner \& Ritchie, 1991). Both of these approaches focus on different aspects of destination image and are often used for different purposes (Kock, Josiassen \& Assaf, 2016; Tasci, Gartner, \& Cavusgi, 2007; Echtner \& Ritchie, 1991). Attribute-based conceptualization of destination image often uses a list of attributes to measure destination image against those attributes or use it to compare destinations on. While holistic ones focus on the overall impression and characteristics that make up or destination image formation (Tasci, Gartner, \& Cavusgi, 2007). For example, Bojanic (1991) defines (holistic) destination image as "the impressions that a person or persons hold about a country in which they do not reside" (p. 353). Although this definition focuses on holistic destination image, it is relatively vague, as it misses to identify key elements that determine one's' image of a destination and assumes that destination image is only perceived by international tourists. Furthermore, destinations at all levels (local, regional, national, and international) have 
distinct perceptual images that are not limited to international tourists or residents only (Tasci, Gartner, \& Cavusgi, 2007).

Chiu, Lee, and Chen (2014) on the other hand, define destination image as "set of qualities, attributes and benefits that visitors hold about the destination; it represents the sum of beliefs and impressions that person has of a destination" (p. 877). This definition acknowledges the subjective nature of image, implying that destination image can vary between people. Additionally, the definition looks at destination image holistically as opposed to adopting attribute-based measures which have been found less effective in examining destination image compared to the ones with holistic focus (Echtner \& Ritchie, 1991; Tasci, Gartner, \& Cavusgi, 2007). This is because attribute-based definitions miss to capture all relevant attributes of a destination yet account for the fact that not all attributes may be perceived by tourists (Ryan \& Cave, 2005; Echtner \& Ritchie, 1991). Gartner (1986) for example, defines destination image by focusing on certain attributes of a destination without actually considering the subjective elements of destination image. Moreover, relying on a list of attributes only, does not capture the multidimensionality of the image component (Baloglu \& McCleary, 1999). For the above mentioned reasons, this thesis will adopt Chiu, Lee, and Chen's (2014) definition when referring to destination image.

\subsubsection{Components of Destination Image}

Destination image is formed by three distinctively different, but hierarchically interrelated components called cognitive affective and conative (Gartner, 1993; Basaran, 2016; Ryan \& Cave, 2005). These key components are represented in figure 2.5, which shows a general theoretical breakdown of destination image. The outer circle represents the holistic destination image, and the inner circles represent the components and their hierarchy within destination image. Cognitive component refers to what we know about an object and affective component is about how we feel about an object (Tasci, Gartner, \& Cavusgi, 2007). In the context of destination image, cognitive component consists of perception of attributes (e.g. the number of tourist attractions or safety). While affective components refers to the emotional response of individuals to a place (e.g. friendly/unfriendly, exciting/boring) (Basaran, 2016). The combination of cognitive and affective components then determines how we act on this information which is known as the conative 
component (Echtner \& Ritchie, 1991; Basaran, 2016). As figure 2.5 indicates, cognitive and affective components can be further broken down into attributes that shape and influence destination image. Within these attributes, we can also distinguish between common (e.g. beaches and oceans, friendly locals) and unique (e.g. culture, attractions) that provide a deeper insight into how each of the components are internalized (Echtner \& Ritchie, 1991; Tasci, Gartner, \& Cavusgi, 2007).

Figure 2. 5: Interactive System of Image Components

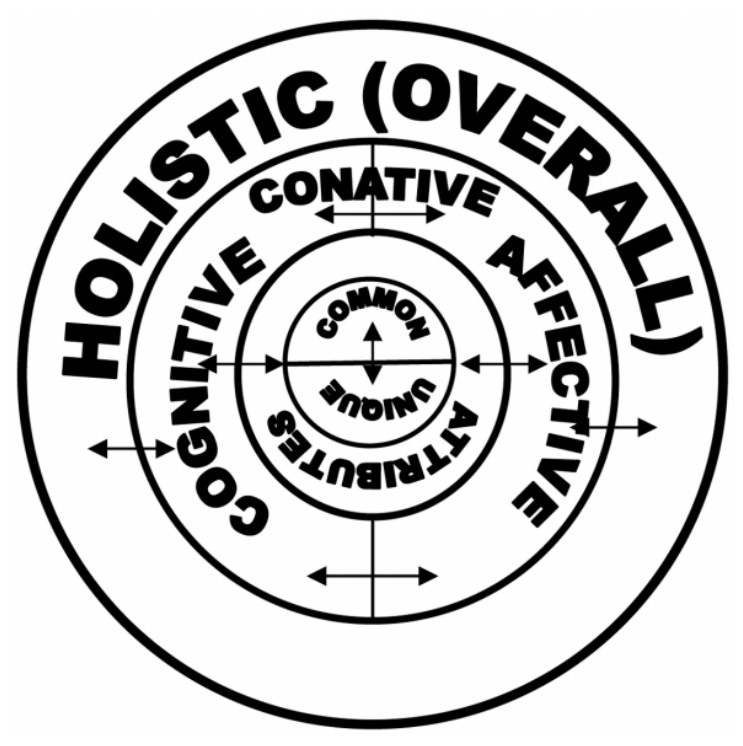

Source: Tasci, Gartner and Cavusgil (2007 p. 200)

Even though cognitive and affective components are presented as equal variables, they influence the formulation of destination image differently throughout the travel process (Baloglu \& McCleary, 1999; Ryan \& Cave, 2005; Basaran, 2016; Nghiêm-Phú, 2015). For example, Basaran (2016) found that cognitive component plays a more important role prior to travelling. However, during travel, the affective component was found to play a greater role in influencing overall destination image (Nghiêm-Phú, 2015). Therefore both components have different impacts on the perceived destination image at different stages of the travel process, as they are interlinked, overlap and also dependent on each other (Echtner \& Ritchie, 1991; 1993). For example, despite the 
significant impact of the affective component during the travel process, it is still formed under the influence of cognitive components (Baloglu \& McCleary, 1999; Tasci, Gartner, \& Cavusgi, 2007; Basaran, 2016). The conative component however depends on both cognitive and affective components but not the same way (Nghiêm-Phú, 2015). The cognitive component found to be a bigger influencer of conative component while, affective component still mediates the relationship between cognitive and conative components (Basaran, 2016). Even though, destination image can be broken down into its components, the components cannot be studied independently as they together make up the holistic image of a destination (Echtner \& Ritchie, 1991; Tasci, Gartner, \& Cavusgi, 2007; Basaran, 2016).

Figure 2. 6: The components of destination image

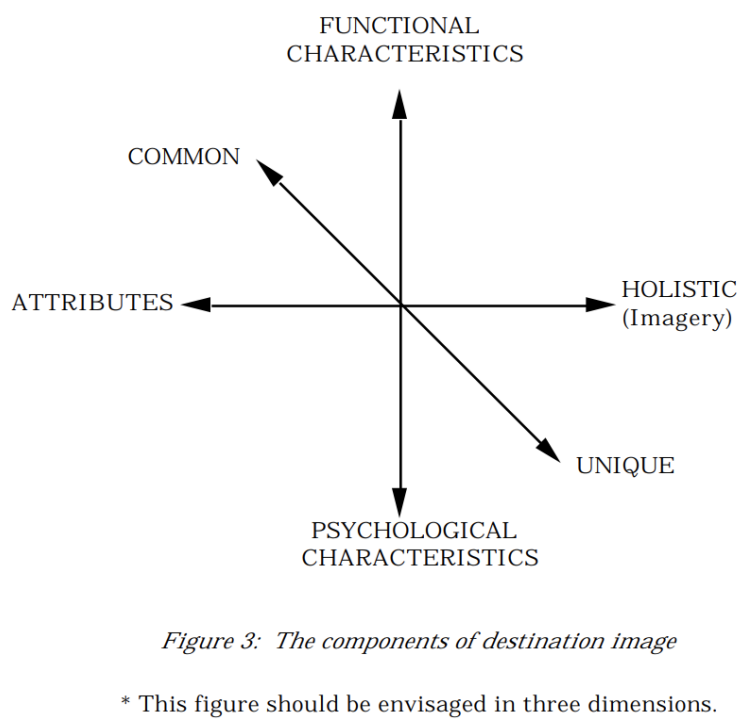

Source: Echtner and Ritchie (1991 p.43)

A more detailed representation of destination image components shown in figure 2.6, which is less theoretical than figure 2.5. Many studies have adopted this three continuum scale to measure destination image components by Echtner and Ritchie (1993), as it accommodates both attributebased and holistic components of image. The figure is based on three continuums, that are: (1) functional-psychological characteristics, (2) attributes-holistic, and (3) common-unique (Echtner \& Ritchie, 1991;1993), which are similar to figure 2.5 except for the consideration of functional 
(e.g. scenery, attractions, accommodation facilities, price levels) and psychological characteristics (e.g. friendliness, safety, atmosphere). Even though figure 2.6 divides the concept of destination image, there are obvious overlaps between the four parts. The combinations and interactions of attributes make up the holistic impression of a destination while the holistic impressions in turn, the perceptions of individual attributes may be influenced by overall impressions (Echtner \& Ritchie, 1991). Each of these components then can be broken down to functional and psychological characteristics. However, this thesis is not concerned with measuring destination image but rather identify the characteristics, attributes, and features that are perceived and/or recognised by tourists and the extent to which these influence their environmentally sustainable behavior. To identify those attributes and characteristics of destination image, it is necessary to consider various components of image and also their impact on behavior.

\subsubsection{Impacts of Destination Image}

Destination image is an evolving concept, it can change over time therefore the way it influences tourist behavior can also differ depending on the travel stage. According to Echtner and Ritchie (1991) there are three stages of destination image formation: phase 1, also known as 'organic image' as it is based on information assimilated from non-touristic, non-commercial sources such as general media, education, and opinions of friends and family. This 'organic image' is also influenced by publicly held common mental picture, also known as stereotypes (Echtner \& Ritchie, 1991). Stereotypes have a direct effect on cognitive and affective images and indirect effect on travel intention (Chen, Lai, Petrick \& Lin, 2016). The more detailed an individual knowledge about the destination attributes, the more detailed their picture, leading to a less stereotypical holistic synthesis by individuals, as stereotypes are often simplified and exaggerated (Chen, Lai, Petrick \& Lin, 2016). Based on this initial mental image of a destination individuals may be inspired to visit or avoid a destination, but either way, individuals can have an image of a destination without being there or having the intent to go there. Phase 2 on the other hand happens in the pre-trip state, where the image of a destination is shaped by more commercial sources of information that can also alter the 'organic image' of destination. Once making the decision to visit a particular destination, individuals start to collect information and are also exposed to more information which 
shape their image of that destination. Phase 3, which is the final stage of destination image formation, takes place during the actual visit of the destination (Tasci, Gartner, \& Cavusgil, 2007; Chen, Lai, Petrick \& Lin, 2016). Most individuals modify their image of destination most at this stage, as a result of visiting destination; images tend to be more realistic, complex, and differentiated (Echtner \& Ritchie, 1991).

Prior to visitation, destination image acts as a psychological pull factor to visit that destination and it plays a key role in influencing behavioral intention, particularly in destination selection (Chiu, Lee \& Chen, 2014; Ryan \& Cave, 2005; Baloglu \& McCleary, 1999; Basaran, 2016; Huete Alcocer \& López Ruiz, 2019) and destination loyalty (Castro, Martín Armario \& Martín Ruiz, 2007; Nghiêm-Phú, 2015; Melo, Moniz, Silva \& Batista, 2017). Destination image can also determine tourists' intention to revisit a destination, to recommend the destination to others, or to say positive things about the destination. Thus, managing destination image prior to travel as well as during travel are equally important as actual visitors are not only future potential visitors but also potential informants (Melo, Moniz, Silva \& Batista, 2017; Nghiêm-Phú, 2015; Baloglu \& McCleary, 1999). If tourists have a good overall impression of a destination, they are more likely to return to that destination and become loyal to it (Nghiêm-Phú, 2015). Additionally, if a destination is perceived positively, it is more likely to result in subsequent positive behavior. Chiu, Lee and Chen (2014) suggest that positive destination image in fact is an antecedent to environmentally sustainable behavior implying that positive image is necessary for environmentally sustainable behavior to take place. Wang, Zhang, Cao, Hu and Yu (2018) also support this by suggesting that people are less likely to care for the environment when it is messy, but will pay more attention to maintain an environment that is clean, supporting that positive image is necessary for pro-environmental behavior. Additionally, if tourists perceive a destination with a high level of environmental background, it is more likely to promote the generation of pro-environmental behavioral intention (Wang, Zhang, Cao, Hu \& Yu, 2018).

Although the literature provides a sufficient understanding of the attributes and characteristics that promote particular behaviors, destination image is still context-dependent. Thus, the impact of destination image on behavior is highly dependent on the context rather than specific destination characteristics or attributes only (Nghiêm-Phú, 2015; Line \& Hanks, 2016; Chiu, Lee \& Chen, 
2014; Tasci, Gartner, \& Cavusgil, 2007). For example, destination image defined by natural attributes as opposed to man-made attributes was found to have a positive impact on tourists' intentions to green hotel purchasing (Line \& Hanks, 2016). This is because destination images defined by natural attributes are perceived as more fragile. Additionally, Wearing, Cynn, Ponting and McDonald (2002) found that when 'benefits' of individuals' own actions are more apparent (which are more observable in destinations that are reliant on natural assets), individuals found to have a higher intent for conservation (Imran, Alam \& Beaumont, 2014).

When looking at the impact of destination image on behavior, tourists' characteristics should not be neglected either as individuals are influenced differently e.g. some require more stimuli while others less (Castro, Martín Armario \& Martín Ruiz, 2007; Bonn, Joseph \& Dai, 2005; Ryan \& Cave, 2005). Respondents' characteristics, their source of information are also found to be determinant of their image of a destination (Tasci, Gartner, \& Cavusgil, 2007). There are also evaluative differences among different cultures (Ryan \& Cave, 2005; Tonge et al., 2014; Baloglu $\&$ McCleary, 1999). The older people get, the less positive their image gets about a destination (Castro, Martín Armario \& Martín Ruiz, 2007). It is also possible for people to contain both positive and negative components of image simultaneously (Ryan \& Cave, 2005). Lastly, tourists' perception of destination image is also influenced by their previous travel experiences in other destinations, which can change their perceptions of other similar destinations as well (Tasci, Gartner \& Cavusgil, 2007).

In conclusion, destination image can have a strong influence on tourist behavior, but little is understood how it influences environmentally sustainable purchasing behavior. This is because existing studies are predominantly product-specific e.g. either focus on 'green hotels' (Line \& Hanks, 2016) or 'ecotourism' (Wearing, Lynn, Ponting \& McDavid, 2002) that do not allow to understand the nature of link between destination image and the intention to purchase environmentally sustainable tourism products. Examining destination image is also difficult due to the subjective and evolving nature of it, meaning that tourists are likely to have a unique image of a destination that changes over time. Additionally, destination image is also context-dependent that influences how destination attributes and characteristics are perceived, while the perceived attributes and characteristics are also influenced by tourists' characteristics (e.g. some require more 
stimuli than others) (Castro, Martín Armario \& Martín Ruiz, 2007). Therefore when examining tourists' perceived destination image, various influential factors needed to be considered e.g. type of visitors (first-time, returning, companion, length of stay, reason to visit), to better understand the context of their image formulation.

\subsection{Conceptual Framework}

This chapter has explored two key research topic areas: environmentally sustainable purchasing behavior and destination image. The following section will go over the relevant findings to identify and bound knowledge from the reviewed literature by using a conceptual framework illustrating the relationships between the key areas of literature to help address the research question.

The conceptual framework (see figure 2.7) is presented in the form of a Venn diagram to best illustrate the connections and overlaps between constructs. The three circles, namely: environmentally sustainable purchasing behavior, value orientation, and destination image represent each of the constructs that will be examined in this thesis. The conceptual framework starts off with environmentally sustainably purchasing behavior (see number 1 on figure 2.7) highlighting the main types of environmentally sustainable behaviors that have been identified in the literature, namely; intended, good intentions, accidental, and convenience. These all imply different ways of behaving environmentally sustainably. 'Intended' is when an individual intentionally practices pro-environmental behavior (Juvan \& Dolnicar, 2016; Mehmetoglu, 2009). 'Good intentions' have been noted in the literature as individuals with intentions to contribute to ecological sustainability, but do not behave accordingly. 'Accidental' is when an individual behaves environmentally sustainably without the intention to do so (Budeanu, 2007; Tölkes, 2018b; Line \& Hanks, 2016; Stanford, 2000). While 'convenience' is when an individual purchases environmentally sustainable tourism products because it is more convenient (e.g. cheaper, faster) and not necessarily for its pro-environmental qualities. As discussed in section 2.1.2.1, (1) environmentally sustainable behavior can take place in various ways and for various reasons. However, it can only be considered environmentally sustainable if consumption attitude and/or behavior that aims to contribute to ecological sustainability in a holiday context is/are 
present (Mehmetoglu, 2009). Therefore all the above mentioned pro-environmental behavior types can be considered as environmentally sustainable behavior because they all have either the proenvironmental attitude and/or behavior present.

Figure 2.7: Conceptual Framework

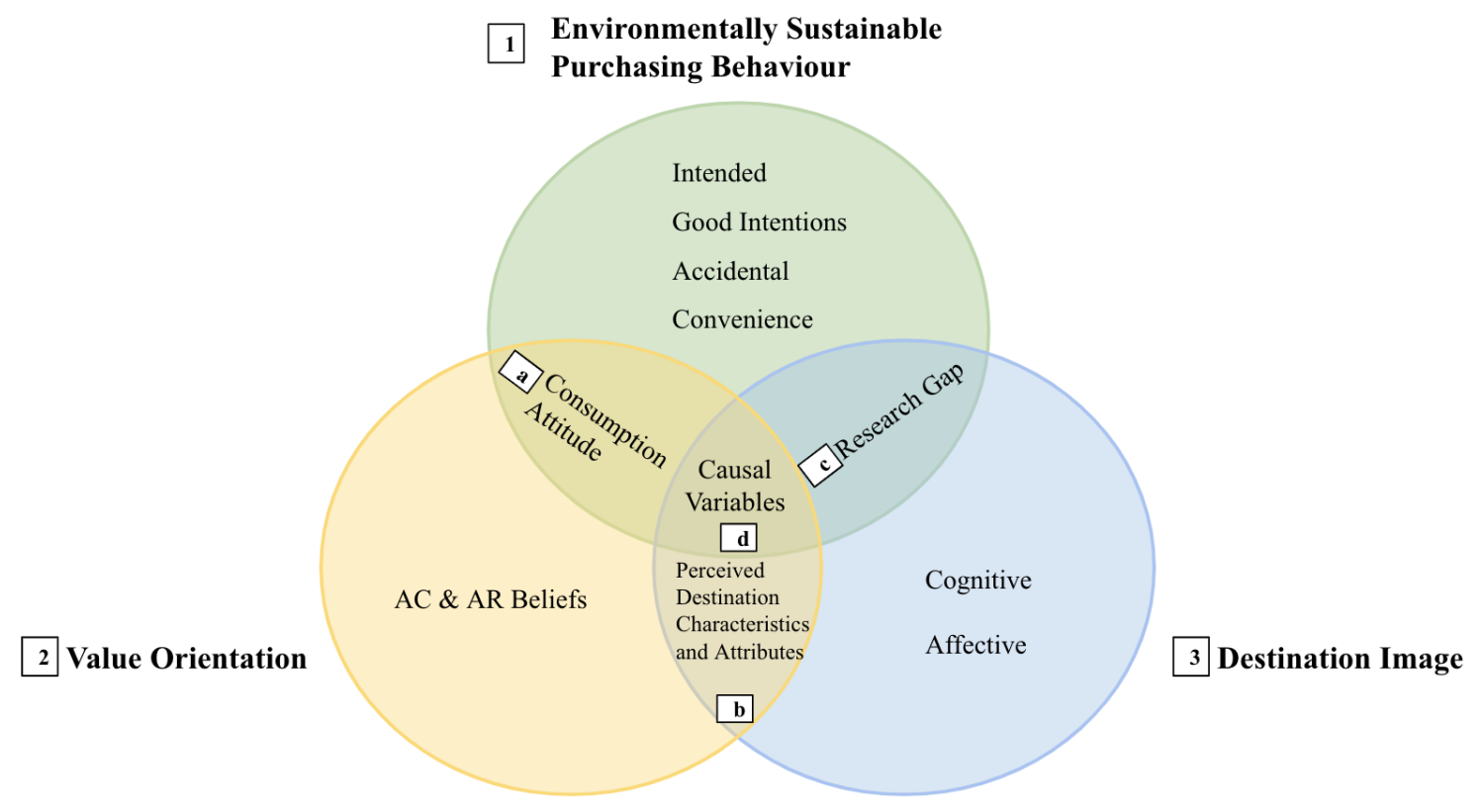

The second circle indicated with number 2 in figure 2.7 is Value Orientation, which has been adopted from the VBN theory by Stern (2000). According to the theory, two beliefs affecting proenvironmental behavior (see number 2 on figure 2.7) which are (1) the awareness of consequences of behavior on the things people value (AC) and (2) the ascription of responsibility for protecting what they value so highly (AR) (Lopez-Mosquera \& Sanchez, 2012; Juvan \& Dolnicar, 2016; Tölkes, 2018b; Stern, 2000). As it was discussed in the literature review (section 2.1.4), the basis of AC and AR beliefs lies on individuals' view on the human-nature relationship. The importance of this is that these beliefs about AC and AR can also determine one's intent to behave environmentally sustainably.

The third and final circle presents destination image components (discussed in section 2.2.2). Destination image consists of two main components, which are cognitive and affective (also shown 
on figure 2.7, number 3). Cognitive component consists of perception of attributes (e.g. the number of tourist attractions or safety). While affective components refers to the emotional response of individuals to a place (e.g. friendly/unfriendly, exciting/boring) (Tasci, Gartner, \& Cavusgi, 2007; Basaran, 2016). These components can influence behavior differently depending on the travel stage and context but they together make up the holistic destination image. It is understood from the literature that certain destination attributes and characteristics can evoke different behavioral responses hence it is essential to examine the cognitive and affective components of destination image to find those characteristics or attributes that have the potential impact to evoke proenvironmental behavior.

Continuing on with the diagram, the following section will discuss the nature of relationships between the constructs. As the conceptual framework indicates, there are certain overlaps between constructs that are worth discussing as they provide the base for this research. First overlap is between environmentally purchasing behavior and value orientation (indicated with $a$ ). As briefly discussed earlier, one's beliefs about AC and AR can determine the tourists' consumption attitude towards environmentally sustainable tourism products/behavior. The second overlap is between value orientation and destination image (indicated with $b$ ) and it highlights that one's value orientation can also influence how characteristics and attributes of a destination are perceived, because people value things differently and for different reasons e.g. emotional affinity towards it, concern for the environment or for self-interests (discussed in section 2.1.4). The third overlap (indicated with $\mathrm{c}$ ) is between environmentally sustainable purchasing behavior and destination image, which highlights the research gap. It is understood from the literature review that certain destination images can influence behavior but these are unclear in general terms. There is also no consensus on the role of destination image in influencing pro-environmental behavior but some aspects of their relationship have been observed and recognized by other researchers, which serves as a good indication that there is a relationship between destination image and environmentally sustainable behavior, but the nature of this relationship is still unclear and hence, my this research.

The last remaining part of the conceptual framework is 'causal factors' that has been placed in the center of the conceptual framework. Causal variables (indicated with d) has been adopted from Stern's (2000) VBN theory. Stern suggests that casual factors account for certain capabilities and 
constraints that affect the efficacy of a tourist undertaking environmentally sustainable behavior. Meaning that each behavior of tourists is determined by a different combination of causal factors that are categorized into: attitudinal (perceived costs and benefits of action, product attributes), personal capabilities (e.g. financial resources, skills), contextual factors (e.g. social norms, advertising), and habit and routine (discussed in section 2.1.4). However, due to the coverage of causal factors, it can not only facilitate the behavioral outcome, but also influence how the constructs interact with each other. For example, contextual factors can influence how a destination is perceived, but also one's ability to purchase environmentally sustainable tourism products. Additionally, causal factors such as habit and convenience can also influence an individual intent to behave environmentally sustainably. The causal factors are relatively complex and interlinked, but they support the literature as they acknowledge that one may have the intention to behave environmentally sustainably but still decide not to do so, due to some causal factors interfering which is a very common phenomenon in environmentally sustainable behaviors.

In conclusion, this conceptual framework has provided an illustrative representation of the extant literature on destination image and environmentally sustainable purchasing behavior. The nature of the relationships between constructs have been identified based on the literature review. The research gap has also been discussed and illustrated on the conceptual framework. By bounding this knowledge from the literature review in the form of this conceptual framework, it will help to design the research instruments and the overall methodology in order to answer the research question, which will be discussed in the following chapter. 


\section{Methodology}

The previous chapter provided an overview of the literature and also introduced the conceptual framework, which serves the basis of the methodology of this research. This chapter outlines the methodological processes conducted in this thesis to answer the research question. This thesis follows a qualitative research approach through semi-structured in-depth interviews, which is discussed in more detail later in the chapter. First, the research question is revisited, which then is followed by an overview of the interpretive paradigm guiding this research. Subsequently, an outline of the research design phases is provided. The chapter concludes with an outline of the limitations and strengths of this study.

\subsection{Research Question(s)}

As discussed throughout this thesis, the aim of this research is to examine the role of destination image in influencing environmentally sustainable purchasing behavior. It has been highlighted in the literature review (section 2.3) that the role of destination image in influencing proenvironmental behaviors is unclear but some aspects of the relationship have been observed and recognized by other researchers, which serves as a good indication that there is a relationship between the two. Regarding environmentally sustainable behavior, it has been noted that it is very complex and can take place in various ways. In order to recognize any influence of destination image on environmental behavior, it is essential to investigate whether tourists have the intention to behave environmentally sustainably in the first place and also, whether they have the intention to behave environmentally sustainably as a result of destination image influence. Therefore, to explore the nature of the linkage between destination image and environmentally sustainable, more information is required to answer the research question:

What is the role of destination image in influencing environmentally sustainable purchasing behavior of tourists? 
It is essential to first (1) understand how the destination is perceived, what cognitive and affective components are being observed and what it means for tourists. Certain destination characteristics and features can promote pro-environmental behavior attitudes (Wang, Zhang, Cao, Hu \& Yu, 2018; Line \& Hanks, 2016) thus, it is necessary to find those characteristics and features of the destination (if there is any) in order to be able to assess and examine their potential influence on environmental behavior. Moreover, it is also necessary (2) to understand whether tourists have the intention to behave environmentally sustainably and how and why it occurs. Part of this requires the examination of the nature of tourists' purchasing behavior and attitudes toward environmental behavior. If tourists display no intention of behaving environmentally sustainably then this question aims to explore the factors that may have contributed to it. As discussed in section 2.1.4 and 2.3, environmental behavior can encounter certain constraints (causal factors) which affect the efficacy or pro-environmental behavior such as habit and routine or personal capabilities. Thus, these also need to be examined, if any causal factor is present, that may have influenced tourists' pro-environmental behavior. Lastly, it is necessary (3) to understand aspects of the destination image that influence tourists' environmentally sustainable purchasing behavior. This requires to explore the environmental perceptions of tourists, and their beliefs and values attached to these. By exploring both, it will help identify any link that may exist between environmental perceptions and pro-environmental behavior. Subsequently, the research question has been broken down to the following sub-questions to address all necessary areas of the research question:

\section{What is tourists' perceived destination image?}

2. Do tourists have the intention and/or actual behavior to purchase their tourism products and services environmentally sustainably? If so, how and why?

3. What aspects of perceived destination image influence tourists' environmentally sustainable purchasing behavior?

Providing answers for these questions will reduce the gap extant literature in understanding the role of destination image in influencing pro-environmental behavior. The generic focus on environmental purchasing behavior will help to understand what attributes or characteristics of the destination influence on different types of environmental purchasing behavior and how one's environmental position may influence the perceived characteristics and attributes of the 
destination. Having revisited these, the following section will now look at the research paradigm underpinning this thesis and the methodological processes conducted in this thesis.

\subsection{Research Paradigm}

Research paradigms are best defined as "a basic set of beliefs that guides action" (Jennings, 2001, p. 35). It tells the researchers how to interpret a phenomena, relationships of ideas and social constructs (Mackenzie \& Knipe, 2006); what method(s) is/are appropriate for the development of knowledge in a given study. Paradigm is based on ontological, epistemological, and methodological assumptions. Ontology refers to the researcher's position and what is perceived as 'social reality' (Mason, 2002). Epistemology refers to the perspective on the research undertaken also referred to as the relationship between the researcher and subjects (Jennings, 2001; Mason, 2002). While the methodological assumptions refer to data collection.

This thesis has adapted an interpretive research paradigm (based on relativist ontology and subjective epistemology), which lies on the assumption that reality is socially constructed, filled with multiple meanings and interpretations, and that emotions are involved (Botterill \& Platenkamp, 2012; Elliot, Fairweather, Olsen \& Pampaka, 2016). In this paradigm, reality (as one knows it) is constructed by social actors and people's perception of reality, which is also ongoing, developing as people engage with society (Pulla \& Carter, 2018; Wahyuni, 2012; Brunt, Horner $\&$ Semley, 2017). Reality is seen as a product of subjective experience thus individuals seen as different, with different backgrounds that shape their interpretation of reality (Brunt, Horner \& Semley, 2017). As destination image is highly subjective as it is shaped by individuals' background, previous travel experiences and existing knowledge of the destination, interpretive paradigm suits well with the overall focus of this thesis. Additionally, interpretive paradigm also enables an in-depth exploration of tourists' environmental beliefs and value orientation through deep reflections in their social context and natural settings through the perspective of tourists themselves. Interpretive paradigm assumes that all knowledge and meanings are acts of interpretation therefore considers all knowledge subjective (Gephart, 1999). From an interpretivist point of view, the social world is hidden, and needs to be brought to the surface through deep 
reflection (Brunt, Horner \& Semley, 2017). Therefore the emphasis of interpretive research is on discovering the meanings that people attach to empirically observed phenomena in order to understand why they act in the way they do (Elliot, Fairweather, Olsen \& Pampaka, 2016).

Interpretive paradigm sees the world as a connected place, sees interconnected elements as one, having influence over one another (Brunt, Horner \& Semley, 2017). Therefore it enables the study of complex phenomena by looking at the social reality from the perspective of individuals themselves. To do that, researchers take the stance of insider perspective by looking at the situation being studied through participants' views (Mackenzie \& Knipe, 2006; Pulla \& Carter, 2018). However, as the researchers' own backgrounds shape their interpretation and understanding that need to be recognized and reflected upon by the researcher (Creswell, 2013), knowledge is essentially co-created between the researcher and participants. Therefore, the experiences and values of both research participants and researchers substantially influence the collection of data and its analysis (Wahyuni, 2012).

\subsection{Research Design}

This section describes the qualitative methods utilized in this thesis. The process of research design has been influenced by the research paradigm, key concepts from the literature review and the conceptual framework (discussed in section 2.3).

\subsubsection{Qualitative Research}

Interpretive paradigm is associated with qualitative research methods as it enables researchers to explore a wide array of dimensions of the social world including the present realities of others (Mason, 2002). Qualitative research is defined as "a situated activity that locates the observer in the world. It consists of a set of interpretive, material practices that make the world visible (...) it involves an interpretive, naturalistic approach to the world. This means that qualitative researchers study things in their natural settings, attempting to make sense of, or, interpret, phenomena in terms 
of the meanings people bring to them" (Denzin \& Lincoln, 2005, p. 3). As noted in the literature review, environmentally sustainable purchasing behavior is complex and is moderated by multiple factors such concern for the environment, social, cognitive, situational and cultural factors (Jurowski \& Black, 2015), qualitative method was found more fitting as it enables the understanding of the cultural and social dimensions of tourist behavior (Phillmore \& Goodson, 2004). While the literature on destination image suggested more qualitative approaches as opposed to quantitative methods. Although structured methodologies were found to be more effective in measuring the specific aspects of destination image, they do not provide a full picture (Echtner \& Ritchie, 1991; Echtner \& Ritchie,1993; Tasci, Gartner, \& Cavusgi, 2007; Ryan \& Cave, 2005). Moreover, structured methodologies such as Likert-type scale force respondents to respond to characteristics that necessarily compromise the image respondents have of the destination being studied (Ryan \& Cave, 2005). Hence considering the nature of information required to answer the research question and the paradigm position taken, this research will adapt a qualitative approach.

The strengths of qualitative approach to research lies in its ability to investigate the issue in-depth therefore provide a richer picture (Brunt, Horner \& Semley, 2017; Mason, 2002). The qualitative methods of data generation "are both flexible and sensitive to the social context in which data are produced (rather than rigid, standardized or structured, or entirely abstracted from real-life contexts) (Mason, 2002, p. 3). From a practical point of view, the strength of qualitative approach are that it can encompass changes over time (e.g. amend questions as a result of feedback from respondents) and enables the researcher jargons, terms or questions to be explained in more detail to avoid confusion (Eriksson \& Kovalainen, 2016; Mason, 2002).

With strengths, there are also limitations with qualitative approaches, such as small sample size due to the timely data gathering processes (Eriksson \& Kovalainen, 2016; Jennings, 2010; Creswell, 2014). As interpretivism regards knowledge and meaning as reality as acts of interpretation (Gephart, 1999), researcher's own knowledge and background also influence the data gathering and analysis process therefore the researcher is also part of what is being observed, engaged in understanding therefore, there is a higher risk for research bias (Brunt, Horner \& Semley, 2017). However, measures are in place to address and consider these limitations throughout the research design phase. 


\subsubsection{Semi-Structured Interviews}

For the data collection method, a semi-structured in-depth interview was selected, which is also known as a non-standardised or qualitative interview. (Wahyuni, 2012). It is semi-structured in a way that the questions are open-ended to create space for participants to narrate their experiences; however, the focus of the questions is very deliberate and carefully tied to the research topic (Galetta \& Cross, 2013). This type of data collection method works well when examining complex issues as it allows for probing and spontaneous questions by the researcher to explore, deepen understanding, and clarify answers to questions (Wilson, 2013, p. 23). It has been chosen as the data collection method as it accommodates subjectivity by enabling participants to narrate their experiences from their own view thus also supported by the interpretive paradigm. Semi-structured interviews also allow the study participants' experiences, beliefs, and meanings in-depth by unfolding their stories through probing to ensure portions of the narrative are clear (Galetta \& Cross, 2013). Key strengths of this method are that it allows research participants to express their views on the situation being studied through a "conversation with a purpose" (Jennings, 2010, p. 171; Mackenzie \& Knipe, 2006). As it is predominantly made up of open-ended questions, it also enables the researcher to undertake a re-exploration of statements or topic made by participants or revisit previous points (Pulla \& Carter, 2018) therefore gain a deeper understanding of participants' attitudes, opinions, and values. Moreover, semi-structured interviews also enable the detection of both verbal and non-verbal cues (e.g. sarcasm, tone or jokes) (Jenning, 2010). For these reasons it has been chosen as the data collection method for this research.

\subsubsection{Interview Guide}

In line with interpretive paradigm, interviews were designed to encourage respondents to talk openly about their experiences, observations, feelings, impressions, attitudes, values and own behavior. Before the interview, a brief explanation of the aim of the research emphasizing the confidentiality, anonymity, and the voluntary nature of the study was given. Participants were informed about the expected length of the interview and the motivation behind the study to have a better understanding of the purpose of the interview. The researcher also introduced herself, putting some emphasis on that she is not a New Zealander to ensure respondents feel more 
confident in sharing their opinion and thoughts about the country freely. This adjustment was made after an interviewee expressed discomfort in sharing his thoughts to the researcher assuming she is local.

The interview started off with a brief conversation to create a relaxed and comfortable environment. Part of this aimed to explore respondents' personal background (e.g. motivation to visit). This has helped to better understand the context that influenced and motivated tourists in their decision to travel to New Zealand and also provided a basis to understand the nature of their purchasing behavior. The full interview guide consisted of a set guiding questions based on the literature review and the research question (see Appendix A). The questions were put in categories to enable the researcher to explore the necessary areas in an order that suits participants (see table 3.1). Due to the flexible nature of semi-structured interview, between questions on the interview guide, there was opportunity to probe and elaborate on or deepen previous points therefore provide opportunities for the respondents to elaborate on their points.

The interview guideline had five main areas of focus, which are personal background, perceived destination image, environmental sustainability, purchasing intent and/or behavior and beliefs (see table 3.1). 
Table 3. 1: Design of interview questions based on the literature (for the full interview guide with introduction and conclusion see Appendix A)

\begin{tabular}{|c|c|c|c|}
\hline $\begin{array}{l}\text { Area of } \\
\text { literature }\end{array}$ & Question asking & $\begin{array}{c}\text { Issue: Why is this } \\
\text { being asked }\end{array}$ & Author(s) \\
\hline $\begin{array}{c}\text { Personal } \\
\text { Background }\end{array}$ & $\begin{array}{l}\text { Where are you visiting from? } \\
\text { Length of stay } \\
\text { Why did you decide to visit } \\
\text { NZ?/What motivated you to } \\
\text { come to NZ? } \\
\text { Have you been in NZ before? } \\
\text { Has any of your friends or } \\
\text { family members been in NZ } \\
\text { before? } \\
\text { Information sources/help with } \\
\text { booking }\end{array}$ & $\begin{array}{l}\text { To explore the social } \\
\text { context of respondents } \\
\text { decision-making and } \\
\text { highlight key } \\
\text { motivational factors to } \\
\text { visit New Zealand. } \\
\text { These generic } \\
\text { questions enabled } \\
\text { tourists to warm-up and } \\
\text { develop a degree of } \\
\text { trust and attain some } \\
\text { reciprocity between the } \\
\text { researcher and the } \\
\text { participants. }\end{array}$ & $\begin{array}{l}\text { Galletta and } \\
\text { Cross (2013) }\end{array}$ \\
\hline $\begin{array}{c}\text { Perceived } \\
\text { Destination } \\
\text { Image }\end{array}$ & $\begin{array}{l}\text { Images/characteristics that } \\
\text { come to your mind when you } \\
\text { think of NZ as a vacation } \\
\text { destination?/ How would you } \\
\text { describe NZ to a friend? } \\
\text { Would you describe the } \\
\text { atmosphere or mood that you } \\
\text { would expect to experience } \\
\text { while visiting NZ? }\end{array}$ & $\begin{array}{l}\text { To identify the } \\
\text { cognitive and affective } \\
\text { image components of } \\
\text { New Zealand. }\end{array}$ & $\begin{array}{l}\text { Echtner and } \\
\text { Ritchie (1993) }\end{array}$ \\
\hline
\end{tabular}




\begin{tabular}{|c|c|c|c|}
\hline & $\begin{array}{l}\text { Can you think of any } \\
\text { distinctive or unique tourist } \\
\text { attractions that you can find in } \\
\text { NZ? }\end{array}$ & & \\
\hline $\begin{array}{c}\text { Environmental } \\
\text { Sustainability }\end{array}$ & $\begin{array}{l}\text { What does environmental } \\
\text { sustainability mean to you? } \\
\text { How do you feel about the } \\
\text { current state of NZ } \\
\text { environment (urban and/or } \\
\text { rural)? } \\
\text { Do you feel NZ is mindful of } \\
\text { the environment? }\end{array}$ & $\begin{array}{l}\text { To assess } \\
\text { environmental beliefs } \\
\text { of respondents and also } \\
\text { explore their values } \\
\text { attached to the } \\
\text { environment. }\end{array}$ & $\begin{array}{l}\text { Stern (2000) } \\
\text { Tölkes (2018b) } \\
\text { Juvan and } \\
\text { Dolnicar (2016) }\end{array}$ \\
\hline $\begin{array}{c}\text { Purchasing } \\
\text { Intent and/or } \\
\text { Behavior }\end{array}$ & $\begin{array}{l}\text { Priorities when purchasing } \\
\text { holiday for/in NZ } \\
\text { Can you recall any } \\
\text { environmentally sustainability } \\
\text { consideration or behavior } \\
\text { when making your booking(s) } \\
\text { for/in New Zealand? } \\
\text { Observations of other people } \\
\text { practicing environmentally } \\
\text { sustainable behavior in NZ }\end{array}$ & $\begin{array}{l}\text { To identify any } \\
\text { intention for pro- } \\
\text { environmental behavior } \\
\text { and also AC and AR } \\
\text { beliefs that feeding into } \\
\text { this. }\end{array}$ & $\begin{array}{l}\text { Stern (200) } \\
\text { Budeanu (2007) } \\
\text { Jurowski and } \\
\text { Black (2015) } \\
\text { Mehmetoglu } \\
\text { (2009) } \\
\text { Line and Hanks } \\
\text { (2016) }\end{array}$ \\
\hline
\end{tabular}




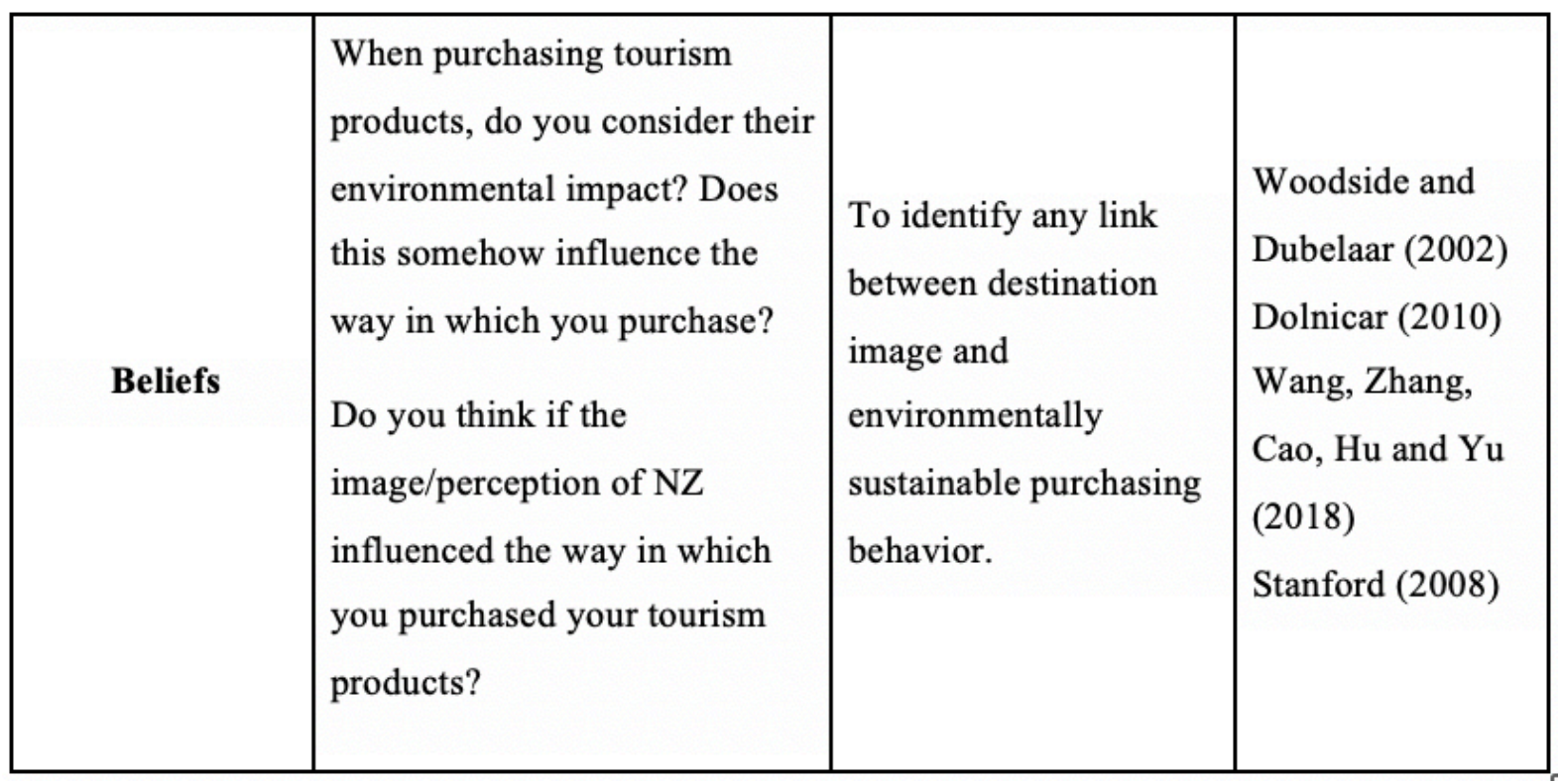

The first section was designed to explore respondents' background, their social context, and details of their holiday in New Zealand to create an initial narrative of their experiences and key motivational factors. The remaining sections of the interview guide were structured according to the research question and sub-questions of this thesis. As discussed in section 3.2, three essential information is needed to answer the research question: first, how New Zealand as a destination is perceived, second, whether tourists have the actual behavior or intention to behave environmentally sustainably and last, what aspects of the destination are influencing that.

Therefore after exploring the social context and motivational factors of tourists (indicated as personal background on table 3.1), the first focus of the interview was to explore the cognitive and affective destination image components. For this, Echtner and Ritchie (1993) questions were adopted that allowed respondents to think freely about the destination and to describe their overall impressions of it. The second main focus was to find out what meaning and values respondents attached to the environment in New Zealand. As the literature review discussed (in section 2.1.4), tourists can value the environment for various reasons such as emotional affinity towards it (Stern, 2000; Dolnicar, Crouch, Long, 2008), concern for the environment (Stern, 2000; Untaru, Epuran \& Ispas, 2014; Line \& Hanks, 2016), or for self interests (Wearing et al., 2002; Dolnicar \& Leisch, 2008). The third main focus of the interview was to examine the nature of respondents' (tourismrelated) environmentally sustainable purchasing behavior in New Zealand to identify any intention 
that may be present and the contributing factors. Lastly, the fourth part of the interview guideline focused on exploring respondents' environmental beliefs, awareness of consequences of their own behavior and identifying any link between destination image and purchasing behavior to understand how the destination image may feed into this.

Once the first draft of the interview guideline was completed, it underwent a small pilot test to identify potential areas of improvement, and to also get an idea of the feasible length of the interview. The pilot study was undertaken with another university researcher face to face in New Zealand. The researcher was from overseas originally thus, was able to apply the questions on himself. The pilot study indicated no major issues, and overall suggested the interviews guideline is suitable for its purpose.

\subsubsection{Sampling and Data Collection}

International tourists visiting New Zealand were targeted as subjects. International tourists refer to persons travelling to a country other that they reside in for at least one day but no more than 12 months (UNWTO, 2008). Therefore the sample population identified for this research is any international tourists above the age of 18, who has stayed in New Zealand for at least one day, but no longer than 12 months at the time of the interview. The reason for selecting international tourists is because the aim of this thesis is to examine the perceived destination image by international tourists. Thus, this group of people hold the specific information required to answer the research question. Additionally, this study aimed to provide a more general understanding of destination image thus, it was necessary to focus on international tourists. 
Table 3. 2: Interview locations

\begin{tabular}{|l|l|c|}
\hline \multicolumn{1}{|c|}{ Interview Locations } & \multicolumn{1}{|c|}{ Reason for Selection } & $\begin{array}{c}\text { Number of } \\
\text { Tourists } \\
\text { Recruited }\end{array}$ \\
\hline The Cable Car & $\begin{array}{l}\text { Popular tourist site, easily accessible, attracts a wide } \\
\text { range of tourists, no permission was required. }\end{array}$ & $\mathbf{9}$ \\
\hline $\begin{array}{l}\text { i-Site } \\
\text { (Wellington Visitor } \\
\text { Information Center) }\end{array}$ & $\begin{array}{l}\text { Frequented by a wide range of tourists, easily } \\
\text { accessible, permission was granted. }\end{array}$ & $\mathbf{7}$ \\
\hline $\begin{array}{l}\text { In front of Te Papa } \\
\text { The National Museum } \\
\text { of New Zealand) }\end{array}$ & $\begin{array}{l}\text { Attracts a wide range of tourists, easily accessible, } \\
\text { only approached tourists who were leaving the } \\
\text { museum, no permission was required. }\end{array}$ & $\mathbf{1}$ \\
\hline $\begin{array}{l}\text { Youth Hostel } \\
\text { Association } \\
\text { (Backpackers) }\end{array}$ & $\begin{array}{l}\text { Frequented by international tourists. The backpacker } \\
\text { itself is sustainable thus tourists staying there } \\
\text { automatically behaving environmentally sustainably, } \\
\text { which provided a good condition to explore } \\
\text { accidental, unintentional or convenient environmental } \\
\text { behaviors of tourists. Permission was also granted. }\end{array}$ & $\mathbf{6}$ \\
\hline $\begin{array}{l}\text { El Rancho (Christian } \\
\text { Holiday Park) }\end{array}$ & $\begin{array}{l}\text { Frequented by international tourists particularly gap } \\
\text { year students who do volunteering and different } \\
\text { perspective and access to different types of tourists as } \\
\text { most of these tourists are students, staying in New } \\
\text { Zealand for a longer period to partake in volunteer } \\
\text { projects and learn. Permission was also granted. }\end{array}$ & $\mathbf{2}$ \\
\hline
\end{tabular}

The recruitment for research participants took place during the peak tourism season, between December 2019 and February 2020 at sites that are frequented by tourists in the Wider Wellington Region namely: The Cable Car, i-Site, Te Papa (The National Museum), Youth Hostel Association (Backpackers), and El Rancho (Holiday Park). These sites were chosen due to their popularity by tourists, suitability of locations and diverse product offerings that enabled the recruitment of various types of tourists. As table 3.2 shows, the majority of tourists were recruited from popular tourist sites to enable representative tourists population to arise. While there were some niche sites such as the Backpacker and the Christian Holiday Park that aimed to introduce different perspectives by different types of tourists. Both types of tourists who favor backpackers and 
holiday parks represent a significant portion of international tourists thus by introducing these to sites aimed to explore those perspectives too. The strategies for participants recruitment aimed to accommodate various types of tourists who represent most tourists in New Zealand. However, by only recruiting tourists at tourist sites and during peak season may have affected the representativeness of the sample. Interviewing tourists during shoulder seasons inside and outside of tourist sites may have offered some new perspectives to the research. These were however considered when recruiting participants but due to the limited time available for this thesis, these could not have been accommodated.

Potential interviewees were chosen by simple random sampling and were approached by the researcher personally. Every third person or group of people who were leaving premises of the tourist site or were sitting down on a bench or looked like not doing anything actively (at the tourist site) were approached. When potential interviewees were approached, they were screened first to ensure they fit within the sample population (above the age of 18 and is/are international tourist(s)). If they did, they were offered to partake in the research and were given a brief overview about the interview and process it involves (see Appendix B).

Once, respondents agreed to partake in the research, they were taken to the cafe available at the tourist site or a suitable seating area on-site to create a comfortable setting for participants for the duration of the interview and also to ensure good hearing conditions. In accordance with the Human Ethics Committee guidelines, the purpose of the interview including process involved and interviewee rights were covered and stated clearly (see Appendix C) that participants had to sign first before in order to start the recording and proceed with the interview. Interviews were recorded electronically, and hand-written notes were taken during the interview to note key points or areas for clarification or for further probing.

A total of 25 interviews were conducted, each lasting between 15-45 minutes. Each interview recording was transcribed within a short period of time after the interview while it is still fresh in the researcher's head. 


\subsection{Data Analysis}

Once all interviews were conducted and transcribed word to word, the data was analysed using a framework analysis technique, which is also supported by interpretive paradigm. This type of approach is a "specific method associated with systematic and discipline research and involves the systematic process of sifting, charting and sorting material according to key issues and themes" (Brunt, Horner \& Semley, 2017, p. 243). This approach has been selected for the analysis as it enables the researcher to explore data in depth while simultaneously maintaining an effective and transparent audit trail, enhancing the rigour of the analytical processes (Ritchie \& Lewis, 2003; Smith \& Flirth, 2011). It provides flexibility though a series of interconnected stages that enables the researcher to move back and forth that results in constant refinement of themes (Smith \& Flirth, 2011). One of the key characteristics of framework analysis is that it reduces data through summaries, through which the data is synthesized, but original links to data are retained through quotes of respondents. This framework analysis is made up of five stages: (1) familiarization; (2) identifying a thematic framework; (3) Indexing; (4) charting; and (5) Mapping and interpretation (see figure 3.1 ).

Figure 3. 1: Stages of framework analysis

Stage 1 \& 2: Familiarization and Identifying a Thematic Framework: Taking notes of emerging themes and sorting them out according to the research questions.

Stage 3: Indexing: Emergent themes applied to data by indexing specific comments and phrases made by respondents.

Stage 4: Charting: Putting and removing key phrases made by respondents which were indexed in the transcripts and placing them in a chart in relation to a particular theme.

Stage 5: Mapping and Interpretation: Mapping out and interpreting patterns and connections of the data. Answer the research question(s).

Adopted from: Brunt, Horner and Semley (2017) 
Each stage is discussed in the context of this research in the following section (3.4.1).

\subsubsection{Analysis Technique}

Stage 1 of the framework analysis requires familiarization with the data through reading the transcripts and making notes about the themes arising from the data. This step enables the researcher to become familiar with the scope, nature and richness of data (Brunt, Horner \& Semley, 2017). This stage is often combined with stage 2 which requires sorting data into a framework of themes, which relate to the research questions of the study (Brunt, Horner \& Semley, 2017). In the context of this research, the first two stages were combined. After the initial two readings, keywords, and themes were recorded on a piece of paper according to individual interview questions first. Then, themes were recorded again on a separate piece of paper according to subquestions of the thesis as opposed to the individual interview questions. Figure 3.2 shows an example of sorting data into a framework of themes and sub-themes. Frequency of themes was also indicated by placing the interview number next to themes and sub-themes (as illustrated on figure 3.2). This ensured that the researcher is able to revisit the original comments or phases of respondents relating to each theme or subtheme to ensure the suitability of themes. 
Figure 3. 2: Example of Stage 1 and 2

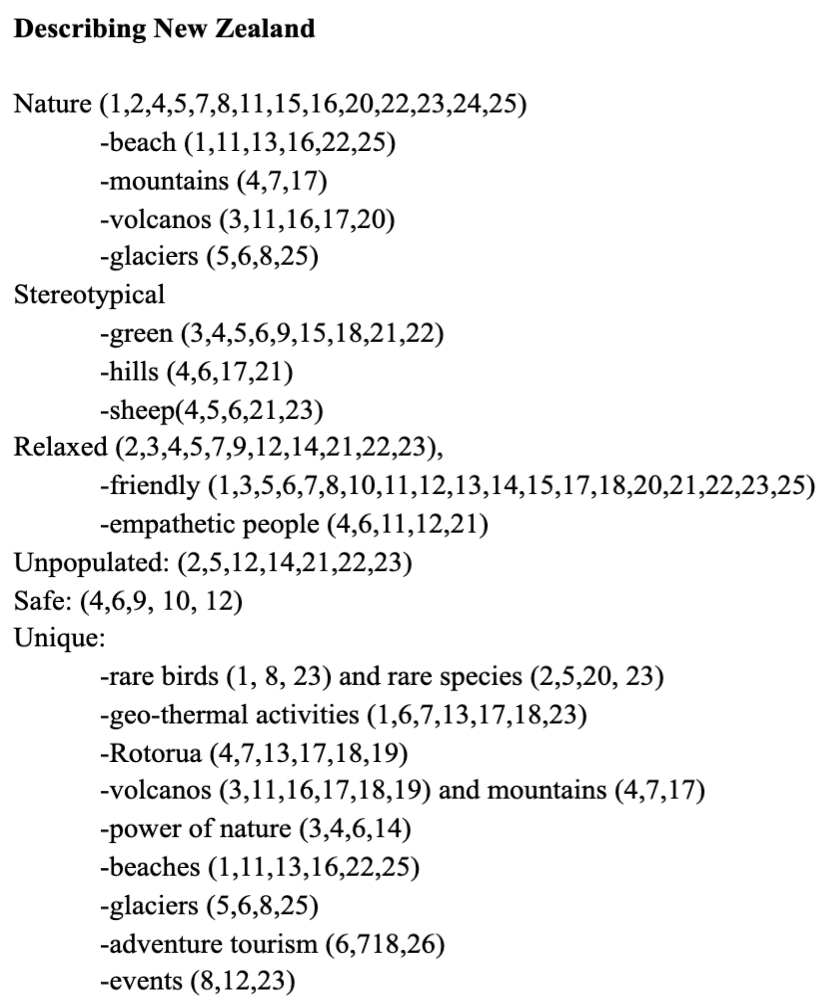

Stage 3 requires specific comments or phrases made by respondents that directly relate or partly relate to a theme or a sub-theme to be indexed or coded. Parts where these themes or sub-themes appeared were indexed and were also tested with the researcher's supervisor to improve accuracy and allow judgments and assumptions to be evaluated.

Following on, Stage 4 required indexed comments and phrases were (from Stage 3) to be copied from transcripts and put in a chart, in relation to a particular theme. This chart aimed to also represent the nature of data, and also retain links to original data through the original quotes and comments by respondents. Table 3.3 presents example from the data analysis for stage 3 and 4 . 
Table 3. 3: Example of Stage 3 and 4

\begin{tabular}{|c|c|}
\hline \multicolumn{2}{|l|}{ Describing New Zealand } \\
\hline $\begin{array}{l}\text { Nature } \\
\text { (beach, mountains, } \\
\text { volcanos, glaciers, green, } \\
\text { hills, sheep) }\end{array}$ & $\begin{array}{l}\text { "Mountains, nature, clean, green rolling hills, sheeps, Maori people, lot of natural } \\
\text { features, picturesque scenery, beautiful, friendly safe, its a bit like Australia but } \\
\text { greener and more sheep. Probably its the mountains the high stokes of mountains } \\
\text { and the beaches too. I mean we have the beaches but quite different. Oh and the } \\
\text { thermals and the springs as we don't really have that" (R4). } \\
\text { "The nature here is something that you won't see in other countries to be honest" } \\
\text { (R12). } \\
\text { "The lot of the places we visit for fun are national parks, beaches, lookouts, things } \\
\text { that are aesthetically pleasing without costing us money" (R6). } \\
\text { "I think the environment like itself, the nature is a big attraction. It doesn't matter } \\
\text { where you go there will be something to do outside somewhere. So if you are an } \\
\text { outdoor person it is the best place. Even in Wellington, if you want to do a hike, } \\
\text { you can go and do a hike, everything is quite close. If you want to hike, NZ is the } \\
\text { best place I think" (R24). } \\
\text { "About nature, there is so many different things to see in one place like you have } \\
\text { to see mountains, dry and wetlands, you have everything here. I really like it" } \\
\text { (R11). }\end{array}$ \\
\hline $\begin{array}{l}\text { Relaxed, laid-back, } \\
\text { friendly people, easy to } \\
\text { talk to, open, welcoming }\end{array}$ & $\begin{array}{l}\text { "Very friendly people" (R14). } \\
\text { "People are really friendly here, they are always smiling and always very helpful" } \\
\text { (R7). } \\
\text { "The people are mostly really friendly out of my experience, I had morning } \\
\text { breakfast paid just by having a nice conversation with a stranger there and like all } \\
\text { these crazy stuff happens that the bus driver pays your ticket. It is just crazy, you } \\
\text { wouldn't experience this in Germany" (R23). } \\
\text { "Everyone has been friendly to me and helpful e.g. the bus drivers, people on the I } \\
\text { stopped on the street, the staff at YHA" (R25) } \\
\text { "I just get this impressions that people in NZ are laid-back..in a nice way" (R14). } \\
\text { "This is no-worry country, everyone is no worries, relax, take it easy, 'we will take } \\
\text { care of it later, no problem..mate"'(R5). } \\
\text { "Just really chilled, and relaxed. Everybody is no stressed, and enjoys each other } \\
\text { company" (R24). } \\
\text { "I think it is very relaxed here and not to stressful, which is a big difference } \\
\text { compared to Hungary. "Take it easy" here, they don't really worry about, "enjoy } \\
\text { your life" (R7). } \\
\text { "You get so happy because everything is so calm and they are like take your time, } \\
\text { do everything chill, but good. They always like don't rush, enjoy the moment }\end{array}$ \\
\hline
\end{tabular}




\begin{tabular}{|c|c|}
\hline & $\begin{array}{l}\text { which makes it a calm atmosphere that make you feel very welcomed, because of } \\
\text { all this friendly people and you feel very supported here" (R22). } \\
\text { "Just really chilled, and relaxed. Everybody is no stressed, and enjoys each other } \\
\text { company" (R24). } \\
\text { "Laid-back, very friendly and sense of humour is quite like what we have in } \\
\text { Denmark. It is easy to talk to people and get along" (R17). } \\
\text { "People say what they mean here, very straight, open, very warm and inviting. } \\
\text { They invite you in their home, I often tram and they invite you in their house: do } \\
\text { you need water or place to stay? And stuff like that. Very open people and friendly" } \\
\text { (R21). }\end{array}$ \\
\hline Unpopulated & $\begin{array}{l}\text { "Empty, big country...so some part are very empty" (R2). } \\
\text { "Large spaces...few people and lot of nature" (R5) } \\
\text { "Here there is still a lot of space" (R14). }\end{array}$ \\
\hline Safe & $\begin{array}{l}\text { "Safe..I feel safe" (R6) } \\
\text { "Safe, it feels safe" (R3). } \\
\text { "Safe and positive environment despite the long flight to get here" (R25). } \\
\text { "Here, I don't have to consider safety but in some countries for example in Cape } \\
\text { Town, I probably gonna think less about the value than safety. Because safety } \\
\text { comes as priority, not just in Cape Town but also in European countries if I go there } \\
\text { for business or leisure I need to check the are of the hotel, but in NZ I don't } \\
\text { consider safety at all" (R12). }\end{array}$ \\
\hline Unique: & \\
\hline $\begin{array}{l}\text { rare species/birds, } \\
\text { geo-thermal activities and } \\
\text { Rotorua } \\
\text { glaciers } \\
\text { adventure tourism } \\
\text { events }\end{array}$ & $\begin{array}{l}\text { "Animal life is very different compared to any other locations, many more birds. } \\
\text { There are lot of animals that are native to NZ. There are no dangerous animal here" } \\
\text { (R20). } \\
\text { "What is also distinctive is the Rotorua are with all the geo-thermal activity that is } \\
\text { very special. We have seen the the Norwegian fjords and they may be similar. What } \\
\text { is special is probably the geo-thermal. It is actually both, that NZ has both activity" } \\
\text { (R17). } \\
\text { "I think the capacity to see the glaciers like the Fox glacier and the other one. } \\
\text { Although I understand, that they are shrinking at the moment, but at the moment } \\
\text { they are accessible. Aussies cannot see a glacier anywhere else, they come to NZ to } \\
\text { see that for now, maybe are the last of our generation" (R6). }\end{array}$ \\
\hline
\end{tabular}

The final stage of framework analysis (stage 5) was made up of mapping and interpretation. This stage included comparing charts, looking for patterns, and exploring connections between particular themes and type of tourists ultimately, to identify any links. When carrying out the data 
analysis, themes were compared between different types of respondents to identify any links (e.g. first-time visitor versus returning; tourists staying for a shorter versus longer period, tourists with companions on single tourists and more). Themes with other themes or sub-themes were also compared e.g. perceived destination characteristics and types of environmentally sustainable purchasing behavior or travelers with companion versus single travelers AC and AR beliefs. Not only over a theme, but within a case comparisons were also possible (see figure 3.3), which allowed for interpretations and explanations to develop throughout the analysis process with direct links to the data.

Figure 3. 3: Example of Stage 5

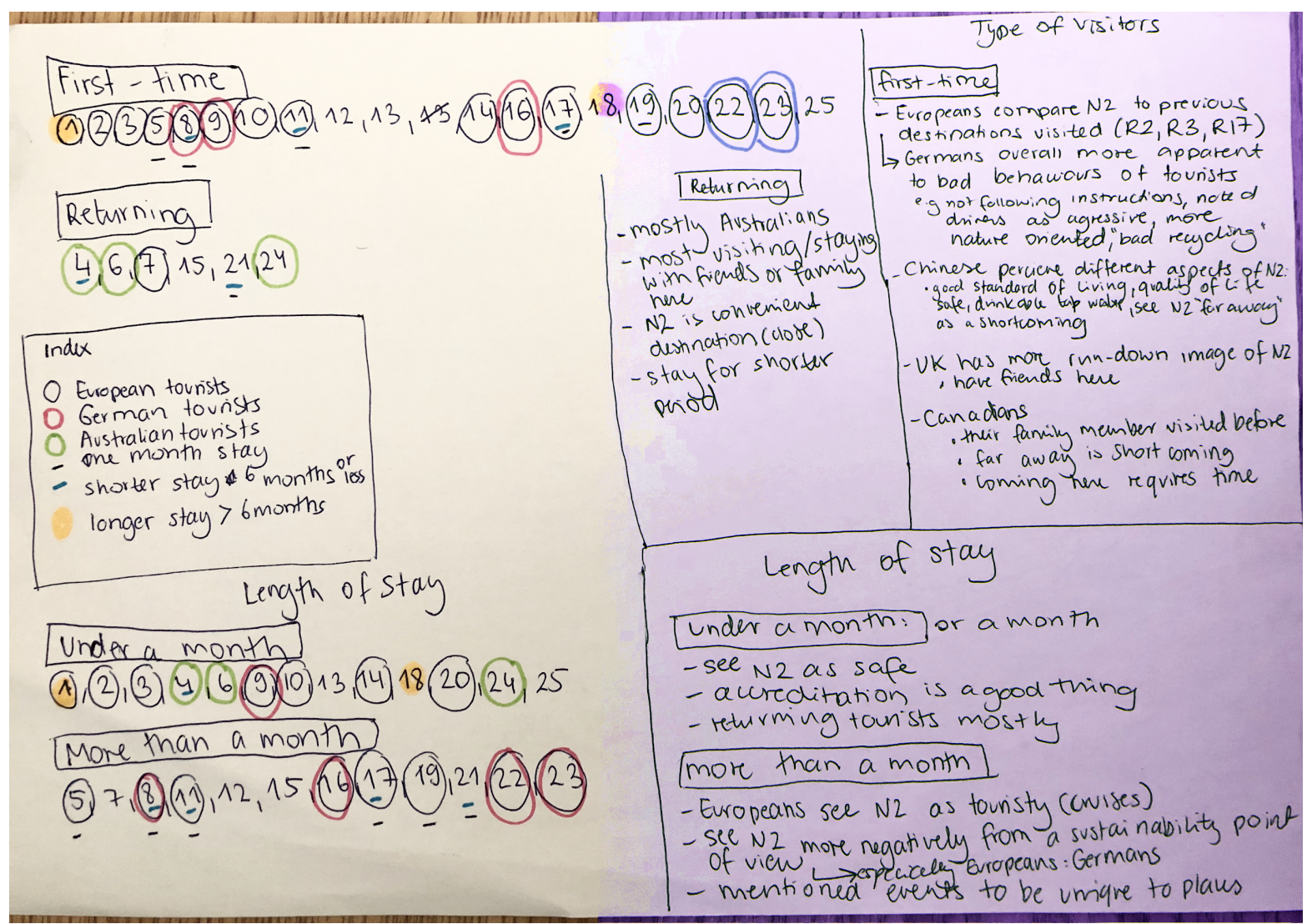




\subsection{Limitations and Strengths}

The limitations are predominantly arising from the nature of qualitative research such as small sample size, lack of generalizability, higher chance of researcher bias, time and research context. However, considerations were made throughout to reduce the extent of these limitations by having a reasonably big (25), varied, and diverse sample. Participants were also recruited from various tourist spots that are frequented by all types of tourists. Niche tourist spots were also incorporated to offer additional insights and to increase the representativeness of the data, but these could potentially led to overrepresentation of certain types of tourists e.g. those who prefer doing popular tourists activities, while those who do not may have offered additional insight. Although researcher bias is often considered to be a major limitation in qualitative research, in the context of this research the researcher's own background had a beneficial impact on the study. This is because the researcher herself was not a resident, which enabled international tourists to share their opinion and thoughts more comfortably and freely (participants have also expressed during the interview). It also enabled the researcher to better understand respondents' perceptions, but it could have also led the researcher to interpret international viewpoints on the basis of her own. Given the interpretive paradigm, a certain level of researcher bias is unavoidable but measures were put in place to reduce the extent of it. By having frequent discussions between the researcher and her supervisor and by undertaking very specific steps, minimizing the possibility of researcher bias.

Additional limitation identified was the time available for this thesis project which only allowed to recruit tourists during the peak tourism season. Recruiting interviewees during the off shoulder season may have offered some additional perspectives. Finally, the specific research context may also potentially limit the transferability of this research as it has a strong impact on the type of tourists interviewed, and the specific destination characteristics and attributes that are perceived that may not be applicable elsewhere.

Limitations regarding data collection was that respondents were predominantly made up of tourists with western background as tourists with different cultural backgrounds either declined or had insufficient language skills to partake in the research. Social desirability bias may have been

present too as this thesis investigates individuals environmental behaviors thus, tourists may have 
altered their response based on what is more socially desirable and not necessarily what they really think or do (Juvan \& Dolnicar, 2016).

The strength of this research lies in its general focus on environmentally sustainable purchasing behavior, which aimed to overcome the shortcomings of extant literature. By taking a more generic focus as opposed to product specific focus enables the understanding of the nature or link between destination image and behavior better. Additionally, the research has also adopted semistructured in-depth interviews for the data collection to overcome the shortcomings of structured methodologies in examining destination image (also discussed in 3.4.1). 


\section{Findings}

The previous chapter has outlined the methodological approaches adopted in this thesis to answer the research question. Following the order of the research questions, the findings are presented in three parts: perceived destination image, environmentally sustainable purchasing behavior and value orientation. Each of these sections addresses the corresponding sub-question underpinning this thesis. However, before presenting these, the chapter will first begin with presenting the sample characteristics.

\subsection{Sample Characteristics}

A total of 25 international tourists were interviewed between 13 December 2019 and 15th of February 2020. As discussed in Chapter 3, simple random sampling was used at sites frequented by tourists in the Wider Wellington Region. Only international tourists above the age of 18 who were in New Zealand at the time of the interview were interviewed. Most common origin of respondents were Germany (5) and Australia (3), which is not surprising considering that both are within New Zealand's top five inbound markets (Tourism New Zealand, 2020). Overall, European source markets were more dominant such as The Netherlands, France, UK and Switzerland. Table 4.1 presents relevant information of respondents such as their length of stay, companion, origin and type. To protect respondents' identity, their personal information such as their names have been de-identified. Majority of respondents were first-time visitors (76\%) and single travelers (68\%). Respondents' length of stay in New Zealand at the time of the interview ranged from one day to up to 10 months, most were a month or less. 
Table 4. 1: List of Participants

\begin{tabular}{|c|c|c|c|c|}
\hline Respondent & Origin & Companion & Type of Visitor & Length of Stay \\
\hline 1 & France & couple & first-time & one day \\
\hline 2 & The Netherlands & single & first-time & three weeks \\
\hline 3 & The Netherlands & single & first-time & one week \\
\hline 4 & Australia & family of 4 & mixed & one week \\
\hline 5 & France & 3 friends & first-time & one month \\
\hline 6 & Australia & single & mixed & one week \\
\hline 7 & Hungary & single & returning & 10 months \\
\hline 8 & Germany & single & first-time & one month \\
\hline 9 & Germany & single & first-time & two weeks \\
\hline 10 & UK & single & first-time & one week \\
\hline 11 & Switzerland & single & first-time & one month \\
\hline 12 & China & single & first-time & 8 months \\
\hline 13 & US & single & first-time & one week \\
\hline 14 & UK & couple & first-time & two weeks \\
\hline 15 & Tonga & single & returning & 3 months \\
\hline 16 & Germany & single & first-time & 3 months \\
\hline 17 & Denmark & couple & first-time & one month \\
\hline 18 & Canada & single & first-time & one day \\
\hline 19 & Switzerland & 2 friends & first-time & one month \\
\hline 20 & Slovakia & single & first-time & two weeks \\
\hline 21 & US & single & returning & one month \\
\hline 22 & Germany & single & first-time & 6 months \\
\hline 23 & Germany & single & first-time & 6.5 months \\
\hline 24 & Australia & single & returning & two days \\
\hline 25 & Canada & single & first-time & two weeks \\
\hline
\end{tabular}

Those respondents who were in New Zealand for less than a month at the time of the interview, were also returning visitors. While almost all European respondents were first-time visitors and on average, they also stayed for longer than returning visitors.

The remaining part of this chapter will now present the findings in three parts namely: perceived destination image, environmentally sustainable purchasing behavior, and value orientation. Each of these sections addresses the corresponding sub questions of this thesis. 


\subsection{Perceived Destination Image}

This section addresses the first sub-question of the research question, which focuses on understanding how New Zealand is perceived by international tourists. In detail, this sections examines the different components that make up tourists' destination image, and the factors feeding into that.

According to the literature, destination image is subjective thus, the perception of destination image is subject to tourists' personal background and previous travel experiences (Tasci, Gartner, \& Cavusgil, 2007; Ryan \& Cave, 2005; Tonge et al., 2014; Baloglu \& McCleary, 1999). Tourists’ destination image also goes through multiple modification phases throughout the travel process e.g. once in the destination, tourists are exposed to the contextual elements of the destination (e.g. landscape, people, social norms), which shapes tourists' image of a destination (Echtner \& Ritchie, 1991). Therefore tourists' perceptions of a destination can vary and are influenced by several factors. The aim of this sub-question is to explore the different elements that are perceived by tourists based on what they know (cognitive image) and how they feel about (affective) New Zealand. These will help understand the components that make up tourists' destination image and the potential factors that may be feeding into that. Accordingly, the findings are presented in two parts: cognitive and affective image, which will now be presented.

\subsubsection{Cognitive Image}

Cognitive image refers to the image tourists have of New Zealand based on what they know about it. Respondents have identified various cognitive image elements of New Zealand such as its nature, geographical location, and infrastructure, which will now be elaborated on.

\subsubsection{Nature}

The main motivation for respondents to visit New Zealand was to experience nature, which is not

surprising considering how the country has been presenting itself internationally (Morrow \& 
Mowatt, 2015). When describing New Zealand's nature, respondents often referred to its incredible scenery and diverse range of landscapes that consist of mountains, active volcanoes, long beaches, and rare wildlife. New Zealand was seen as special due to the variety of nature experiences it offers compared to other countries.

"I think the nature here is incredible and a lot of things to do and see" (R7).

"The nature here is something that you won't see in other countries" (R12).

"The nature is very beautiful and very special" (R16).

Out of all, the most unique attraction for respondents was the geo-thermal activities such as geysers and hot springs:

"Hot water springs...this is really New Zealand for me.....I never heard [of] other places you can do that. I know in some places very cold you can jump into lake in Iceland..in Europe but in New Zealand, I imagine hot springs in my head" (R1).

Rotorua was seen as the ultimate hot spot for geysers and hot springs, which was also commonly associated with Māori cultural experiences that together were seen as the most unique aspects of New Zealand.

\subsubsection{Geographical Location}

Apart from the natural characteristics, respondents also commonly referred to the geographical location of New Zealand when describing it. Europeans especially, enjoyed the fact that it is far away. Being far also meant different climate, time difference which was seen as special. Chinese and Canadian respondents on the other hand considered New Zealand's geographical location as an actual drawback for tourists to visit the country: 
"New Zealand from my understanding is sort of less popular destination for Chinese people, ..because New Zealand is very isolated and far far away from China...we gotta take minimum of 12 hours from China to New Zealand" (R12).

Given the geographical location, New Zealand was also considered to be a more expensive destination that also requires a significant time commitment from tourists to be able to explore the country. Thus respondents, especially first-time visitors came with the intention to stay for a longer period (from a couple of months, up to a year).

Australian tourists on the other hand liked that New Zealand is 'close', and considered it an easy and cheap get-away destination:

"It was cheap, easy to get to, we don't need visa and could come in with our passports.

You speak English..but still have a cultural experience so that was good" (R6).

Most Australian tourists were also returning tourists, staying for shorter periods (less than a month) as opposed to first-time visitors.

\subsubsection{Infrastructure}

Regarding infrastructure, respondents have expressed various concerns particularly with the public transport and recycling facilities available in New Zealand. Respondents found the public transport limited, considering that New Zealand is a developed country that is advanced in many other aspects. There were also tourists who already came to New Zealand knowing that they will be needing to rent a car or buy one as they have been informed by friends that the public transportation is limited:

"I bought a car before we came here. I wanted to buy a car because I got told that the traffic, bus system, and the train is very bad so if I wanted to travel New Zealand, I need a car" (R22). 
Another reason was that many of the hikes and natural attractions are in the nature thus hard to access without private transport. Tourists who do not drive also found it hard to get around and were limited to only a certain number of touristic experiences e.g. tourist excursions, group tours and so on:

"If you don't have a car, it is going to be really though for you to go around. The public transportation probably one the main issue for New Zealand tourism” (R12).

Another infrastructural concern that was raised by tourists was recycling. Although most tourists liked the fact that there are a lot of recycling bins around that are highly visible and convenient to use, some questioned whether anything gets recycled as New Zealand has limited infrastructure for that. It was also apparent that the distribution of recycling bins are also inconsistent between different cities and towns for example, Wellington as the capital city was often compared to other parts of New Zealand:

"In Wellington they do a lot more than in other cities in New Zealand...It is like New Zealand is wanting to do stuff but it is still not into it yet. Which is like people know they have to recycle and stuff but there is no infrastructure for that....People recycle, but I am not even sure anything is getting recycled I have to say. This is just 'please recycle' but then it is not recycled. It goes to a giant landfill. It is not working yet" (R5).

Usually first-time visitors who have already stayed a couple of months at time of the interview in New Zealand were more critical about these limitations. While German tourists in particular, were the least happy with recycling facilities, often compared them with Germany. Other tourists who have been in Germany previously have also made references to Germany regarding their better recycling system that could be potentially be implemented in New Zealand. While the public transport limitations were primarily raised by first-time European visitors, there were also tourists who simply preferred renting a car as it was more convenient and were not actually apparent to potential limitations of the public transport. 


\subsubsection{Affective Image}

Having explored the cognitive image components mentioned by tourists, this section now presents the findings on affective image components. Affective image refers to the image tourists have of New Zealand based on how they feel about it. Respondents have identified multiple affective image components of New Zealand such as being friendly, and also touristy, which are presented below.

\subsubsection{Friendly}

New Zealand was mainly described by respondents as a friendly, relaxed, and safe country. Respondents describing New Zealand as friendly; referred to locals as being open, always smiling, being easy to talk to, caring, and overall welcoming:

"The people they are all really friendly and really open and taking care of each other. Like I am travelling in a camper van and I often asked if I am travelling by myself and make sure that you are safe. Like really caring about where I am staying and safe. I stayed at a few places and they are always so welcoming" (R11).

This level of care by locals also made respondents feel safe. Service standard was also found consistent regardless of the type of accommodation respondents stayed at:

"In New Zealand, I don't consider safety at all. I stayed at different kinds of hotels in NZ, hostels, hotels, five star hotels and the service is really good...People... just generally want to give you good hospitality and that is that so that is really good. I don't have to worry about picking a hotel because I still get good customer service" (R12).

This also made respondents less concerned of where they stay at. 


\subsubsection{Touristy}

At times New Zealand felt touristy for some due to the ratio between tourists and locals at certain tourists spots. Usually European first-time visitors who have stayed in New Zealand for longer than a month perceived it as touristy.

"Sometimes a lot of tourists are around and you don't see New Zealanders like "where are they?" (R16).

"New Zealand is pretty good for tourism and they welcome a lot of tourists....you could also tell they are used to tourists. I don't know how long they have been coming here but it seems to me that New Zealand is quite used to tourists. I also believe it makes up a big income for New Zealand, probably top industry. It remains natural but still a bit touristic" (R5).

Despite being touristy, it was not seen as entirely negative thing but there were certain parts of it that were seen as less positive such as cruise traffic. Europeans especially were more apparent to cruises that indicated certain places as being 'touristy'. New Zealand being reliant on its nature including its waters, cruises were perceived negatively and wasteful.

"Well, you do have a lot of cruise ships coming in all the time, so that part is probably not that great for your seas as it produces a lot of waste" (R20).

Some German tourists also expressed a sense of annoyance among locals towards tourists in areas that were frequented by tourists, mostly when it came to driving. 


\subsubsection{Conclusion}

In conclusion, the perceived destination image of New Zealand is not too different from how the country has been presenting itself internationally for the last two decades: being a nature wonderland. The most unique attribute of New Zealand was the hot springs, geysers and Māori culture while the more common was the natural environment, which consists of scenic and diverse landscapes. However, findings revealed additional elements that previously did not arise from the literature review such as some of the less positive aspects e.g. being perceived as touristy, having infrastructural limitations for public transport and recycling. There were also differences noted between different types of tourists and the aspects that have been perceived but these are commonly linked to respondents' origin, length of stay, and type (first-time or returning). European tourists for example when describing New Zealand often compared it to their previous destinations visited, while Australian and German respondents compared it with their own country. Additionally, those tourists who have stayed in New Zealand longer than a month at the time of the interview, were also the ones who had a less positive image of the country. Despite some of the infrastructural limitations and being perceived a bit touristic, respondents still perceived New Zealand positively overall.

The following chapter will now look at the nature of tourists' environmentally sustainable purchasing behavior particularly examining whether respondents have any intention to behave environmentally sustainably and also the factors influencing or constraining it.

\subsection{Environmentally Sustainable Purchasing Behavior}

This section addresses the second sub-question of the research question, which examines respondents' intention to behave environmentally sustainable by looking at the nature of their (environmentally sustainable) purchasing behavior, the factors that are influencing this, how and why it occurs. 
The literature review has highlighted that people can display environmentally sustainable behavior by either having a consumption attitude and/or behavior that intends to contribute to environmental sustainability (Mehmetoglu, 2009). Meaning, that even if tourists only display good intentions with no actual behavior, that can still be regarded as environmentally sustainable behavior. Tourists can behave environmentally sustainably for various reasons e.g. as a result of emotional affinity towards nature or for self-interests (Wearing, Cynn, Ponting \& McDonald, 2002, Stern, 2000) and may not at all for the protection of the environment. Regardless of the underlying motive or reason, each behavior of tourists is determined by a combination of causal factors that account for certain capabilities and constraints that affect the efficacy of tourists undertaking environmentally sustainable behavior. Thus even if tourists have the intent to behave environmentally sustainable, they may not be able to due to these constraints. Therefore to understand the nature of tourists' purchasing behavior, it is also necessary to examine the causal variables that are present and potentially affecting tourists' pro-environmental attitudes and behaviors. This will also help to identify the destination elements that influence tourists purchasing behaviors. Subsequently, the findings are presented in two parts: purchasing behavior, and causal factors.

\subsubsection{Purchasing Behavior}

Environmentally sustainable purchasing behavior refers to any consumption attitude or purchasing that intends to contribute to ecological sustainability (Mehmetoglu, 2009). The literature distinguished between four types of environmentally sustainable purchasing behavior namely: intended, good intentions, accidental, and convenient. The difference between these four is the combination of consumption attitude or intent and actual behavior. Each of these will be explored in relation to respondents' behaviors, but before, a general overview of respondents' purchasing behavior is presented.

In general, the main priority for respondents was price, specifically cheap costs. This is because coming to New Zealand was already considered to be expensive. Staying for longer periods also meant that respondents looked for cheaper stays such as renting a camper van or buying an actual 
car with bed in it, which also provided flexibility to move around the country easily. Most European especially German tourists did not have a travel plan or bookings for the period of their stay because they preferred to take their time when traveling around New Zealand. These tourists also intended to stay for longer period, were first-time visitors and had their own transport. Regards to tourism-related purchases, most consisted of nature experiences as opposed to other tourist experiences, which not surprising given that nature is the biggest motivation for tourists to visit New Zealand (Yeoman \& Mcmahon-Beattie, 2014; Morgan, Pritchard \& Piggott, 2002):

"[New Zealand] is more about the nature and cultural aspects that I obviously buy more natural experiences. There is not much history, and I wouldn't visit the oldest castle like Larnach in New Zealand because I don't think it is special, there isn't many old stuff here. When you have nature all the time, you want to go, you want to do all this like canoeing and stuff like that in the nature. And of course the Māori culture" (R23).

"When you hear what New Zealand is like you always hear about the nature, green, the mountains, the waterfalls, which is kind of special. For example in Germany, we don't have stuff like this, we don't have ocean around us, we don't have those mountains, we don't have waterfalls so everywhere you see these nature things it impacts you very hard, because it is very special and unique. Also when coming here I expected to do a lot of nature experiences" (R22).

As most activities undertaken by respondents revolved around nature, these provided various opportunities for tourists to develop pro-environmental attitudes or engage in pro-environmental behavior. Examples of each type of environmentally sustainable purchasing behavior displayed by respondents (such as intended, good intentions, accidental, and convenience) will now be presented.

\subsubsection{Intended}

Intended environmentally sustainable purchasing behavior refers to when tourists have both intent and actual behavior. Respondents displayed various examples of intended environmentally sustainable behavior e.g. using public transport instead of renting a car or avoiding certain 
activities all together due to potential negative impacts of these or taking a flight, which sometimes cheaper than taking public transport:

"I don't tend to go on tourist excursions, I don't rent cars, I always use the bus or hitch hike. I try to have a small footprint. I don't use package tours. I don't fly between Auckland and Nelson even though it is really cheap, cheaper than the bus" (R21).

Another example of intended purchasing behavior displayed by respondents was buying local products:

"I always do try to buy local products for instance, when I order wine, I always ask for local products, reusable products-and I also try to buy as little as possible like clothes..Local, made of natural product, something that helps local people" (R3).

Or visiting bird sanctuaries with the intent to support their conservation:

"I visited a bird sanctuary that way I tried to keep rare species alive. In general I am interested in birds and are also rare, they are nowhere else in the world. It is not like in Australia where kangaroos are quite normal" (R2).

As the examples demonstrate, these respondents did not only displayed environmentally sustainable behaviors, but also intention to contribute to ecological and social sustainability through their purchases, which was also the most common type of environmentally sustainable purchasing behavior making up almost one-fourth of all respondents. Tourists displaying intended behavior were predominantly Europeans.

\subsubsection{Good Intentions}

Good intentions refers to people with the intention to behave environmentally sustainable, without the actual behavior. Respondents displaying good intentions often highlighted the awareness of 
negative impacts of their own behavior, which was then followed by an explanation as to why not practicing environmentally sustainable behavior. For example, despite being aware, Respondent 19 mentioned using private transport to be able to see New Zealand, which otherwise would have been difficult:

"We did a lot of weekend trips and we always rent a car because it is like you cannot travel a lot by bus, it is hard to travel by bus. Then you think that this may not be the best way to rent a car but otherwise you want to see" (R19).

Similarly, Respondent 11 reasoned her use of private transport to have access to trails and hikes, which otherwise would have also been difficult:

"The only thing I did when I arrived in Auckland and I did my booking for the rental van. I was looking for the cheapest one. Also what road services they had but the I picked the one that was faster to respond to me. I mean I knew I am going to travel and live in this van so that is the only thing I booked and I knew it is going to be a lot of time in the car, which affects the environment but otherwise cannot really say anything else. I was aware of this but I knew I did want to do a lot of hikes and be outside and doing outdoor activities so I needed to have access to trails heads" (R11).

Most respondents displaying good intentions were travelling with a companion (family and friends), which suggests when tourists are not travelling by themselves, they care more about the experience and less about their impact. More than half of tourists with good intentions were accompanied by family or friends, while the total of respondents displaying purchase related good intentions made up $20 \%$ of all respondents. The vast majority of these respondents were also Europeans. 


\subsubsection{Accidental}

Accidental pro-environmental behavior refers to tourists behaving environmentally sustainably with no awareness or intention of doing so. An example of this occurring is when Respondent 24 stayed at the Youth Hostel Association (YHA), without perceiving the environmental benefits of staying there. The respondent's reason for staying at YHA was mainly due to its location and previous stay at YHA with no indication of being aware of its sustainable practices or the fact that it is environmentally sustainable:

"I stayed [at YHA] last time, I was here because I came last time and it was really hard to get hostels so you had to be fast. So I booked this because I have stayed here before and it is also close to the museum, good kitchen" (R24).

Accidental environmental behavior was relatively rare with only one respondent displaying such behavior. This is likely because most respondents seemed to be aware of their pro-environmental behavior or lack of pro environmental behavior. Except for Respondent 24, every other respondent either displayed a form of environmentally sustainable purchasing behavior or non-purchasing related pro-environmental consideration, which suggested that respondents are overall aware.

\subsubsection{Convenient}

Convenient environmental sustainable purchasing is when individuals purchase environmental sustainable products out of convenience e.g. lower cost. For example, Respondent 18 said her primary reason for staying at YHA was due to cheap cost despite being aware of YHA has sustainable initiatives, which was rather considered an added bonus:

"I am still a student [so] cost is a priority.. I did notice when I looked around for hostels like all the YHA one, maybe it was something on their website maybe I didn't pay super close attention to but that was a nice thing that they think about their sustainability" (R18). 
Another example was when Respondent 6 rented smaller car because it is cheap and also better for the environment:

"We have a small car, which uses less petrol and that is all we needed. We don't need a big car, we just needed something to take us from A to B, which is economical and environmentally safe (R6).

Convenient behavior was the second most popular pro-environmental behavior displayed by respondents from all backgrounds making up $20 \%$ of all respondents. The popularity of convenient environmental behavior is mostly related to cheaper costs. Respondents displaying this behavior were partially or fully aware of pro-environmental benefits of such products, which was rather seen as a bonus. This suggests that respondents are more likely to engage in environmentally sustainable purchasing if it is convenient or perceived as easy.

This section now concludes the types of environmental sustainable behaviors displayed by respondents and will continue with causal factors that potentially have influenced respondents engagement with pro-environmental behavior.

\subsubsection{Causal Factors}

Causal factors (adopted from the VBN theory) refers to certain capabilities and constraints that influence tourists' environmentally sustainable behavior. There are four types of causal factors, which are attitudinal, personal capabilities, contextual factors, habit and routine, (also outlined in table 4.1 with examples from respondents). Throughout the interviews, it was apparent that respondents faced many constrains when booking and making their purchases for New Zealand. 
Table 4. 2: Causal factors mentioned by respondents

\begin{tabular}{|c|c|}
\hline Causal Factor Type & Examples by Respondents \\
\hline $\begin{array}{l}\text { Attitudinal } \\
\text { (e.g. perceived costs, benefits of } \\
\text { action) }\end{array}$ & $\begin{array}{l}\text { - seen as more expensive } \\
\text { - unsure if it makes any difference or what is going } \\
\text { on behind the scene }\end{array}$ \\
\hline $\begin{array}{c}\text { Personal Capabilities } \\
\text { (e.g. financial resources, skills) }\end{array}$ & $\begin{array}{l}\text { - unsure how to look up sustainable information } \\
\text { - limited time available }\end{array}$ \\
\hline $\begin{array}{c}\text { Contextual Factors } \\
\text { (e.g. social norms, advertising) }\end{array}$ & $\begin{array}{l}\text { - infrastructural limitations to support } \\
\text { pro-environmental behavior } \\
\text { - limited availability and uneven distribution or } \\
\text { environmentally sustainable tourism products }\end{array}$ \\
\hline Habit and Routine & $\begin{array}{l}\text { - home and away behavior } \\
\text { - membership/loyalty }\end{array}$ \\
\hline
\end{tabular}

\subsubsection{Attitudinal Causal Variables}

Regarding attitudinal factors (see table 4.1), tourists overall perceived environmentally sustainable tourism products as more expensive, which was also the main put off for respondents to behave environmentally sustainably:

"Back in Germany, I did think about [the environmental impact of my purchasing] but I also had more money because my parents were there, but here in New Zealand I don't have the money to think about every item I buy. [..] I.. think that environmentally sustainable products are more expensive" (R23). 
Some respondents were also unsure whether their pro-environmental behavior would actually make any difference partly because they did not know what is going on behind the scene or what businesses' real intention with their environmental practices (e.g. conservation or perhaps greenwashing).

\begin{abstract}
"When we are shopping for clothing, I am very aware of environmental considerations..this top I am wanting to get is really nice but I didn't know the brand or if it is sustainable so I looked it up if they have any sustainable records before going and buy that. Yeah I think about that especially with clothing, as it can be really bad for the environment. But then again, I don't know if I am just being greenwashed-well, it is something I think about whether I am home or on a holiday.” (R4).
\end{abstract}

Overall respondents had mixed views on environmental sustainable tourism products. Most saw it as more expensive, almost out of reach, which was a common comment by more than half of all respondents predominantly by Europeans and Australians. Despite perceiving pro-environmental products as more expensive, many still purchased them. While others were unsure what are the direct benefits of their behavior or what businesses' real intention with their pro-environmental products, however this was only raised by a few.

\title{
4.3.2.2 Personal Capabilities
}

Regarding personal capabilities, some respondents were unsure how to find information about the sustainability of tourism products or simply did not have time to cross-check everything:

"Certainly, I wouldn't know how to research whether something is good for the environment or not, when I was booking the Hilton or Rydges, which one has the better environmental rating. We just wouldn't bother, we wouldn't even know how to" (R6). 
Limited time also appeared to be a constraint for some respondents. Many first-time visitors, specifically European tourists came with no plan.

"I just booked my flights, I also booked a rental car and came where I wanted to go. I didn't plan anything because I didn't have the time to and I also didn't want to" (R9).

While there were also a few respondents who had everything booked, which in a way also limited them to what they have booked and purchased previously.

"I didn't [make any environmentally sustainable consideration when purchasing my holiday] I just booked with a reputable travel agent and got very reasonable prices (R10).

These three respondents were also retired, first-time visitors and on average stayed between one to two weeks. Given that these respondents had everything pre-booked, they were limited to these despite some showing intention to more environmentally sustainable choices.

\subsubsection{Contextual Factors}

Various contextual factors were raised by respondents, some of these contextual factors included infrastructural limitations, limited availability and uneven distribution of environmentally sustainable tourism products.

Due to the infrastructural limitations, some respondents felt the need to rent a car due to have access to some of the less accessible tourist sights e.g. great walks and treks. Inaccessibility of such tourists spots was raised by more than half of all respondents. However, there were some exceptions, as few respondents who rented a car, primarily for convenience and were not necessarily apparent to the limitations around public transport. There were only two examples for this. 
Limited availability and uneven distribution of environmentally sustainable tourism products were also commonly emphasized by tourists when explaining their own behavior.

"I think the eco-tourism products are not even[ly distributed], they are less than the other [tourism products]" (R16).

"I think. It is still very rare an eco hotel..even though I would want to protect the environment" (R7).

Although most contextual factors that had an impact on behavior were rather constraining, there were also examples of contextual factors that had a rather encouraging and enabling influence on respondents' pro-environmental behavior e.g. social norms. Respondents often highlighted the fact that they are in a foreign environment thus, they felt the need to adapt local behavior:

"You are a guest, you don't need to irritate the host. I am visiting New Zealand so I adjust to New Zealand standard. In the Netherlands when I drive my car, I drive very fast like a 140 which is not allowed anymore. If I know there is no police officer, I drive fast but in New Zealand I don't do that, I drive 100 in the car" (R2).

Seeing New Zealanders undertaking environmentally sustainable behavior also created a social pressure to adopt local behavior. At the same time, seeing New Zealand touristy and dependent on its nature created some concerns and need to protect it by respondents.

\subsubsection{Habit and Routine}

Regarding habit and routine, respondents especially Australians had an easier job adapting to the New Zealand environment, while tourists from Europe mentioned some difficulty in practicing 
pro-environmental behavior that they practice at home due to the different travel environment (home and away behavior):

"I am aware my habits are affecting the environment...Just the way I live I try to make it as good as possible for the environment this way but it is kind of hard when you are travelling [due to different home and away environment]" (R11).

Despite the intention to be more environmentally sustainable, Respondent 12 would still prefer tourism products that they have membership with even if that means being less sustainable. However, being loyal to a company that communicate their pro-environmental practices clearly to their customers seem to have factored into this as well:

'Hmm.. I [don't' consider the environmental sustainability of tourism products]. Maybe it is bad but to be honest, I haven't really thought about those certain things before, yeah I just couldn't come up with an example saying I purchased this either this service or product because I considered the sustainability practice. I cannot really recall that.

Quite a few hotel start to do their CSR thing. For example I have a membership with Hilton and they sort of have program saying ways they embracing eco-friendly practices so like not changing the towels every day so you sort of contributing to the environment. So that is something I really think through so as a member of brand I am sort of contributing to this as well. Maybe if they have to options e.g. Marriott even if they similar program I go for Hilton because I already have membership" (R12).

Although membership with a brand only appeared once in the interviews, this example from Respondent 12 indicates that brand pro-environmental efforts are taken positively by tourists and also help with reducing potential 'guilt' from choosing less environmentally sustainable products. 


\subsubsection{Conclusion}

In conclusion, the findings confirm that respondents overall care and try to incorporate proenvironmental elements in their holiday, mostly if these are also convenient. Respondents have displayed various types of environmentally sustainable purchasing behaviors for various reasons e.g. lower costs, or for protection of the environment but most of these revolved around price and convenience. The causal factors that were present among respondents appeared to be diverse, influencing respondents' engagement in pro-environmental behavior both positively and negatively. Contextual factors, especially social norms, influenced respondents' pro-environmental

intentions more positively. For example, the foreign environment, perceiving locals actively engaging in environmentally sustainable behavior provided a rather encouraging and enabling environment for respondents to do the same. While personal capabilities and attitudinal factors influenced respondents' pro-environmental behavior rather negatively, many respondents had the impression that tourism products that are environmentally sustainable are also more expensive.

\subsection{Value Orientation}

This section addresses the third sub-question of the research question, which focuses on the aspects of the perceived destination image that influence tourists environmentally sustainable purchasing behavior. In detail, this question focuses on tourists' value orientations (values and beliefs attached to the environment), its influence on environmentally sustainable purchasing behavior and how these are affected by the perceived destination image. By exploring these, it will help identify any link that may exist between environmental perceptions and pro-environmental behavior.

The VBN theory suggests that environmentally sustainable behavior is determined by one's value orientation. There are three types of value orientation exist namely: altruistic (concerned about the well-being of others), biospheric (concerned about the environment) and egoistic (aim to increase their personal benefits through their behavior). Regardless of which one(s) people may possess, it determines the extent to which they are apparent to the consequences of their own behavior (AC), and the extent to which they feel responsible to protect the environment (AR) (De Groot \& Steg, 2009). Therefore, to understand the influence of perceived destination image, it is necessary to 
first explore tourists' value orientations and how they influence their pro-environmental behavior. Second, how perceptions of the destination influence these. This will then help to understand whether the environmental perceptions together with the other destination image elements evoke any pro-environmental attitudes or behavior. Accordingly, the findings are presented in two parts: beliefs and values attached to the environment and environmental perceptions.

\subsubsection{Beliefs and Values Attached to the Environment}

Exploring respondents' beliefs and values attached to the environment will help better understand tourists' view on the human-nature relationship. This will then also help to identify the extent to which tourists are aware of the consequences of their own behavior (AC) and the extent to which they consider themselves to be responsible to protect it (AR). Accordingly, findings are presented in three parts: view on the human-nature relationship, awareness of consequences, and ascription to responsibility, which will now be discussed.

\subsubsection{View on the Human-Nature Relationship}

Findings suggest that the majority of respondents had a biospheric value set meaning that most respondents based their decision to act pro-environmentally, on the perceived costs and benefits for the environment. Given that nature was found to be the biggest draw for tourists to visit New Zealand, this is not surprising. Examples of biospheric value orientation by respondents are provided below:

"I think we should keep our ecological footprint small as possible. We should not leave anything behind of us, don't rubbish, don't buy things that we don't need, and look after our children because every children want to grow up like their parents" (R7).

"I am not directly working on [environmentally sustainability] it but I do support it e.g. minimal water consumption at home, I do not heat even in the winter, I just dress myself 
warmer, I bike to work, I don't use car. I am not saying I am 100\%, I don't buy items that are wrapped in plastic, I still produce some garbage but I do try to minimize it” (R20).

"Even if I had the money to get on 10 international flights for private purposes. I wouldn't, I know it is pretty bad for the environment so yeah I would consider this overall" (R9).

Biospheric value set was most common among respondents with two-thirds of all respondents displaying it. There were also examples of altruistic value orientation among respondents, for instance, Respondent 21 mentioned organising beach clean-ups with his friends:

"[Environmental sustainability means] not using more than we need to. My motto in life for years and years. When I go back in April for Earth day, I always do a beach clean up. I invite a whole bunch of friends and we clean up the beach" (R21).

Egoistic value orientations were also apparent when some respondents preferred to put their hedonic desires over the environment despite being aware of their potential impact:

"To be honest, when we are on a holiday, the experience now be over the environment. If it something I really wanted to do-its a bit like airplane travel, I know it is not a good thing to do but its the only way we could do it"(R4).

Although value orientations of respondents seemed to be stable, there were also signs of it shifting. For example respondent 6 mentioned appreciating nature more once in New Zealand, which indicates change in people's value orientation once exposed to a different environment or context.

"Because it is so beautiful, it had an effect on me in terms of understanding why people don't litter, understanding why people recycle, understanding why people taking care of the land.... It is because you have something so beautiful and you are inclined to take care of it and whereas in Australia "Hi this is my desserty piece of shit that looks horrible 
therefore, I am gonna leave my rusty car crapple over the place and I can do whatever, whenever I want" and that is not for the greater good of anything. There is a collective sense of we have something exceptional, let's look after it and that is nice and affected me" (R6).

Similarly, respondent 19 response also indicated a slight shift in her value orientation once being exposed to New Zealand environment and efforts to protect it:

"I think of [environmentally sustainability] more when I am here, I realize much more here to look after the environment. I think when I go home, because I normally go by car, and for lunch I go home with my car and back to work with my car so, I thought to stop, just go work and lunch stay at work because I felt that I have to do something different now because I think we need to change something now... [New Zealand tries] to look after the environment a lot..they always remind you to do this and that. I think the people we know now all care about the environment." (R19).

Both of these examples show the strong impact of the contextual environment of New Zealand on value orientations of respondents. Not only the well-maintained environment, but also locals behavior appeared to influence this.

\subsubsection{Awareness of Consequences}

Most respondents were aware of the negative impacts of their behavior, specifically aware of the significant carbon footprint created just by flying to New Zealand. Some also highlighted ways they intend to compromise this by undertaking activities with no harm on the environment such as walking or kayaking: 
"We are driving in a car, that is not so sustainable and we have been flying here which is not that eco-friendly, but when we go out and do things we like to do things with our bodies. We don't go quad biking or jet boating or things like that. We go biking or kayaking so that is mix of the fact that we like to use our body but we also like to do something experience, we want to experience stuff without doing harm-if we can. I know that sounds a bit hollow, having flown 24 hours, which is very bad for the environment" (R17).

There were also respondents who admitted not caring about the impacts of their behavior often out of ignorance but they would not do things that would deliberately hurt the environment.

"[Environmental sustainability] should have meaning to us, as much as we should be conscious of how much we are impacting when we don't tick those things off...I don't think we would purposely choose something that harms anyone or anything without any good reason, but at the same time I reckon we probably do a lot of things in ignorance" (R6).

This still indicates an extent of awareness by respondents of the things that are possibly bad for the environment or the ones they should not be doing. Therefore it can be concluded that respondents are overall aware, some are more or less.

\subsubsection{Ascription of Responsibility}

When talking about some of the natural experiences respondents undertook, they did express concern about the well-being of the environment and also the need to protect it. However, respondents' ascription of responsibility was relatively varied. For example, when talking about responsibility, respondents commonly referred to their home country or used the word "we", implying collective responsibility, indicating reduction of their perceived individual responsibility:

"I believe that we should be doing our bit, do as much as we can. The UK is slowly beginning to catch-up and we can learn a lot from places like Australia and New Zealand (R14). 
While those addressing their own responsibility were common too. Examples of this often emerged as a result of exposure to fragile environments:

"In Catlins, I was hesitant to go in the water or not but informed myself first. There were signs like "you should always be $3 \mathrm{~m}$ away from dolphins, never touch them" I read before. I also wasn't swimming towards the dolphins, they came to me. I was also took a way of them okay if if they want to come to , they come to me if don't want to come to me don't come to me. I always took a distance from them" (R22).

This indicates that being exposed to 'certain' environments trigger direct ascription of responsibility while if it comes to common pro-environmental practices such as recycling, tourists consider it as collective responsibility.

\subsubsection{Environmental Perceptions}

The previous section has looked at tourists value orientations and how these have influenced tourists' pro-environmental intentions. Having explored that, this section now looks at the perceived destination image particularly, tourists' environmental perceptions as these are ought to influence tourists' value orientations and their corresponding behavior. Interviews revealed that New Zealand from and environmental perspective seen as responsible.

Perception of New Zealand as responsible towards its environment is primarily due to clean streets and lack of rubbish everywhere that gave respondents the impression that the environment is wellmaintained. This was mentioned by more than $80 \%$ of all respondents. In addition, tourists have also noted various signs that they have noticed throughout their travel that promote proenvironmental behavior. Other measures such as biosecurity check at the airports were also mentioned that gave tourists the impression that the country is responsible towards its environment: 
"I have noticed all these signs everywhere that the government is trying to promote sustainability for all the national parks e.g. warning about what to do and what not to do. Also before going to some forest, you have to clean your shoes so you don't bring in anything when entering the forest. Same with the biosecurity when entering the country. Very thorough checking with the gear that it is clean and no dirt on it" (R20).

These efforts were also regarded as positive by respondents which is important as positive image is considered to be antecedent of pro-environmental behavior meaning, tourists must perceive destination positively to foster pro-environmental attitudes (Chiu, Lee \& Chen, 2014; Giacon, 2014). This is because people are less likely to care for the environment when it is messy, but will pay more attention to maintain an environment that is clean (Wang, Zhang, Cao, $\mathrm{Hu} \& \mathrm{Yu}, 2018$ ). This was also apparent among tourists for example:

"If you were throwing something on the floor, everyone would be looking at you and think "what are you doing?". It is just something you just automatically do when coming to a country like this. Whereas when you go to Vietnam for example and throw something on the floor would be just normal" (R24).

Clean and well-maintained image was also associated with 'being green' by almost $60 \%$ of all respondents. Those who were apparent to these efforts, were also expressed interest in maintaining it. However, there were a few respondents who perceived these efforts as New Zealand is only 'trying' as it does not actually have the right infrastructure to support environmentally sustainable behaviors.

"I was aware that people wanted to be responsible, but the infrastructure is not there to support it” (R6).

Examples of these limitations included limited public transport, recycling facilities (also discussed under 4.2.1.3). A few respondents also criticized the availability of environmentally sustainable tourism products but despite these, most respondents agreed that New Zealand is responsible 
towards its environment though their different signage, biosecurity measures, and that locals also seem to care and be aware.

It was also apparent from the interviews that most respondents associated recycling, clean streets, signage, and lack of trash as a sign of a well-maintained environment and sustainability. Europeans, Germans especially were more critical around infrastructural limitations, but still overall regarded the state of the environment positively overall.

\subsubsection{Summary}

In conclusion, this sub-question aimed to explore tourists' value orientations, how these influenced their pro-environmental behavior, and how environmental perceptions of the destination influence this to identify any link between destination image and pro-environmental behavior. Findings revealed that respondents were mostly aware of the consequence of their behavior and the extent they feel responsible for the protection of the environment. It was apparent that respondents, usually those with a positive image of New Zealand had a stronger sense of responsibility to protect it and were also more conscious of the impacts of their own behavior. Being apparent to New Zealand's efforts to protect its nature also contributed to respondents' positive image and inclination to take care of it. There was also an indication of shift in respondents' value orientations as a result of exposure to nature which supports earlier points. Despite some criticisms, the perceived environmental characteristics were still seen as positive that helped tourists to develop a sense of responsibility to protect it.

The next chapter will now present the interpretation and significance of these findings. It will also provide a revised conceptual framework and will address the answers for both sub questions and the research question. 


\section{Discussion}

This chapter discusses the results of the findings and address the research question:

What is the role of destination image in influencing environmentally sustainable purchasing behavior of tourists?

First, this chapter will explore the perceived destination image of New Zealand, the cognitive and affective components are being observed, and what they mean for tourists. Second, this chapter will examine tourists' intention to behave environmentally sustainably including how and why it occurs. Third, aspects of the destination image will be explored to identify the values and beliefs attached to the environment. Lastly a revised conceptual framework will be presented that incorporates previously missing information and additional findings that contribute to the understanding of the role of destination image in influencing environmentally sustainable purchasing behavior. By revising the conceptual framework, the contribution to academic literature will also be illustrated.

\subsection{Perceived Destination Image}

The aim of this sub-question was to examine the destination image perceived by respondents, to identify any destination characteristics or attributes that are perceived by respondents.

\subsubsection{Conceptualization of Destination Image}

In simple terms, destination image is a mental representation of the destination in the individual's mind (Kock, Josiassen \& Assaf, 2016). The most common approach in extant literature to examine destination image is by breaking it down to its cognitive and affective components (Gartner, 1993; Basaran, 2016; Ryan \& Cave, 2005; Tasci, Gartner, \& Cavusgi, 2007; Echtner \& Ritchie, 1991). The combination of cognitive (what we know about a destination) and affective (how we feel about 
the destination) components then determine how people act on this information (Echtner \& Ritchie, 1991; Basaran, 2016). Based on the cognitive and affective components mentioned by respondents, New Zealand was mainly described by its natural features, clean, green environment and friendly people. Although these characteristics represent the most common descriptions of New Zealand by respondents, there was not one image that was found to be applicable for all respondents. Each respondent perceived New Zealand slightly differently or highlighted different characteristics or attributes depending on what respondents valued or were interested in about the destination. For example, Chinese respondents valued the standard of living aspects (safe, drinkable tap water, high standard of living, English-speaking country), while Europeans appreciated the nature, opportunities for outdoor activities. Australians on the other hand enjoyed that New Zealand is close and is also English-speaking. These slight differences between perceptions of tourists is because destination image is subjective (Bramwell \& Rawding, 1996; Line \& Hanks, 2016; Huete Alcocer \& López Ruiz, 2019) tourists' images of a destination is strongly influenced by their own background and previous experiences (Castro, Martín Armario \& Martín Ruiz, 2007; Tasci, Gartner, \& Cavusgil, 2007; Ryan \& Cave, 2005; Tonge et al., 2014). This was apparent in the findings for example, when describing New Zealand, respondents often compared it with their previous destination visited or home country. Personal characteristics also affected the elements of the destination image perceived e.g. nature-oriented tourists were more interested in the environmental aspects of the destination.

Destination image is not only subjective but is also evolving, Echtner and Ritchie (1991) argue that it changes throughout the different travel stages for example, once tourists are in the destination, images tend to become more realistic, complex and differentiated (Tasci, Gartner, \& Cavusgil, 2007; Chen, Lai, Petrick \& Lin, 2016). Evidence was found of this change occurring, once respondents were exposed to nature, it enabled them to develop a connection with it. Many expressed appreciating nature more once exposed to it. While those respondents who stayed for longer, were overall more critical about the destination efforts to protect the environment. These confirm the evolving nature of destination image but also the strong influence of tourists' own background and characteristics. 


\subsubsection{Destination Characteristics}

The literature on environmentally sustainable behavior and destination image often suggest that destinations need possess certain characteristics and attributes to evoke pro-environmental intentions of tourists. In their research, Line and Hanks (2016) argue that destinations that are characterized by nature attributes as opposed to man-made attributes influence tourists attitudes differently. If a destination is mainly characterized by nature attributes, it is more likely to promote pro-environmental behavior as these destinations are also often seen as more fragile (Giacon, 2014; Wang, Zhang, Cao, $\mathrm{Hu} \& \mathrm{Yu}, 2018$ ). This was also apparent among respondents once exposed to nature, many have indicated a sense of responsibility to protect it. This is because respondents perceived New Zealand to be dependent on its natural environment as that is the biggest draw for tourists to visit and most tourist attractions also revolve around that. Seeing New Zealand touristy also contributed to strengthening respondents' pro-environmental intentions. As Stern (2000) suggests, pro-environmental intention can be activated by beliefs that environmental conditions threaten things people value, and that person can act to reduce that threat, which findings have also validated.

In addition to high environmental background, Wang, Zhang, Cao, Hu and Yu (2018) argue that destinations also need to be clean and well maintained as people are less likely to care for the environment when it is messy, but will pay more attention to maintain an environment that is clean (also known as the broken window theory). This was prominent when respondents highlighted the lack of rubbish everywhere and seeing locals practicing pro-environmental behavior, which created a social pressure to adapt or maintain pro-environmental behavior. Clean and wellmaintained environment was also associated with being green thus, findings also support this.

Continuing with destinations that are characterized by natural attributes, Wearing, Cynn, Ponting and McDonald (2002) suggest that benefits' of individuals' own actions are more apparent in destinations that are reliant on natural assets. This is because these destinations are also often seen as more fragile thus, individuals are more likely to develop pro-environmental intentions (Imran, Alam \& Beaumont, 2014). This was apparent when one respondent mentioned that what New

Zealand is beautiful and special thus he understands why people want to protect it. This supports 
Wearing, Cynn, Ponting and McDonald (2002) point. However, there were quite few respondents who mentioned being unsure about the difference their pro-environmental behavior makes, but it is unclear how this may factor into the perception of benefits of their own behavior. Most respondents were apparent to the obvious negative impacts of their own behavior e.g. flying, cruise travel are bad, but these were rather seen as negative impacts/costs to the environment.

Regardless of destination image components, Chiu, Lee and Chen (2014), assert that destinations that are perceived positively, are more likely to promote pro-environmental attitudes therefore, positive image is necessary for environmentally sustainable behavior to take place. Perceiving a destination positively can be for various reasons e.g. clean environment or friendly people; certain landscapes are also more inclined to promote environmentally sustainable behaviors more than others (Giacon, 2014; Tasci, Gartner, \& Cavusgi, 2007; Basaran, 2016). Despite some criticism among respondents around public transport and recycling the vast majority of respondents had a positive image of New Zealand overall, which was regarded as necessary to enable proenvironmental behavior (Chiu, Lee \& Chen, 2014)

Additional findings regarding the destination image were that New Zealanders overall care about the environment, but New Zealand is also touristy. These findings were particularly interesting as both of these characteristics contributed to developing a sense of responsibility among respondents. On one side, locals were seen to care and be mindful about the environment therefore respondents felt they should care too due to social pressure. On the other side, some respondents perceived New Zealand as touristy and expressed concerns, and the need to protect it. However, there were some negative criticisms around New Zealand's recycling facilities having little capacity and being inadequately distributed around the country. Public transport was also commonly mentioned, making some respondents having to rent or purchase a car for their stay.

Despite these, New Zealand's image provides a rather enabling and encouraging environment for environmentally sustainable behavior. The literature regarded positive and clean image as antecedents of pro-environmental behavior and New Zealand possessed both of these characteristics. Additional findings also revealed that the social norms in New Zealand and somewhat touristic image also helped respondents to foster a sense of responsibility mostly as a 
result of concern or due to social pressure. There was however an example of a respondent who admitted not caring about his environmental impact despite finding New Zealand environment appealing, but this was rather rare.

\subsection{Environmentally Sustainable Purchasing Behavior}

The following sub-question aimed to examine whether tourists have any intention and/or actual behavior to purchase environmentally sustainably and if so, how and why that occurs.

\subsubsection{Conceptualization of Environmental Sustainable Behavior}

The literature defines environmentally sustainable behavior by either having a consumption attitude (intention) and/or behavior that intends to contribute to environmental sustainability (Mehmetoglu, 2009). Accordingly, tourists can either display environmentally sustainable behavior or not and they can either have pro-environmental intent or not. Based on the combination of pro-environmental intention and/or behavior, Juvan and Dolnicar (2016) distinguished between four types of environmental sustainable behavior: Intended (both intent and actual behavior are present), good intentions (intention is present but no actual behavior), accidental (only actual behavior present but no intention) and convenient (purchasing of environmental sustainable products primarily out of convenience e.g. lower cost). All these types of environmentally sustainable behaviors were present among respondents, which supports both Mehmetoglu's (2009) definition and Juvan and Dolnicar (2016) typologies of environmentally sustainable behavior.

The most popular types of environmentally sustainable behavior among respondents were intended, convenient, and good intentions. All three types contain the "intention" component meaning that the majority of respondents not only had the actual behavior, but also the intention to contribute to environmental sustainability. While the least popular pro-environmental behavior was accidental (almost non-apparent among respondents) only have the behavior component with 
no intention. The make-up of these behaviors suggests that respondents were overall aware, and had the intention to contribute to ecological sustainability of the destination with their purchasing.

Additional findings also indicated that tourists are more lenient towards environmentally sustainable products when they seem to require less effort. While environmentally sustainable products that were perceived as requiring additional effort were less popular, which may also explain why convenient pro-environmental behavior was the second most popular behavior. For instance, respondents with companions were overall more concerned about the experience of their travel than their environmental impact. Convenient behavior being the second most popular proenvironmental behavior displayed by respondents also supports this, suggesting that when tourism products are more 'convenient' or seen as an easier choice tourists are more lenient towards undertaking it.

However, environmentally sustainable behavior cannot be examined on intention or behavioral outcome only. Stern (2000) argues that even if tourists have the intention to behave environmentally sustainable, their behavior is determined by a combination of causal factors such as attitudinal factors, personal capabilities, contextual factors, habit and routine (see table 4.1). These causal factors account for certain capabilities and constraints that affect the efficacy of individuals undertaking environmentally sustainable behavior (Tölkes, 2018b; Stern, 2000). Such constraints were also apparent among respondents e.g. not knowing how to look up environmentally sustainable tourism products, having limited time available for planning, infrastructural limitations or limited availability of pro-environmental products. These however are not new, the literature also highlighted such limitations of environmentally sustainable products e.g. having limited availability of it or not being communicated clearly to people (Wearing, Cynn, Ponting, \& McDonald, 2002; Jurowski \& Black, 2015; Tölkes, 2018a; 2018b). Sustainability communication is particularly interesting in this regard as it aims to promote sustainable purchases, but it has been found largely ineffective in the literature (Tölkes, 2018a; Wearing, Cynn, Ponting \& McDonald, 2002; Line \& Hanks, 2016; Jurowski \& Black, 2015). Findings also showed similar results regarding the ineffectiveness of sustainability communications for instance, one respondent highlighted being apparent to accreditations, but simply was unsure what it means or and by the time he noticed it, he already made bookings. 
Behaving environmentally sustainably while on a holiday is also often seen to conflict with tourists short-term personal gains or hedonic desires (Budeanu, 2007; Dolnicar, 2010; Juvan \& Dolnicar, 2014; Untaru, Epuran \& Ispas, 2014). Findings also confirmed this when respondents reasoned their lack of pro-environmental behavior (despite intentions to behave environmentally sustainably) with experience being over the environment when on a holiday, which suggests that some respondents perceive holiday as a break away from pro-environmental responsibilities.

\subsubsection{Understanding Environmentally Sustainable Purchasing Behavior}

Understanding tourist purchasing behavior is a complex process as tourists' choices are moderated by multiple factors such as their concern towards the environment, social, cognitive, situational, and cultural factors (Jurowski \& Black, 2015; Budeanu, 2007). Tourists may purchase environmentally sustainable tourism products, but that does not necessarily mean willingness to protect the environment (Budeanu, 2007). Tourists may engage in environmentally sustainable behavior due to emotional affinity towards nature, present and past experiences with nature (Juvan, Crouch \& Long, 2010; Giacon, 2014; Stern, 2000) or for self-interests (Wearing, Cynn, Ponting \& McDonald, 2002; Stern, 2000) or to save cost (Juvan \& Dolnicar, 2016). The three most common reasons for engaging in environmentally sustainable behavior by respondents were (1) to reduce own impact, (2) seen as more convenient, or (3) due to emotional affinity towards nature. Essentially all these came down to pricing as there was a common misconception by respondents that environmentally sustainable product are more expensive. While there were also some respondents who thought the opposite, in fact, considered such products a lot cheaper.

The choice of destination also had implications for the tourists' purchases (Woodside \& Dubelaar, 2002; Dolnicar, 2010; Wang, Zhang, Cao, Hu \& Yu, 2018; Stanford, 2008). Given that most tourist attractions in New Zealand are nature based (Yeoman \& Mcmahon-Beattie, 2014), this was also reflected in tourists' purchases, which mostly consisted of nature experiences as opposed to e.g. visiting historical buildings. Additionally, as New Zealand is located far away from most countries, coming here was also seen as expensive therefore, the biggest attribute sought after by tourists was affordable price or good value. 
In summary, respondents overall hold a positive attitude towards the environment and do not wish to behave in a way that negatively impacts the environment. However, environmentally sustainable behavior is not easy as it is determined by certain constraints and capabilities while personal factors also play a key role in influencing decisions. Given that most tourist experiences offered in New Zealand are nature based, it provided various opportunities for tourists to engage in proenvironmental purchasing behavior as opposed to other destinations.

\subsection{Value Orientation}

The final sub-question of this thesis aimed to explore the aspects of destination image that influence environmentally sustainable purchasing behavior. In detail this question focuses on the nature of link between destination image and environmentally sustainable purchasing behavior by exploring tourists' environmental perceptions and the values and beliefs attached to these, which is believed to determine one's pro-environmental action.

\subsubsection{Nature of Respondents' Value Orientation}

Value orientation (adopted from Stern's (2000) VBN theory), suggests that individuals' value orientation (beliefs and values attached to the environment) determines their pro-environmental behavior (Stern, 2000; De Groot \& Steg, 2009; Tölkes, 2018b). There are three types of value orientation that Stern distinguishes between which are altruistic (prosocial, concerned about the well-being of others), egoistic (consider costs and benefits of pro-environmental behavior for them personally) and biospheric (ecocentric). Each of these value orientations determine individuals' pro-environmental beliefs, intentions and behavior (De Groot \& Steg, 2009). These proenvironmental beliefs (based one's value orientation) determine the extent to which individuals are apparent to the consequences of their own behavior (AC), and the extent to which they feel responsible to protect (AR) what they value so highly e.g. the environment (De Groot \& Steg, 2009). Findings also validated this with the presence of all three types of value orientations 
(altruistic, egoistic and biospheric) among respondents with biospheric being the most common among all respondents. Tourists with this value set were worried about the negative impact of their behavior on the environment (AC) (e.g. flying long haul, renting a car) and aimed to reduce these (AR) by supporting conservation, buying local products and more. Following this, egoistic was the second most common value set displayed by tourists. These tourists were primarily concerned with their overall experience, and based their decisions on perceived personal costs and benefits such as comfort and convenience. The majority of respondents with egoistic value set were aware of the consequence of their own behavior (AC) and the activities one should not be doing. Most expressed interest in behaving environmentally sustainable, while some considered experience to be more important given that they are on a holiday. Continuing with value orientation, altruistic value set was the least common among respondents. These respondents were overall concerned about 'doing the right thing' (e.g. donate to charities, collect rubbish). They were also less apparent to the consequence of their own behavior (AC), but more aware of others' behaviors. Similarly with their ascription of responsibility (AR), respondent with altruistic value orientation were interested in informing themselves on what is appropriate to do when visiting fragile places (e.g. swim with dolphins) and overall 'doing the right thing'. These findings therefore support literature that individuals' value orientation determine the basis of both their AC and AR beliefs.

Although Stern's (2000) assumes individuals only possess only one value set at a time, De Groot and Steg (2009) argue otherwise. They suggest that all individuals hold egoistic, altruistic, and biospheric values to some extent and all three types may provide a distinct basis for proenvironmental behavior. Findings also indicated this for example, some respondents rented a smaller car due to its lower emission (biospheric), while other respondents chose it purely because it was a cheaper option (egoistic). There were also certain overlaps between value orientations, primarily between altruistic and biospheric value sets. Tourists demonstrating both were concerned about what is 'the right thing' but also their impact on the environment with their own behavior. For example, one of these tourists highlighted that he organises beach clean-ups with his friends every year on earth day (altruistic/biospheric), volunteers each year (altruistic), prefer to use public transport instead of flying (biospheric), and donate when asked (altruistic). Another overlap was apparent when a respondent displayed all three value sets e.g like to follow instructions, stay on track when hiking (altruistic), wants to reduce negative impact and are worried about nature 
(bispheric), but do think comfort is important (egoistic). When values conflict, it can become quite problematic as people act priori on egoistic considerations and less on altruistic and biospheric considerations (De Groot \& Steg, 2009). This was also apparent with the respondent displaying all three value orientations who ended up prioritizing comfort over other options. Although egoistic value orientation can result in pro-environmental behavior, altruistic and biospheric consideration provide the most stable base for pro-environmental behavior (De Groot \& Steg, 2009). This is because individuals behaving on the basis of altruistic and/or biospheric values, they are less influenced by personal or situational factors, which then leads to a more stable environmentally sustainable behavior. This was also indicated with tourists displaying altruistic and biospheric value orientation were highly influenced by their pre-existing habit and routine around proenvironmental behavior (e.g. recycling, using smaller car or avoiding private transport, supporting local businesses, and avoiding waste). Tourists with these value sets were also more apparent to the pro-environmental efforts by New Zealand and the availability of environmentally sustainable products. While tourists with egoistic value sets were more directly influenced by price, convenience and the overall experience. These tourists when describing their pro-environmental behaviors commonly explained their actions with 'being on holiday thus, experience is more important' than doing 'the right thing'.

The literature suggests that individuals' value orientation are stable, but findings indicate otherwise (Stern, 2000; De Groot \& Steg, 2009). Once exposed to a different environment, Respondent 6's value orientation indicated change, shifting from egoistic to altruistic/biospheric. Respondent 6 , who previously did not have any special connection with nature mentioned valuing it more once exposed to it though his travels around New Zealand. Respondent 6 also admitted acting out of ignorance mostly, but being apparent to benefits of pro-environmental behavior he planned to behave more sustainably (for its benefits for the environment). This shift is likely to be explained partly by the nature of travel context, where tourists are exposed to different destination environments (that is different from their usual environment), which impacts both tourists' beliefs and values attached to the environment. The value orientation shift was from egoistic to altruistic/biospheric once, Respondent 6 realised things he should not be doing but has been doing them out of ignorance. Being apparent to the benefits of well-maintained environment also influenced this. This finding contradicts literature, which suggests values of people are stable and 
enduring, but findings indicate the dynamic of this changes due to the travel context. As neither of these papers (Stern, 2000; De Groot and Steg, 2009) focus on tourism context, it explains the potential overlook of this factor.

Continuing on with value orientation, Stern (2000) study suggests that awareness of consequences

of own behavior (AC) directly influences ascription of responsibility (AR) but this was not always the case. For instance, tourists with good intentions were often overridden by factors such as price, convenience or experience. While VBN theory suggests that individuals need to possess both of these beliefs, there was an example where a respondent behaved environmentally sustainably but did not have corresponding AC and AR beliefs. In that case, the VBN theory missed to account for the fact that individuals can behave environmentally sustainably without recognising the product attributes or added value. Tölkes (2018b) also had similar findings using VBN theory to understand special interest tourists and their sustainable behaviors, and found that many special interest tourists who undertook sustainability accredited holidays were not apparent to the product attributes or the added value of it or the fact that their holiday was sustainable. Therefore this also highlights that VBN theory is limited in way to understand environmentally sustainable behavior.

Despite the shortcomings identified, Stern's (2000) VBN theory was found suitable for this research to understand the role of destination image in influencing environmental sustainable tourists behavior. The strength of VBN theory lies in the fact that it does not account for all factors that potentially influence environmental sustainable behavior which allows for a wider and flexible application such as the area of tourism. It also acknowledges certain capabilities and constraints that moderate the overall process of pro-environmental behavior (causal factors) that were also validated by findings.

\subsubsection{Environmental Perceptions}

Environmental perceptions are ought to influence the connection respondents develop with the destination based on what is perceived and recognized. From an environmental perspective, New Zealand was seen as responsible toward its environment, due to lack of rubbish on streets, well 
maintained healthy environment, and visible pro-environmental efforts. New Zealanders were also seen to actively practice pro-environmental behaviors, which also influenced tourists to adopt such behaviors. However, New Zealand was also seen to be dependent on its nature given that most tourist products revolve around it and it is essentially what draws tourists to visit the country in the first place. Some also criticized New Zealand for being a bit touristy. Surprisingly, both of these observations (being dependent on nature and being a bit touristy) influenced respondents' pro-environmental intentions rather positively. These perceptions of the environment evoked a sense of responsibility to protect the environment (what is valued by tourists) from high flow of tourists that may threaten the conditions of the environment.

In general respondents were aware of the negative impacts of their behavior (AC) e.g. flying while those not caring about their own impact were still aware of what behaviors are bad for the environment and the things that one should not do. Certain environments (e.g. fragile, aesthetically pleasing, tourists attractions) triggered direct ascription of responsibility, respondents felt responsible to protect it. While common pro-environmental practices such as recycling, were regarded as collective responsibility. Similarly, when describing bad behavior respondents sometimes referred to the country or people in that country which also provided additional insight as how tourists ascribe to responsibility and to what extent they hold others responsible.

In conclusion, value orientation does determine the extent to which respondents are aware of the consequences of their own behavior and the extent they feel responsible to reduce them, but the nature of these relationships are complex given the dynamics of one's value orientation, and the nature of travel context. New Zealand being perceived as responsible, dependent on its nature and touristy influenced respondents positively in fostering pro-environmental intentions. The fact that respondents were in a 'foreign environment', also had implications on the impact of these perceptions.

\subsection{Summary}

In conclusion, the discussion suggests that destination image does play a role in influencing environmentally sustainable purchasing behavior by not only evoking pro-environmental 
intentions, but by also providing an encouraging and enabling environment. Both the findings and discussions emphasize the characteristics and qualities of New Zealand that were found particularly influential in evoking a sense of responsibility and/or connection towards nature (fragile environment, dependence on nature, unique, aesthetically pleasing) mainly as these were overall perceived positively. Additionally, the contextual condition of the destination appeared to also influence tourists' view on what behavior is appropriate in a given context e.g. Respondent 24 highlighted that during her stay in Vietnam throwing rubbish on the floor appeared to be the norm, but in New Zealand, she would likely to be called out for such behavior (discussed in section 4.4.1.1). Another example of this was when a respondent said although he would normally drive above the speed limit in his home country, he would not do that in New Zealand as he is in a foreign environment outside of his usual environment thus, he needed to adopt local behavior. Such examples show the strong impact of the contextual factors that can have on behavior especially in a tourism context where tourists are often in a foreign environment.

Although it is understood now that destination image can play a key role in evoking, enabling and influencing pro-environmental behavior, there are also many other factors that were found to contribute to the extent of destination image influence on behavior. The presence of these factors have been previously highlighted by Stern (2000) such as contextual factors, habit and routine, personal capabilities, and attitudinal factors, but it was unclear how each of these influence or moderate the process of environmentally sustainable behavior. In addition to these four causal factors, personal factors were also found to play an important role in shaping how a destination is perceived or what elements are appreciated by tourists based on the preferences and previous travel experiences. Despite these, causal factors were found to be very influential in evoking environmentally sustainable behavior. In New Zealand, these contextual factors included visible pro-environmental efforts, social norms, availability of environmentally sustainable products, all these enabled and also encouraged tourists to behave environmentally sustainably.

To illustrate the contributions of the findings to literature, the following section will present a revised conceptual framework, which will explain and interpret these, in relation to the original conceptual framework. 


\subsection{A Revised Conceptual Framework}

The previous sections have elaborated on the contributions of this thesis to academic literature. The original conceptual framework in chapter 2, illustrated a solid base to examine the role of destination image in influencing pro-environmental behavior, but it was also lacking in many aspects. The nature of relationship between constructs were unclear, and some components were also missing that prohibited a comprehensive understanding of the role of destination image in influencing environmentally sustainable purchasing behavior. Therefore, to address the shortcomings of the original conceptual framework, a revised conceptual framework is provided with additional information that has emerged and contributed to a more in depth understanding of the influence of destination image on environmentally sustainable purchasing behavior.

The original framework illustrated the fundamental base for this research indicating a possible link between destination image and environmentally sustainable behavior, which findings also validated. However, the nature of the link between each construct have been revisited, and additional factors have also been added based on findings. The revised conceptual framework is presented in the form of a flow chart to best represent the link between the three main constructs namely: (1) perceived destination image, (2) value orientation, and (3) environmentally sustainable purchasing behavior (see figure 5.1). These three constructs however are influenced by various factors such as (a) personal factors, (b) habit and routine, (c) contextual factors, (d) personal capabilities, and (e) attitudinal. The nature of relationship between these will now be elaborated on. 
Figure 5. 1: Revised conceptual framework

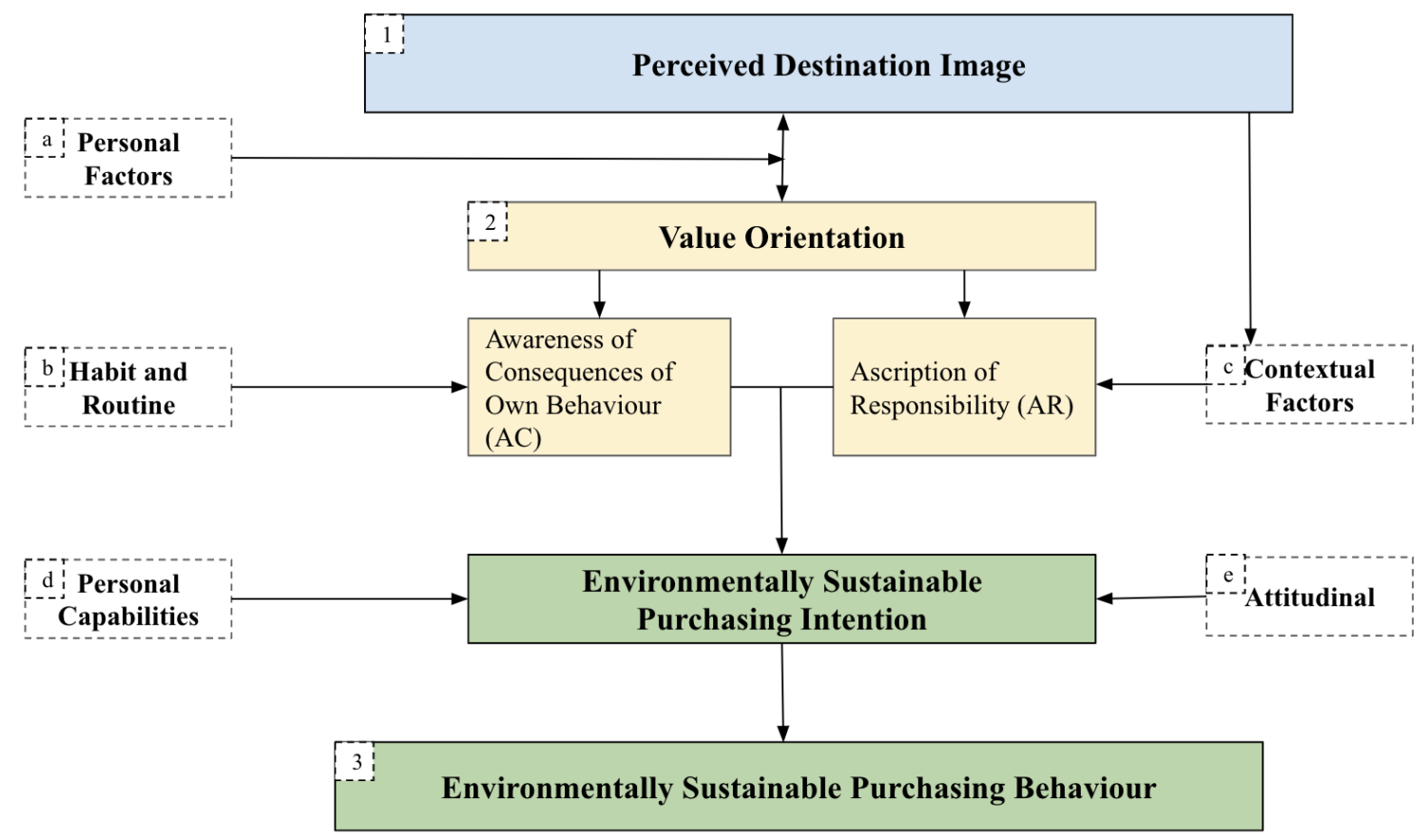

The revised conceptual framework starts with perceived destination image (indicated with 1 on figure 5.1), which is influenced by both (a) personal factors and (2) value orientation. Both the literature and findings suggest that individuals' own background and previous experiences influence how they perceive a destination, and their perception of the destination also influence their value orientation (indicated with 2). Personal factors were previously missing from the original conceptual framework despite its influence on both perception of destination image and on value orientation.

Value orientation (indicated with 2 on figure 5.1) is influenced by both perceived destination image and personal factors, but it also influences how the destination is perceived, especially what is valued about the destination (based on personal interests, preferences, and values attached to the environment). Value orientation (determined by the perception of destination image) then influences individuals' beliefs about the negative impact of their behavior (AC) and also the extent they feel responsible (AR) which findings are also validated. 
As figure 5.1 indicates, AC beliefs are also influenced by individuals' pre-existing habits and routines (in addition to value orientation) for instance, tourists actively undertaking proenvironmental behavior at home, were also looking for opportunities to continue these while on holiday. However, tourists' habit and routine can also hinder individuals' awareness of the consequence of their own behavior. AR on the other hand is influenced by the contextual factors present in the destination (in addition to value orientation). Examples of these contextual factors include social norms, availability of pro-environmental products in the destination, local policies around environmental behavior that may evoke or hinder sense of responsibility. All of these can both enable and prohibit tourists' ability to engage in pro-environmental behavior.

The way value orientation translates into AC and AR beliefs validate Stern's VBN theory. However, AC does not always directly influence AR as Stern suggests, but the combination of AC and AR beliefs determine individuals' pro-environmental inventions. These are then also moderated by (d) personal capabilities (such financial resources, skills) and (e) attitudinal factors (such as perceived benefits and costs of environmentally sustainable behavior, product attributes), which then determine the actual behavior of tourists.

The added factors on figure 5.1 apart from (a) personal factors have been adopted from Stern's causal factors, which account for certain capabilities and constraints of environmentally sustainable behavior, but were never incorporated into the actual VBN theory. This research not only examined the presence of these causal factors but also their role in facilitating the role of destination image in influencing environmentally sustainable purchasing behavior. Based on the findings, these factors were incorporated into the revised conceptual framework given their moderating effect on the process of pro-environmental behavior.

The original conceptual framework has illustrated the base for this research indicating overlaps and relationship between constructs. However, the nature of the links between constructs were unclear which the revised conceptual framework aimed to address based on the findings of this research. Additional components such as personal factors, contextual factors, personal capabilities, attitudinal factors, and habit and routine were also added to the revised framework, given their importance in influencing the impact of destination image on environmental behavior, which was 
revealed by findings. By identifying these, a better understanding of the role of destination image in influencing environmental sustainable purchasing behavior was provided, which focuses on the nature of pro-environmental behavior in general as opposed to having a product-specific focus (e.g considering ecotourism products only). The findings of this thesis also revealed additional components and the sequential order between components. 


\section{Conclusion}

The previous chapter has already summarized the key findings and illustrated its contribution to academic literature through the revised conceptual framework (in section 5.5). The following chapter will now conclude the research question(s), go over the implications of the findings of this thesis. This is then followed by limitations and areas for future research.

\subsection{Concluding the research question(s)}

The research question underpinning this thesis was:

What is the role of destination image in influencing environmentally sustainable purchasing behavior?

To ensure all parts of the research question is answered, it was broken into three sub questions which are presented below, together with the corresponding summary of findings.

\section{What is tourists' perceived destination image?}

As the discussions previously highlighted (see section 5.1), New Zealand's image provides a rather enabling and encouraging environment for environmentally sustainable behavior. The literature regarded positive and clean image as antecedents to pro-environmental behavior and New Zealand possessed both of these characteristics. Additional findings also revealed that the social norms in New Zealand and somewhat touristic image also helped respondents to foster a sense of responsibility mostly as a result of concern or due to social pressure. These findings are relatively new as previous literature often neglects the contextual environment of destinations when studying destination image impact on behavior. 


\section{Do tourists have the intention and/or actual behavior to purchase their tourism products}

and services environmentally sustainably? If so, how and why?

Respondents overall hold a positive attitude towards the environment and do not wish to behave in a way that negatively impacts the environment (discussed in section 5.2). However, environmentally sustainable behavior is complex as it is moderated by multiple factors that include personal factors, habit and routine, attitudinal, contextual and personal capabilities as also illustrated on the conceptual framework in section 5.5). In general, tourists were more lenient towards environmentally sustainable products that seemed to require less effort, while those seen as requiring additional effort were less popular.

\section{What aspects of perceived destination image influence tourists' environmentally} sustainable purchasing behavior?

The VBN theory underpinning this thesis suggests that one's value orientation determine the extent to which tourists are aware of the consequences of their own behavior and the extent they feel responsible to reduce them indeed. The findings of this thesis also validated this, but the nature of these relationships are more complex given the dynamics of one's value orientation, and the nature of travel context (discussed in more detail in section 5.3). New Zealand being perceived as responsible, dependent on its nature and touristy influenced respondents positively in fostering pro-environmental intentions. Given that respondents were in a foreign environment, it also had an impact on these perceptions.

Thus, it can be concluded (see section 5.4) that destination image does play a role in influencing environmentally sustainable purchasing behavior by not only evoking pro-environmental intentions, but by also providing an encouraging and enabling environment. Both the findings and discussions emphasize the characteristics and qualities of New Zealand that were found particularly influential in evoking a sense of responsibility and/or connection towards nature (fragile environment, dependence on nature, unique, aesthetically pleasing) mainly as these were 
overall perceived positively. Additionally, the contextual condition of the destination appeared to also influence tourists' view on what behavior is appropriate in a given context.

Additional factors moderating the extent to which destination image influences behavior were also identified. The presence of these factors has been previously highlighted by Stern (2000) such as contextual factors, habit and routine, personal capabilities, and attitudinal factors, but it was unclear how each of these influence or moderate the process of environmentally sustainable behavior. These four causal factors were also extended with personal factors as it found to play an important role in shaping how a destination is perceived or what elements are appreciated by tourists based on the preferences and previous travel experiences. In New Zealand, these contextual factors included visible pro-environmental efforts, social norms, availability of environmentally sustainable products, all these enabled and also encouraged tourists to behave environmentally sustainable.

\subsection{Implications}

Theoretical and practical implications of findings will now be discussed.

\subsubsection{Theoretical Implications}

Two key topic areas were explored throughout this thesis: destination image and environmentally sustainable purchasing behavior. In the literature review in Chapter 2, it was identified that these topics are very complex and multifaceted. Through the literature review, qualitative interviews, and framework analysis, a better understanding of the key concepts was gained, which is also illustrated by the revised conceptual framework in section 5.5. This contribution of thesis is visible between the revised and original conceptual framework (in section 2.3). This thesis addressed not only the research gap, but also identified the nature of relationships between different concepts and factors influencing the impact of destination image on behavior (see the revised conceptual framework in section 5.5). 
Previous literature only had a narrow insight into the nature of link between destination image and environmentally sustainable behavior thus, by adopting a more generic approach, and taking travel context into account, this thesis provides a comprehensive understanding of the nature of relationship, and the moderating factors present.

The application of Stern's (2000) VBN theory in tourism literature has been relatively scarce, but it was found overall suitable to better understand the nature of relationship between environmentally sustainable (tourism-related) purchasing behavior and destination image. However, findings also revealed certain shortcomings of its applicability in the area of tourism, which aid future research looking to apply the VBN theory in tourism.

\subsubsection{Practical Implications}

The findings of this thesis carry important implications particularly for destination managers, and destination marketers. First, findings clearly indicated that both positive and negative perceptions of the destination image can evoke pro-environmental intentions but positive overall impression is more influential in evoking pro-environmental behavior.

Second, the contextual environment of the destination can have a strong influence on tourists proenvironmental behavior as there are various factors present such as social norms and infrastructure that can both support or hinder pro-environmental behavior of tourists. Thus, destination managers need to ensure to communicate opportunities for pro-environmental behavior clearly (both prior and during travel) and support it with appropriate infrastructure to make it more convenient for tourists.

Third, the discussions also highlighted that altruistic and biospheric considerations provide the most stable base for pro-environmental behavior and people behaving on the basis of these are less influenced by personal or situational factors. While egoist consideration can also result in environmentally sustainable behavior it is less stable as it is easily overridden by factors such as 
price and convenience. Thus when promoting pro-environmental behavior, it is necessary to address both altruistic and biospheric beliefs by communicating "the right thing to do" to foster altruistics and/or biospheric values as the base for purchasing decisions.

Regarding environmentally sustainable behavior, various types were identified e.g. tourists may demonstrate pro-environmental behavior but that does not necessarily mean willingness to protect the environment or that sustainable attributes are perceived and understood. Barriers to environmentally sustainable behavior were also identified some of these included infrastructural limitations, cost, convenience. Destination managers therefore need to minimize these.

\subsection{Limitations and Future Research}

Although the findings make valuable contributions to enhance the understanding of the role destination image, several limitations exist that provide interesting avenues for future research. First, it is important to note that this study only focused on New Zealand, which had a strong influence both on the methodology and the findings. Thus, if this thesis research were repeated in a different destination then it would likely to produce different findings and the findings of this thesis may not be applicable to all destinations either. Second, the resources available for this research did not allow for a sampling design that extended outside of the Wider Wellington Region. Consequently, tourists interviewed may not be entirely representative of all international tourists of New Zealand. Therefore, future research may look into the applicability of these findings in different research contexts. Involving both domestic and international tourists could also provide a richer insight into how destination image potentially influence tourists' behaviors. It would be also interesting to investigate whether findings differ if tourists were to be interviewed prior to visiting a destination, during and after to better understand the influence of destination image on behavior. However, the strength of this thesis lies in its generic focus on environmentally sustainable purchasing behavior and the sole focus on international tourists, which contributes to the research gap and also increases the transferability of findings. 


\section{Appendices}

Appendix A: Interview Guideline

Appendix B: Information Sheet

Appendix C: Consent Form 


\section{Appendix A: Interview Guideline}

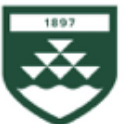

TE HERENGA WAKA

WELLINGTON

VICTORIA UNIVERSITY OF WELLINGTON

The role of destination image in environmentally sustainable purchasing behaviour

\section{Interview Guidelines}

\section{Introduction}

- Personal introductions

- Thank you for taking the time

- Confirm that respondent is an international tourist and above the age of 18

- Research purpose: The aim of this project is to investigate how New Zealand is perceived by international tourists and how this translate into their environmentally sustainable tourism-related purchasing behaviour. Your participation will support this research by sharing your destination image of New Zealand. Additionally, sharing some of your tourism-related purchasing decisions in New Zealand either prior to coming here or during your visit in New Zealand.

- Confirmation of agreement to information sheet

\section{Personal Background}

- Where are you (visiting) from?

- Length of stay

- Why did you decide to visit NZ?/What motivated you to come to NZ?

- Have you been in NZ before?

- Has any of your friends or family member been here before?

- Information sources/help with bookings

\section{Perceived Destination Image}

- Images/characteristics that come to your mind when you think of $\mathrm{NZ}$ as a vacation destination? /How would you describing NZ to a friend (functional and holistic component)

- Would you describe the atmosphere or mood that you would expect to experience while visiting NZ? (psychological and holistic component)

- Please list distinctive or unique tourist attractions that you can think of in NZ

\section{Environmental Sustainability}

- Meaning of environmentally sustainability to you

- How do you feel about the current state of NZ environment (urban and/or rural)?

- Do you feel that NZ is mindful of the environment?

\section{Purchasing Intent and/or Behaviour}

- Priorities when purchasing holiday for/in NZ

- Can you recall any environmentally sustainability consideration or behaviour when making your booking(s) for/in New Zealand?

- Observations of other people practicing environmentally sustainable behaviour in NZ 


\section{Beliefs}

- When, purchasing tourism products, do you consider their environmental impact?

- Does this somehow influence the way in which you purchase?

- Do you think if the image/perception of NZ influenced the way in which you purchased your tourism products?

\section{Conclusion}

- Anything else you would like to add

- Thank you for taking the time 


\section{The Role of Destination Image in Tourist Behaviour-}

\section{Participant Information Sheet}

Kia Ora and thank you for your interest in this research project! Please read this information sheet carefully before deciding if you would like to participate.

My name is Diana Kham and I am a Master's student in Tourism Management at Victoria University of Wellington. This research project is work towards my Master's Thesis.

The aim of this project is to investigate how New Zealand is perceived by international tourists and how this translate into their environmentally sustainable tourism-related purchasing behaviour. By understanding this, it can assist destination tourism managers and marketers in understanding how destination image may influence tourist behaviour. Your participation will support this research by sharing your destination image of New Zealand. Additionally, sharing some of your tourism-related purchasing decisions in New Zealand either prior to coming here or during your visit in New Zealand.

Interviews are expected to last approximately 15 to 30 minutes and will take place at tourists' sites in New Zealand. As a koha (gift) you will be offered some refreshments during the interview and will receive a little souvenir from Wellington to take home with you.

Interviews will be audio recorded, transcripts will be anonymised, and individual participants will not be identifiable by name or by association. Results of this research will be shared between me and my supervisor and the aggregated findings may be published in academic journals or presented at conferences.

Your participation in this project is entirely voluntary. In the evpnt that the line of questioning during the interview develops in such a way that you feel hesitant or uncomfortable you may decline to answer any particular question(s) and/or may withdraw from the project immediately. You may also withdraw your contribution to the project until Saturday, 15 February 2020 , via email. As a consequence, your contribution to the study will immediately be destroyed. All recordings, notes and transcripts will be destroyed at the end of 2023 after completion of this project.

If you would like more information about this research project or would like to withdraw your contribution, please contact me via khamdian@myvuw.ac.nz or my supervisor: Dr Ina Reichenberger via ina.reichenberger.vuw.ac.nz or call 044635375.

This research has been approved by the Victoria University of Wellington Human Ethics Committee (number 0000028039).

If you have any concerns about the ethical conduct of the research, you may contact the Victoria University HEC Convener: Dr Judith Loveridge at judith.loveridge@vuw.ac.nz or 044636028. 


\section{Appendix C: Consent form}

\section{WELLINGTON \\ VICTORIA UNIYERSITY OF WELLINGTON}

The Role of Destination Image in Tourist Behaviour- Consent Form

I have read the Information Sheet concerning this project and understand what it is about. All my questions have been answered to my satisfaction.

\section{I know that:}

- My participation in this project is entirely voluntary.

- In the event that the line of questioning during the interview develops in such a way that I feel hesitant or uncomfortable I may decline to answer any particular question(s) and/or may withdraw from the project immediately. As a consequence, my contribution to the study will immediately be destroyed.

- I may withdraw my contribution to the project until Saturday, 15 February 2020 via email. As a consequence, my contribution to the study will be destroyed immediately.

- The interview is expected to last between 15 and 30 minutes and it is being electronically recorded.

- All recordings, notes and transcripts will be destroyed at the end of 2023 after the completion of this project.

\section{I would like (please tick box as required)}

$\square$ A summary copy of the interview notes to be sent to my email address.

$\square$ A summary copy of the full research findings to be sent to my email address.

Email:

I agree to take part in this project. 


\section{References}

Abdullah, S. I. N. W., Samdin, Z., Teng, P., \& Heng, B. (2019). The impact of knowledge, attitude, consumption values and destination image on tourists' responsible environmental behaviour intention. Management Science Letters, 9(9), 1461-1476 DOI: https://doi.org/10.5267/j.msl.2019.5.005

Ateljevic, I., \& Doorne, S. (2002). Representing New Zealand: Tourism Imagery and Ideology. Annals of Tourism Research, 29(3), 648-667. https://doi.org/10.1016/S01607383(01)00077-9

Avramidis, E., \& Smith, B. (1999). An Introduction to the major research paradigms and their methodological implications for special needs research. Emotional and Behavioural Difficulties, 4(3), 27-36. https://doi.org/10.1080/1363275990040306

Baloglu, S., \& McCleary, K. (1999). A model of destination image formation. Annals of Tourism Research, 26(4), 868-897. https://doi.org/10.1016/S0160-7383(99)00030-4

Basaran, U. (2016). Examining the relationships of cognitive, affective, and conative destination image: A research on Safranbolu, Turkey. International Business Research, 9(5), 164-179. http://dx.doi.org/10.5539/ibr.v9n5p164

Bell, C. (2008). 100\% Pure New Zealand: Branding for back-packers. Journal of Vacation Marketing, 14(4), 345-355. https://doi.org/10.1177/1356766708094755

Bramwell, B., \& Rawding, L. (1996). Tourism marketing images of industrial cities. Annals of Tourism Research, 23 (1), 201-221.

Bloor, M.A. \& Wood, F.A. (2006). Keywords in Qualitative Methods: A Vocabulary of Research Concepts. London, United Kingdom: Sage Publications.

Bojanic, D. (1991). The use of advertising in managing destination image. Tourism Management, 12(4), 352-355. https://doi.org/10.1016/0261-5177(91)90047-W

Bonn, M., Joseph, S., \& Dai, M. (2005). International versus Domestic Visitors: An Examination of Destination Image Perceptions. Journal of Travel Research, 43(3), 294301. https://doi.org/10.1177/0047287504272033

Botterill, D., \& Platenkamp, V. (2012). Key Concepts in Tourism Research. London, United Kingdom: Sage Publications. DOI:10.4135/9781473914674 
Budeanu, A. (2007). Sustainable tourist behaviour a discussion of opportunities for change. International Journal of Consumer Studies, 31(5), 499-508. https://doi.org/10.1111/j.1470-6431.2007.00606.x

Brunt, P., Horner, S., \& Semley, N. (2017). Research methods in tourism, hospitality \& events management. London, UK: Sage Publications.

Castro, C., Martín Armario, E., \& Martín Ruiz, D. (2007). The influence of market heterogeneity on the relationship between a destination's image and tourists' future behaviour. Tourism Management, 28(1), 175-187. https://doi.org/10.1016/j.tourman.2005.11.013

Chen, C., Lai, Y., Petrick, J., \& Lin, Y. (2016). Tourism between divided nations: An examination of stereotyping on destination image. Tourism Management, 55, 25-36. https://doi.org/10.1016/j.tourman.2016.01.012

Chiu, Y., Lee, W., \& Chen, T. (2014). Environmentally Responsible Behavior in Ecotourism: Exploring the Role of Destination Image and Value Perception. Asia Pacific Journal of Tourism Research, 19(8), 876-889. https://doi.org/10.1080/10941665.2013.818048

Creswell, J. (2014). Research design : qualitative, quantitative, and mixed methods approaches (4th ed.). Thousand Oaks, USA: Sage Publications.

Creswell, J., \& Creswell, J. (2007). Qualitative inquiry \& research design : choosing among five approaches (2nd ed.). Thousand Oaks, USA: Sage Publications.

Crompton, J. L. (1979). An assessment of the image of Mexico as a vacation destination and the influence of geographical location upon that image. Journal of Travel Research, 17(4), 18-24. https://doi.org/10.1177/004728757901700404

De Groot, J., \& Steg, L. (2009). Mean or green: which values can promote stable proenvironmental behavior? Conservation Letters, 2(2), 61-66. https://doi.org/10.1111/j.1755-263X.2009.00048.x

Dolnicar, S. (2010). Identifying tourists with smaller environmental footprints. Journal of Sustainable Tourism, 18(6), 717-734. https://doi.org/10.1080/09669581003668516

Galletta, A., \& Cross, W. (2013). Mastering the semi-structured interview and beyond:from research design to analysis and publication.New York, USA: New York University Press. 
Gössling, S., \& Hall, C. M. (2006). An introduction to tourism and global environmental change. In S. Gössling, \& C. M. Hall (Eds.), Tourism \& global environmental change (pp. 1-33). Oxon, United Kingdom: Routledge.

Gössling, S., Scott, D., Hall, C., Ceron, J., \& Dubois, G. (2012). Consumer behaviour and demand response of tourists to climate change. Annals Of Tourism Research, 39(1), 3658. https://doi.org/10.1016/j.annals.2011.11.002

De Groot, J., \& Steg, L. (2009). Mean or green: which values can promote stable proenvironmental behavior? Conservation Letters, 2(2), 61-66. https://doi.org/10.1111/j.1755-263X.2009.00048.x

Denzin, N., \& Lincoln, Y. (2005). The SAGE handbook of qualitative research (3rd ed.). Thousand Oaks, USA: Sage Publications.

Department of Conservation. (2018). Summer Campaign Pocket Guide. Retrieved from: https://doc.brandkit.io/assets/263406

Dolnicar, S. (2010). Identifying tourists with smaller environmental footprints. Journal of Sustainable Tourism, 18(6), 717-734. https://doi.org/10.1080/09669581003668516

Dolnicar, S., Crouch, G., \& Long, P. (2008). Environment-friendly Tourists: What Do We Really Know About Them? Journal of Sustainable Tourism, 16(2), 197-210. https://doi.org/10.2167/jost738.0

Dolnicar, S., \& Leisch, F. (2008). Selective marketing for environmentally sustainable tourism. Tourism Management, 29(4), 672-680. DOI:10.1016/j.tourman.2007.07.010

Duignan, J. (2016). A dictionary of business research methods. Oxford, UK: Oxford University Press.

Echtner, C., \& Ritchie, J. (1991). The measurement of tourism destination image (ProQuest Dissertations Publishing). Retrieved from http://search.proquest.com/docview/303907248/

Echtner, C., \& Ritchie, J. (1993). The Measurement of Destination Image: An Empirical Assessment. Journal of Travel Research, 31(4), 3-13. https://doi.org/10.1177/004728759303100402 
Elliot, M., Fairweather, I., Olsen, W., \& Pampaka, M. (2016). A dictionary of social research methods. Oxford, UK: Oxford University Press.

Eriksson, P., \& Kovalainen, A. (2016). Qualitative methods in business research (2nd edition.). Los Angeles, USA: SAGE.

Festinger, L. (1957). A theory of cognitive dissonance. London, UK: Tavistock.

Gartner, W. (1986). Temporal influences on image change. Annals of Tourism Research, 13(4), 635-644. https://doi.org/10.1016/0160-7383(86)90006-X

Gartner, W.C. (1993). Image formation process. Journal of Travel and Tourism Marketing, 2(2/3), 191-216.

Gephart, R. (1999) Paradigms and Research Methods. Academy of Management Research Methods Forum, 4, 1-12.

Giacon, I. (2014). Are 'green' landscapes associated with 'green' behaviours? A study into the relationship between urban green space visitation and pro-environmental behaviour in Wellington, New Zealand. (Unpublished Master's Thesis). Victoria University of Wellington, Wellington, New Zealand.

Hares, A., Dickinson, J., \& Wilkes, K. (2010). Climate change and the air travel decisions of UK tourists. Journal of Transport Geography, 18(3), 466-473. https://doi.org/10.1016/j.jtrangeo.2009.06.018

Huete Alcocer, N., \& López Ruiz, V. R. (2019). The role of destination image in tourist satisfaction: the case of a heritage site. Economic research-Ekonomska istraživanja, 118.https://doi.org/10.1080/1331677X.2019.1654399

Imran, S., Alam, K., \& Beaumont, N. (2014). Environmental orientations and environmental behaviour: Perceptions of protected area tourism stakeholders. Tourism Management, 40, 290-299. https://doi.org/10.1016/j.tourman.2013.07.003

Jennings, G. (2001). Tourism Research. Milton, Australia: John Wiley and Sons.

Jennings, G. (2010). Tourism research (2nd ed.). Milton, Australia: John Wiley \& Sons. 
Jurowski, C. \& Black, R. (2015). Theoretical Perspectives on Environmental Attitudes and Travel Choices. In Bricker, K. S., \& Donohoe, H. (Eds.). (2015). Demystifying Theories in Tourism Research (pp. 177-195). Wallingford, UK: CABI International.

Juvan, E., \& Dolnicar, S. (2014). The attitude-behaviour gap in sustainable tourism. Annals of Tourism Research, 48, 76-95. https://doi.org/10.1016/j.annals.2014.05.012

Juvan, E., \& Dolnicar, S. (2016). Measuring environmentally sustainable tourist behaviour. Annals of Tourism Research, 59, 30-44. https://doi.org/10.1016/j.annals.2016.03.006

Keaveney, S. M., \& Hunt, K. A. (1992). Conceptualization and operationalization of retail store image: A case of rival middle-level theories. Journal of the Academy of Marketing Science, 20(2), 165-175.

Kenworthy, A. (2018). Making the most of sustainable tourism in New Zealand. Sustainable Business Network. Retrieved from: https://sustainable.org.nz/sustainable-businessnews/making-sustainable-tourism-new-zealand/

Kiatkawsin, K., \& Han, H. (2017). Young travelers' intention to behave pro-environmentally: Merging the value-belief-norm theory and the expectancy theory. Tourism Management, 59, 76-88. https://doi.org/10.1016/j.tourman.2016.06.018

Kock, F., Josiassen, A., \& Assaf, A. (2016). Advancing destination image: The destination content model. Annals of Tourism Research, 61, 28-44. https://doi.org/10.1016/j.annals.2016.07.003

Kumar, B., Manrai, A., \& Manrai, L. (2017). Purchasing behaviour for environmentally sustainable products: A conceptual framework and empirical study. Journal of Retailing and Consumer Services, 34, 1-9. https://doi.org/10.1016/j.jretconser.2016.09.004

Kurz, T. (2002). The Psychology of Environmentally Sustainable Behavior: Fitting Together Pieces of the Puzzle. Analyses of Social Issues and Public Policy, 2(1), 257-278. https://doi.org/10.1111/j.1530-2415.2002.00041.x

Leave No Trace. (2020). About. Retrieved from: https://leavenotrace.org.nz/

Lee, T., Jan, F., \& Yang, C. (2013). Conceptualizing and measuring environmentally responsible behaviors from the perspective of community-based tourists. Tourism Management, 36, 454-468. https://doi.org/10.1016/j.tourman.2012.09.012 
Line, N., \& Hanks, L. (2016). The effects of environmental and luxury beliefs on intention to patronize green hotels: the moderating effect of destination image. Journal of Sustainable Tourism, 24(6), 904-925. https://doi.org/10.1080/09669582.2015.1091467

Lopez-Mosquera, N., \& Sanchez, M. (2012). Theory of Planned Behavior and the Value-BeliefNorm Theory explaining willingness to pay for a suburban park. Journal of Environmental Management, 113.

Mackenzie, N., \& Knipe, S. (2006). Research dilemmas: paradigms, methods and methodology. Issues in Educational Research, 16(2), 193-205.

Mason, J. (2002). Qualitative researching (2nd ed.). London, UK: Sage Publications.

Mehmetoglu, M. (2009). Predictors of sustainable consumption in a tourism context: a CHAID approach. Advances in Hospitality and Leisure, 5, 3-23. https://doi.org/10.1108/S17453542(2009)0000005005

Melo, H. M. P., Moniz, A. I., Silva, F. J. F. \& Batista, M. D. G. (2017). Tourist destination image and consumer behaviour: The case of the Azores. Journal of Spatial and Organizational Dynamics, V(2), 73-82. Retrieved from https://doaj.org/article/631762357991460bbcc28231ba49642f

Miller, D., Merrilees, B., \& Coghlan, A. (2015). Sustainable urban tourism: understanding and developing visitor pro-environmental behaviours. Journal of Sustainable Tourism, 23(1), 26-46. https://doi.org/10.1080/09669582.2014.912219

Mohaidin, Z., Wei, K. T., \& Ali Murshid, M. (2017). Factors influencing the tourists' intention to select sustainable tourism destination: A case study of penang, malaysia. International Journal of Tourism Cities, 3(4), 442-465. doi:http://dx.doi.org.helicon.vuw.ac.nz/10.1108/IJTC-11-2016-0049

Morgan, N., Pritchard, A. \& Piggott, R. (2002). New Zealand, 100\% Pure. The creation of a powerful niche destination brand. Journal of Brand Management, 9(4), 335-354. https://doi.org/10.1057/palgrave.bm.2540082

Morrow, J., \& Mowatt, S. (2015). The Implementation of Authentic Sustainable Strategies: iSITE Middle Managers, Employees and the Delivery of 100\% Pure New Zealand. Business Strategy and the Environment, 24(7), 656-666. https://doi.org/10.1002/bse.1897 
Moularde, J. (2015). Mountain bikers' attitudes towards mountain biking tourism destinations (Master's thesis). Retrieved from: https://viewer.waireto.victoria.ac.nz/client/viewer/IE182980/rep/REP182999/FL18300 0?dps_dvs=1582149913696 403

Nghiêm-Phú, B. (2015). A confirmation of the four-component structure of destination image, and their relationships with tourists' loyalty. European Journal of Tourism Research, 11,147-153. Retrieved from http://search.proquest.com/docview/1732757642/

Pacquet, G. (1993) Capital cities as symbolic resources. In: Taylor, J., Lengellé, J. and Andrew, C. (eds) Capital Cities: International Perspectives (pp. 271-285) Ottawa, Canada: Carleton University Press.

Pearce, D. (2012). Frameworks for tourism research . Wallingford, UK: CABI.

Phillimore, J., \& Goodson, L. (2004). Qualitative Research in Tourism: Ontologies, Epistemologies, and Methodologies. New York, USA: Routledge.

Pulla, V., \& Carter, E. (2018). Employing Interpretivism in Social Work Research. International Journal of Social Work and Human Services Practice. DOI: 10.13189/ijrh.2018.060102

Ramkissoon, H., Nunkoo, R., \& Gursoy, D. (2009). How consumption values affect destination image formation. Advances in Culture, Tourism and Hospitality Research, 3, 143-168. https://doi.org/10.1108/S1871-3173(2009)0000003008

Ritchie, J., \& Lewis, J. (2003). Qualitative Research Practice. London, UK: Sage Publications

Ryan, C., \& Cave, J. (2005). Structuring Destination Image: A Qualitative Approach. Journal of Travel Research, 44(2), 143-150. https://doi.org/10.1177/0047287505278991

Salvatierra, J., \& Walters, G. (2017). The impact of human-induced environmental destruction on destination image perception and travel behaviour: The case of Australia's Great Barrier Reef. Journal of Vacation Marketing, 23(1), 73-84. https://doi.org/10.1177/1356766715626966

Smith, J., \& Firth, J. (2011). Qualitative data analysis: The framework approach. Nurse Researcher, 18(2), 52-62. https://doi.org/10.7748/nr2011.01.18.2.52.c8284 
Stanford, D. (2008). "Exceptional Visitors": Dimensions of Tourist Responsibility in the Context of New Zealand. Journal of Sustainable Tourism, 16(3), 258-275. https://doi.org/10.1080/09669580802154082

Stern, P., Dietz, T., Abel, T., Guagnano, G., \& Kalof, L. (1999). A Value-Belief-Norm Theory of Support for Social Movements: The Case of Environmentalism. Human Ecology Review, 6(2), 81-97.

Stern, P. (2000). Toward a coherent theory of environmentally significant behavior. Journal of Social Issues, 56(3), 407-424. http://search.proquest.com/docview/38997604/

Tan, Johnstone, \& Yang. (2016). Barriers to green consumption behaviours: The roles of consumers' green perceptions. Australasian Marketing Journal (AMJ), 24(4), 288-299. DOI: http://dx.doi.org/10.1016/j.ausmj.2016.08.001

Tasci, A., Gartner, W., \& Tamer Cavusgil, S. (2007). Conceptualization and Operationalization of Destination Image. Journal of Hospitality \& Tourism Research, 31(2), 194-223. https://doi.org/10.1177/1096348006297290

Terlau, W \& Hirsch, D. (2015). Sustainable Consumption and the Attitude-Behaviour-Gap Phenomenon - Causes and Measurements towards a Sustainable Development. International Journal on Food System Dynamics, 6(3), 159-174. https://doi.org/10.18461/ijfsd.v6i3.634

Tonge, J., Ryan, M., Moore, S., \& Beckley, L. (2015). The Effect of Place Attachment on Proenvironment Behavioral Intentions of Visitors to Coastal Natural Area Tourist Destinations. Journal of Travel Research, 54(6), 730-743. https://doi.org/10.1177/0047287514533010

Tölkes, C. (2018a). Sustainability communication in tourism - A literature review. Tourism Management Perspectives, 27, 10-21. DOI: DOI: 10.1016/j.tmp.2018.04.002

Tölkes, C. (2018b). The role of sustainability communication in the attitude-behaviour gap of sustainable tourism. Tourism and Hospitality Research. DOI: $10.1177 / 1467358418820085$

Tourism New Zealand. (2009). Pure As: Celebrating 10 Years of 100\% Pure New Zealand. Retrieved from: https://www.tourismnewzealand.com/media/1544/pure-as-celebrating10-years-of-100-pure-new-zealand.pdf 
Tourism New Zealand. (2018). Travellers invited to act as guardians of New Zealand. Retrieved from: https://www.tourismnewzealand.com/news/travellers-invited-to-actas-guardians-of-new-zealand/

Tourism New Zealand. (2020). International Visitor Arrivals. Retrieved from: https://www.tourismnewzealand.com/

Wahyuni, D. (2012). The Research Design Maze: Understanding Paradigms, Cases, Methods and Methodologies. Journal of Applied Management Accounting Research, 10(1), 6980. Retrieved from http://search.proquest.com/docview/1034602171/

Wang, C., Zhang, J., Cao, J., Hu, H., \& Yu, P. (2019). The influence of environmental background on tourists' environmentally responsible behaviour. Journal of Environmental Management, 231, 804-810. https://doi.org/10.1016/j.jenvman.2018.10.089

Wearing, S., Cynn, S., Ponting, J., \& Mcdonald, M. (2002). Converting Environmental Concern into Ecotourism Purchases: A Qualitative Evaluation of International Backpackers in Australia. Journal of Ecotourism, 1(2-3), 133-148. https://doi.org/10.1080/14724040208668120

Wilson, C. (2013). Semi-Structured Interviews. In Interview Techniques for UX Practitioners (pp. 23-41). https://doi.org/10.1016/B978-0-12-410393-1.00002-8

Woodside, A. G., \& Dubelaar, C. (2002). A General Theory of Tourism Consumption Systems: A Conceptual Framework and an Empirical Exploration. Journal of Travel Research, 41(2), 120-132. https://doi.org/10.1177/004728702237412

Untaru, E., Epuran, G., \& Ispas, A. (2014). A Conceptual Framework of Consumers' ProEnvironmental Attitudes and Behaviours in the Tourism Context. Bulletin of the Transilvania University of Brasov. Economic Sciences. Series V, 7(2), 85-94. Retrieved from http://search.proquest.com/docview/1658463195/

UNWTO. (2005). Making Tourism More Sustainable - A Guide for Policy Makers. Retrieved from: https://sdt.unwto.org/content/about-us-5

UNWTO. (2008). Glossary of Tourism Terms. Retrieved from: https://www.unwto.org/glossary-tourism-terms 
WCED. (1987). Our Common Future. Retrieved from: https://www.are.admin.ch/are/en/home/sustainable-development/internationalcooperation/2030agenda/un-_-milestones-in-sustainable-development/1987-brundtland-report.html

Yeoman, I., \& Mcmahon-Beattie, U. (2014). New Zealand Tourism: Which Direction Would it Take? Tourism Recreation Research, 39(3), 415-435. https://doi.org/10.1080/02508281.2014.11087009 